WHOI $-76-72$

\title{
SHORE-BASED RECEIVERS USED IN POLYMODE PROGRAM
}

by

\author{
Roger S. Walen \\ WOODS HOLE OCEANOGRAPHIC INSTITUTION \\ Woods Hole, Massachusetts 02543
}

August 1976

TECHNICAL REPORT

Prepared for the National Science Foundation under Grant OCE 75-18931 and MODE Contribution NO. 19-T.

Reproduction in whole or in part is permitted for any purpose of the United States Govermment. In citing this manuscript in a bibliography, the reference should be followed by the phrase: UNPUBLISHED MANUSCRIPT.

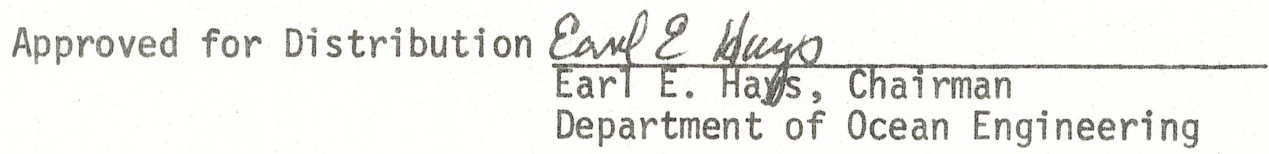


FOREWORD

\begin{abstract}
Under the support of the National Science
Foundation, Office for the International Decade of

Ocean Exploration and at the request of Mr. Douglas C.

Webb, the author has undertaken the writing of this

manual for release in conjunction with the completion

of the last six shore-based receivers for the POLYMODE

Float Program.
\end{abstract}

Roger S. Walen

Research Associate

July 1976 

handbook that will serve as a maintenance manual as well as a permanent record for each Shore-Based Signal Receiver deployed.

This manual explains the operation of the receiver and its logical components in sufficient detail for a good technician to be able to service all but catastrophic malfunctions.

In addition, record forms are included to provide up to ten years of permanent records of receiver function and preventive maintenance. 
The author wishes to thank particularly Mr. Douglas C. Webb and Dr. Albert M. Bradley for their constructive criticism and Mr. Donald I. Dorson who was co-designer with Dr. Bradley of the Swept-Frequency Receiver.

Mr. William Letendre did the construction and testing of the receivers, after working on the prototype models with Mr. Douglas White, and kept the drawings and schematics up to date.

Mr. Kenneth D. Fairhurst did much of the original mechanical

layout. Mr. Stanley $R$. Deane helped with the assembly of the final six receivers.

Thanks, too, to Mrs. Susan Witzell for schematic drawing as well as board assembly and to Mr. Thomas B. Aldrich for board layout drawing.

Mrs. Karen M. Pires faithfully translated the handwritten indications into a presentable text. 
Abstract. . . . . . . . . . . . . . . . . . i

Acknowledgements..................... ii

List of Figures ...................... vi vi

List of Tables. . . . . . . . . . . . . . . . . vii

1.0 Introduction .................... 1

2.0 System Description ............... 2

3.0 Receiver Description ............... 3

3.1 Functional ..................... 3

3.1.1 Functioning of the Receiver............. 3

3.1.1.0 Receiver Specifications.............. 3

3.1.1.0.1 Clock and Timing Signals ............ 3

3.1.1.0.2 Analog Filter............... 6

3.1.1.1 Receiver, General. . . . . . . . . . . 8

3.1.1.2 Input Signals. . . . . . . . . . . . . 8

3.1.1.3 Data Output. ................ 8

3.1.1.4 Signal Level ............... 12

3.1.1.5 Time Code Clock. . . . . . . . . . . . 12

3.1.1.6 Power Supply . . . . . . . . . . . . . 12

3.1.1.7 Sweep Calibrator . . . . . . . . . . . . 13

3.1.1.8 Description of Signaling System. . . . . . . . 13

3.1.2 Functions of Panel Controls, Front Panel ........ 14

3.1.2.0 The Meter................... 14

3.1.2.1 Meter Function Select Switch ........... 14

3.1.2.2 Oscillator Trim Control. . . . . . . . . . 14

3.1.2.3 Input Attenuator .............. 15 
3.1.2.4 AGC Run/Preset Switch.............. 15

3.1.2.5 Real Time Display Preset Select Switch ....... 15

3.1.2.6 Clock Adjust Selector Switch ........... 15

3.1.2.7 Advance/Reload/Run Switch............. 15

3.1.3 Rear Panel ....................... 16

3.1.3.0 Channel Select Switch............. 16

3.1.3.1 Analog Outputs ............... 16

3.1.3.2 I $\mathrm{MHz}$ and $100 \mathrm{KHz}$ BNC's. ........... 16

3.1.3.3 Line Cord Connector Module ........... 16

3.1.3.4 Clock Digital Output ............ 16

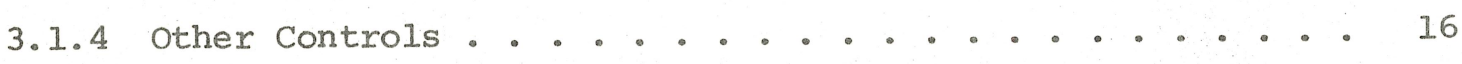

3.1.4.0 Input Amplifier, Card 004. ........... 16

3.1.4.1 Single Channel Filter, Card 005. . ........ 17

3.1.4.2 Clock Counter Board, Card 013............ 17

3.1.4.3 Ten-Channel Scanner, Card 019........... 17

3.1.4.4 Voltage Regulator, Card 022........... 17

3.1.4.5 Battery-Voltage $A / D$ and Sweeper Generator, Card 023. . 17

3.2 Technical. . . . . . . . . . . 18

3.2 .0 Specification........................ 18

3.2 .0 .0 Power Required ............... 18

3.2.0.1 Frequency Range Covered............. 18

3.2 .0 .2 Overall Voltage Gain ............ 18

3.2.0.3 Manual Gain Control Range. ............ 18

3.2 .0 .4 AGC Range........................ 18

3.2.0.5 Clock Backup Battery . . . . . . . . . . 18

3.2.0.6 Sea Data Recording Subsystem ............ 19

3.2.1.0 Printed Circuit Cards.............. 19 
3.2.1.0.0 Input Amplifier, Card 004. . . . . . . . . . . . 19

3.2.1.0.1 Single Channel Filter, Card 005. . . . . . . . . 24

3.2.1.0.2 Display Board, Card 006. . . . . . . . . . . 27

3.2.1.0.3 clock Board, Card 011.............. . 29

3.2.1.0.4 Clock Counter Board, Card 013. . . . . . . . . . 31

3.2.1.0.5 Ten Channel Scanner, Card 019............ 33

3.2.1.0.6 Data Format Board, Card 020............. 36

3.2.1.0.7 Voltage Regulator, Card 022. . . . . . . . . 39

3.2.1.0.8 Battery Voltage A/D and Sweeper Generator, Card 023. - 41

3.2.1.1 Schematics and Layouts . . . . . . . . . . . . . . 45

3.2 .1 .2 Wiring List. . . . . . . . . . . . . . . . 63

3.2.1.3 Parts Lists...................... . 73

3.2.2 Alignment. . . . . . . . . . . . . . . . . 83

3.2.2.0 Setting Up and Dynamic Range . . . . . . . . . . 83

3.2.2.1 Phase Measurement. . . . . . . . . . . . . . 84

3.2.3 Overal1 Record .................... 101

3.2.3.0 Weekly Clock Set................... 102

3.2.3.1 Monthly Meter Readings . . . . . . . . . . . 106

3.2.3.2 Bimonthly Sea Data Transport Check . . . . . . . . 118

3.2.3.3 Battery Replacement. . . . . . . . . . . . . 120

3.2.3.4 Yearly Function Checks . . . . . . . . . . . . . 121 
Fig. 1 Receiver, Front View. . . . . . . . . . . 4

Fig. 2 Receiver, Back View .............. 5

Fig. 3 Receiver Block Diagram. ............ 10

Fig. 4 Record Format ................. 11

Fig. 5a Input Amplifier, 004C . . . . . . ...... . 46

Fig. 5b Parts Placement ............... 47

Fig. 6a Single Channel Filter, 005B . . . . . . . . . 48

Fig. 6b Parts Placement ............. 49

Fig. 7 a Display Board, 006C ........... 50

Fig. 7b Parts Placement ............. 51

Fig. 8a Clock Board, 011B ............. 52

Fig. 8b Parts Placement .............. 53

Fig. 9a Clock Counter Board, 013-1............ 54

Fig. 9b Parts Placement .......... 55

Fig. 10a Ten Channel Scanner, 019B........... 56

Fig. 10b Parts Placement ............ 57

Fig. Ila Data Format Board, 020-1. . ......... 58

Fig. 1lb Parts Placement ........... 59

Fig. 12a Voltage Regulator, 022B . . . . . . . . 60

Fig. 12b Parts Placement............ 61

Fig. 13a Battery-Voltage A/D and Sweeper Generator, 023B . . . 62

Fig. 13b Parts Placement................ 62a

Fig. 14 Data Flow Chart.............. 34

Fig. 15 Three Channel Scan Cycle Timing ......... 35

Fig. 16 PMC Modification. . . . . . . . ... 40

Fig. 17 Typical Battery Voltage vs. Binary Nos........ 43

Fig. 18 Phase Reference Card. . . . . . . . . . . 85

Fig. 19 Universal Phase/Frequency Chart . . . . . . . 86

Fig. 20 Top View of Receiver, Cover off . . . . . . . 98

Fig. 21 Bottom View of Receiver, Cover off.......... 99

Fig. 22 Card Placement. .............. 100 
Page No.

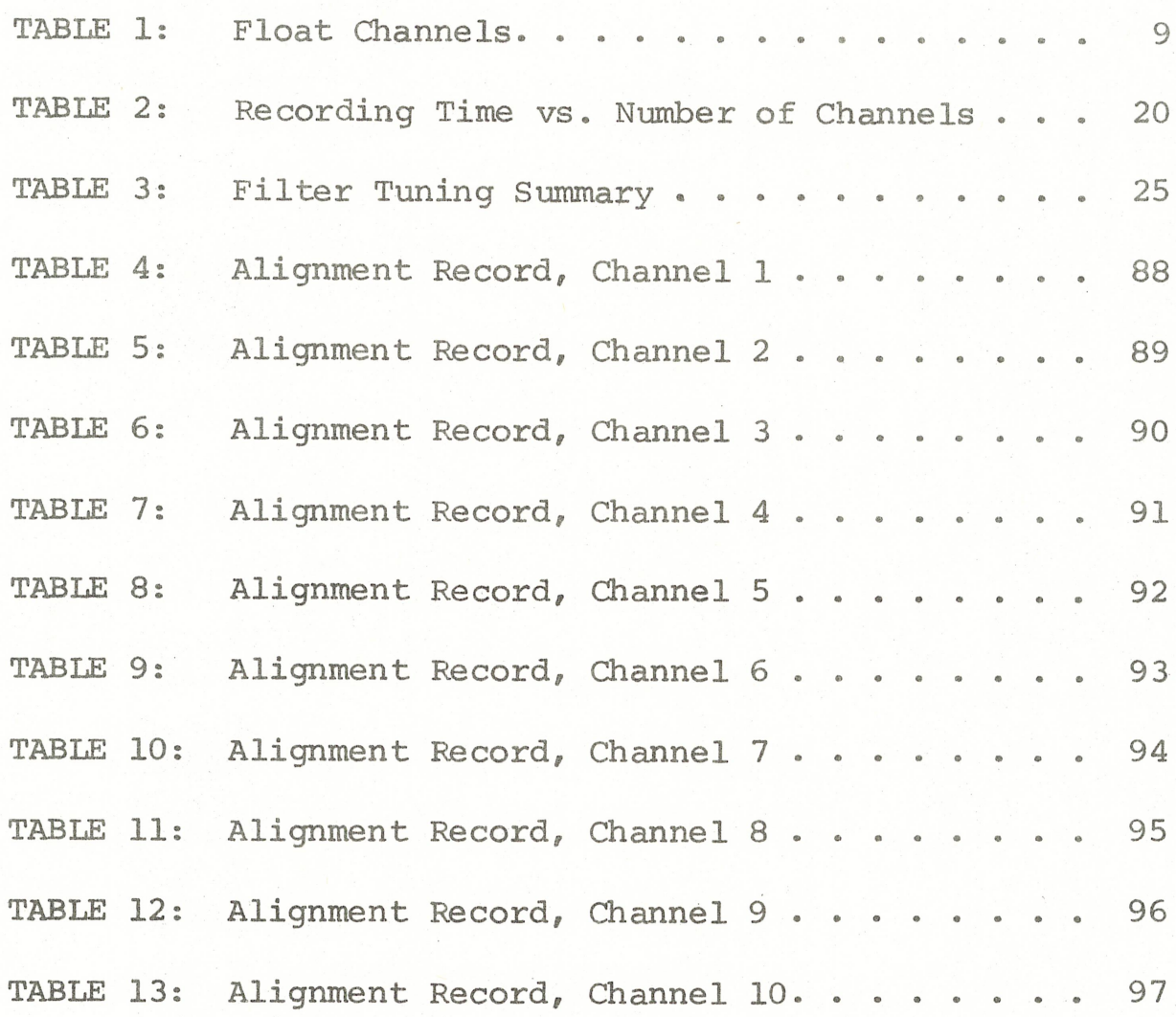


"SHORE-BASED RECEIVERS USED IN POLYMODE PROGRAM"

\subsection{INTRODUCTION}

The purpose of the manual is to explain the operation of the POLYMODE Shore-Based Signal Receivers in sufficient detail for a good technician to be able to service all but catastrophic malfunctions.

The text gives some background to explain the function of the receivers in the POLYMODE Float Program and a general description of the receivers for interested parties who may not have time to study the more technical descriptions included for the circuits on the individual printed circuit cards.

Also included are alignment records for up to ten Single Channel Filter cards and permanent record sheets for routine preventive maintenance checks on weekly, monthly, bi-monthly, and yearly tests. Sheets are provided for up to ten years of record-keeping. 


\subsection{SYSTEM DESCRIPTION}

The systematic function of the receivers to be described is to collect data from which to determine the positions in the ocean of as many as 288 POLYMODE floats.

Each POLYMODE float transmits a signal on its assigned frequency and at an assigned time every eight hours. Each POIYMODE receiver within signaling distance records this signal along with an arrival time. The recorded data is used by a computer program to determine the float position. Thus, data for determining each float's position are updated every eight hours. The data analysis technique enables the determination of the distance between a float and a receiving site to within 2 to 4 kilometers. The data from any two receiving sites having a good base line is used to determine by triangulation the position of a float with a precision of $\pm 1 \mathrm{kilometer}$ and an accuracy of \pm 2 to $4 \mathrm{kilometers.}$

Additionally temperature and pressure are transmitted by a telemetering signal alternately once every twenty-four hours. This information is represented by the delay time between the main signal and the telemetering signal. 


\subsection{RECEIVER DESCRIPTION}

\subsection{Functional}

\subsubsection{Functioning of the Receiver}

A receiver for the swept frequency SOFAR float signaling system is shown in Figures 1 and 2. The receiver is connected to a suitable hydrophone situated near the local sound speed minimum via a separate preamplifier. The receiver filters and separates the swept frequency signals from each float channel and records them on a digital magnetic tape cassette for subsequent computer analysis to determine the time of arrival of the signal and the geographical position of the float. The receiver occupies a 7" high span in a standard rack mount cabinet and is mounted on slides.

The following sections describe the receiver, its input and output signals and its operation.

\subsubsection{Receiver Specifications}

\subsection{Clock and Timing Signals}

A. Time base oscillator TCXO with stability of $1 \times 10^{-7} /$ day over temperature range of $20^{\circ}-30^{\circ} \mathrm{C}$ (external VCO type trim)

B. Power

1. 12 VDC for oscillator and timing chain

2. Internal Leclanché battery to supply standby power for oscillator and timing chain for up to 48 hours

3. 5 VDC for LED display

4. Standby load not to exceed $1 / 2 \mathrm{~W}$

C. Outputs (all outputs to be C-MOS logic compatible)

1. I pulse per second available for synchronizing to external 1 PPS reference

2. $\mathrm{BCD}$ ( 1248 format) information for eleven digits of time (50 pin connector on back). (Buffered with $2.2 \mathrm{~K}$ series resistors)

a. two decimal digits for .1 and .01 seconds b. six digits of standard 24 hour clock information

c. three decimal digits of days information

D. Front panel controls LED display of seconds, minutes, hours, and days 


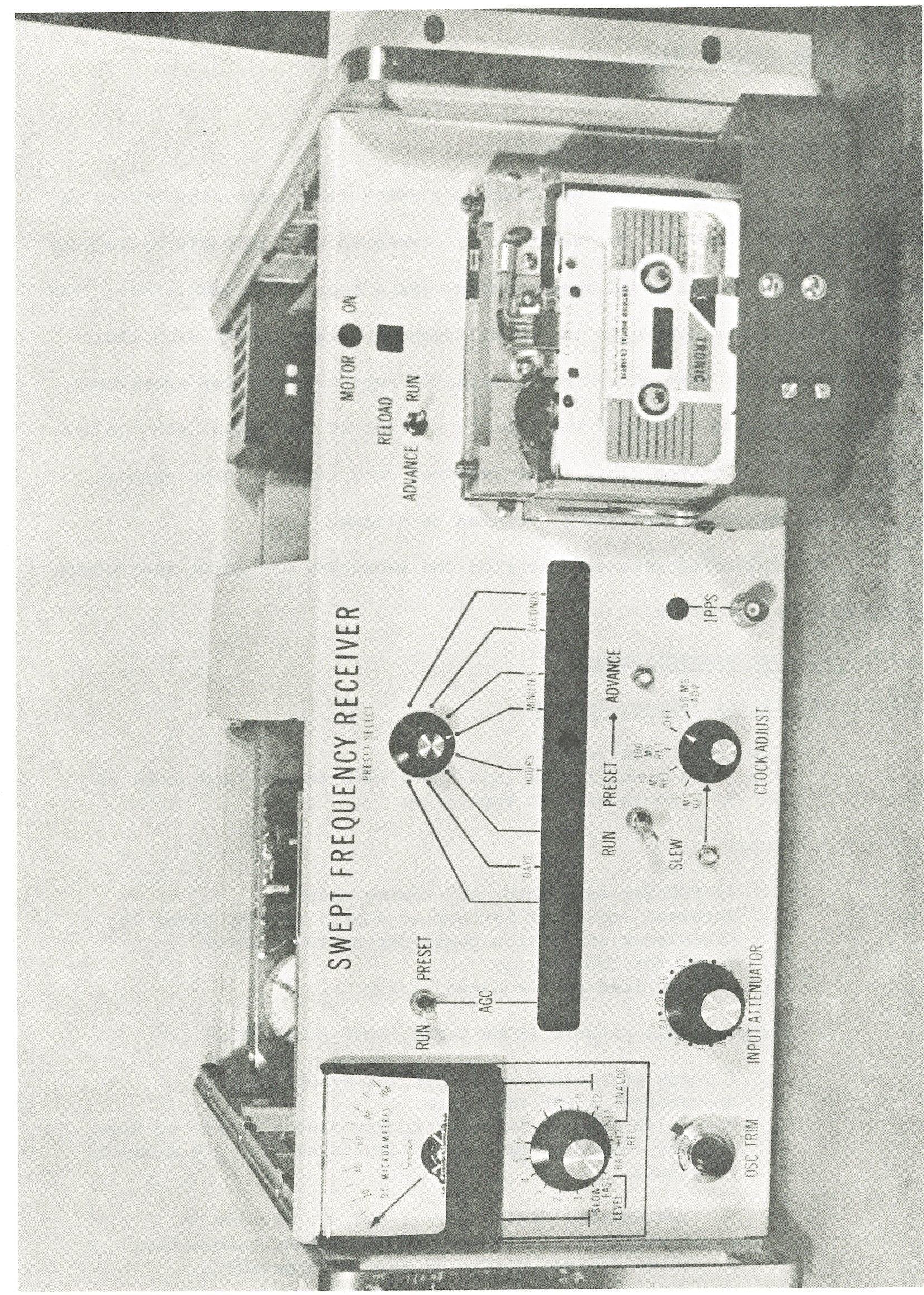

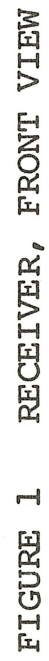




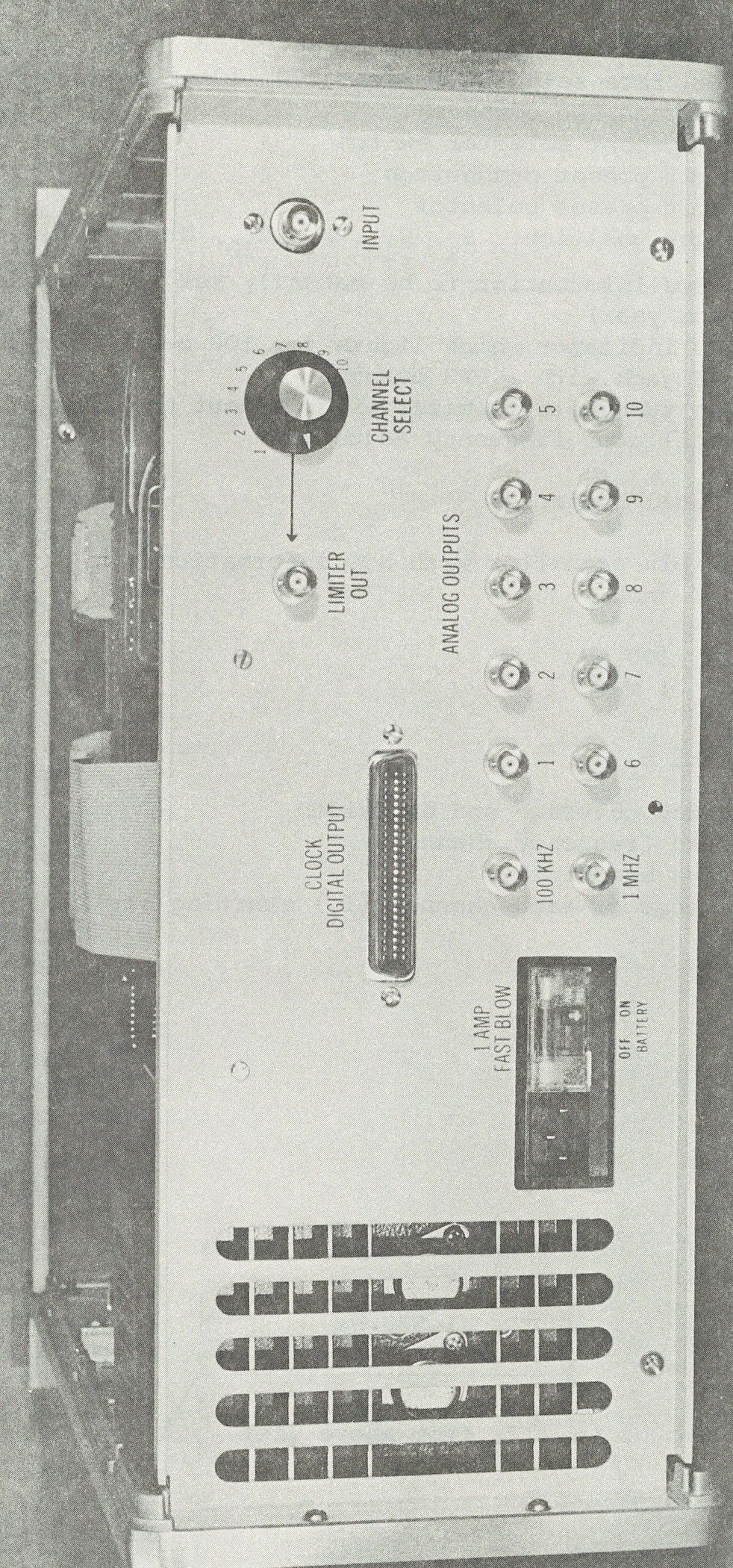

恿 
1. Timebase slew pushbutton

2. Slew rate selector switch; 100,10 or $1 \mathrm{~m}-\mathrm{sec} / \mathrm{sec}$ retard $50 \mathrm{~m}$-sec/sec advance

3. Run/preset selector switch

4. Digit preset pushbutton

5. Digit preset selector

Eight position: $\mathrm{S}_{1}, \mathrm{~S}_{10}, \mathrm{M}_{1}, \mathrm{M}_{10}, \mathrm{Hr}, \mathrm{D}_{1}, \mathrm{D}_{10}, \mathrm{D}_{100}$

(Days information to be manually set to 001 on January 1 of each year)

6. IED indicator which lights for $100 \mathrm{~m}-\mathrm{sec}$ every 1 second

7. BNC jack with 1 PPS output

8. Ten turn potentiometer with readout and locking dial for oscillator frequency adjustment

E. Back panel controls

1. 50 pin connector with $B C D$ information

2. BNC jack
a. $100 \mathrm{kHz}$
b. $1 \mathrm{MHz}$

3.1.1.0.2 Analog Filter

A. Frequency coverage and bandwidth

10 fixed frequency channels

$1.523 \mathrm{~Hz}$ bandwidth

Lower edge of each channel $\left(f_{1}\right)$ starting at: 231.250

235.938

240.625

245.313

250.000

254.688

259.375

264.063

268.750

273.438

Overall bandpass limits

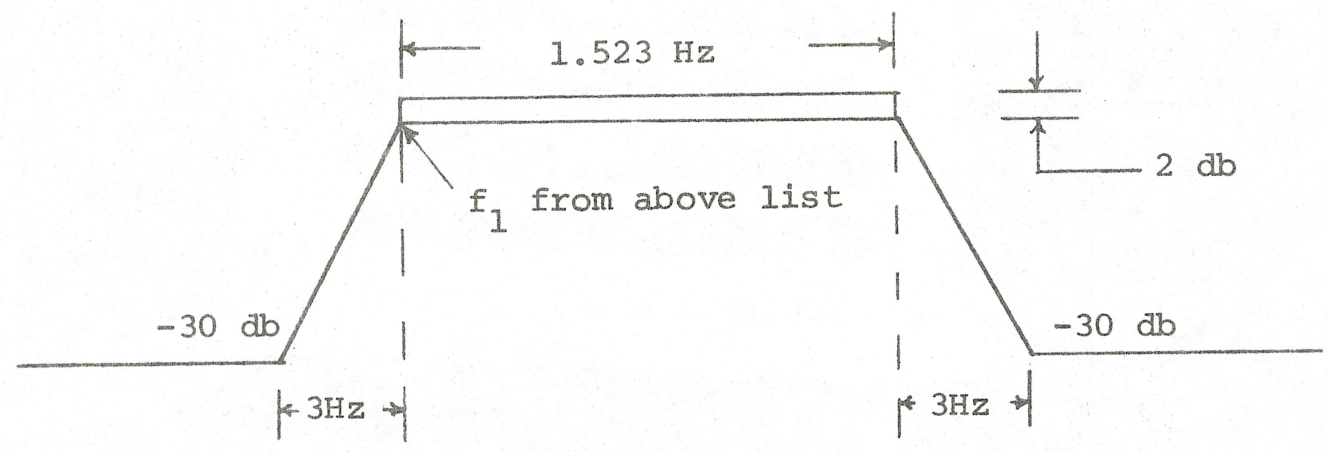


B. Gain

1. Overall gain from input to output of last stage before

limiter to be $65 \mathrm{db}$. Output is hard limited C-MOS compatible logic level

2. Manual gain control over a range of $40 \mathrm{db}$

3. Automatic gain control over a range of $45 \mathrm{db}$ in $3 \mathrm{db}$ steps

a. A large step function in signal level at receiver input shall cause the AGC to change full scale in no less than 1 hour.

4. Input signal level to be at least 10 millivolt

5. Amplifier noise referred to input, with input shorted, not to exceed $200 \mu$ volts rms within a passband.

C. Phase

1. Overall phase response not to deviate from a straight line by more than $\pm 15^{\circ}$ within a passband

D. Front Panel Control

1. Manual gain control calibrated in $2 \mathrm{db}$ increments from 0 to $40 \mathrm{db}$

2. LED display of AGC level
a. Decimal reading of 0 to 15 to represent steps of $3 \mathrm{db}$ attenuation per step

3. Two position toggle switch to select AGC or preset to one of 16 levels determined by internal board mounted switches (AGC to preset to position 8 upon power on)

4. Front panel meter to display average signal level within a frequency band between 230 and $275 \mathrm{~Hz}$

a. Time constant of at least $10 \mathrm{sec}$

5. Meter selector switch to monitor following:
a. Signal level, slow
b. Signal level, fast
c. Battery voltage
d. +12 volt line
e. -12 volt line Analog supply
f. +12 volt line, recorder power
g. Output of each channel before limiting

E. Power

1. Plus and minus 12 VDC

2. Power not to exceed $250 \mathrm{mw} /$ channel 
F. Back panel controls

1. 10 BNC jacks for low frequency analog outputs

(before limiting)

2. 10 position selector switch and BNC

jack to select limiter outputs

3. BNC jack for input signal

\subsubsection{Receiver, General}

The swept frequency float signals will be in the 10 frequency channels listed in Table 1. Each channel used requires a separate filter circuit card. These channel filters use a double frequency conversion technique with two I.F. filters to achieve the desired bandwidth and to produce a low frequency output which is then hard limited and sampled at a $10 \mathrm{~Hz}$ rate by the data scanner. This data, along with the time AGC level, and standby battery voltage is presented to the data formatter and recorded on digital tape. Figure 3 is the overall block diagram of the receiver.

The time of day clock will continue to run on battery power if the $110 \mathrm{AC}$ power fails.

\subsubsection{Input Signals}

The receiver input will be from a broad band, constant time delay, low noise, fixed gain preamp. Signal levels between $10 \mathrm{mv}$ to $8 \mathrm{v} \mathrm{rms}$ and. $10 \mathrm{~K} \Omega$ or less source impedance are acceptable.

\subsubsection{Data Output}

All data is recorded on a Phillips-type tape cassette using a Sea Data Model 610 recorder. This recorder records data on four parallel tracks in blocks of 78 4-bit characters with 7 character inter-record gaps. These blocks will be in one format. The format (Figure 4) contains 60 characters of the sampled outputs of the receivers plus the full time of day information from the clock, $1 . e$. days $\times 100, x 10, x I$; hours $\times 10, x I$; minutes $\times 10$, $x I$; and seconds $\times 10, x 1, x 0.1$. In addition, the setting of the AGC attenuator, 
TABLE 1

\section{Float Channels}

\begin{tabular}{cr} 
Channel & Frequency Band (Hz) \\
\hline 1 & $231.250-232.773$ \\
2 & $235.938-237.461$ \\
3 & $245.313-246.836$ \\
4 & $250.000-251.523$ \\
5 & $254.688-256.211$ \\
6 & $259.375-260.898$ \\
7 & $264.063-265.586$ \\
8 & $268.750-270.273$ \\
9 & $273.438-274.961$ \\
10 &
\end{tabular}

Frequency Band Width $=1.523 \mathrm{~Hz}$ 

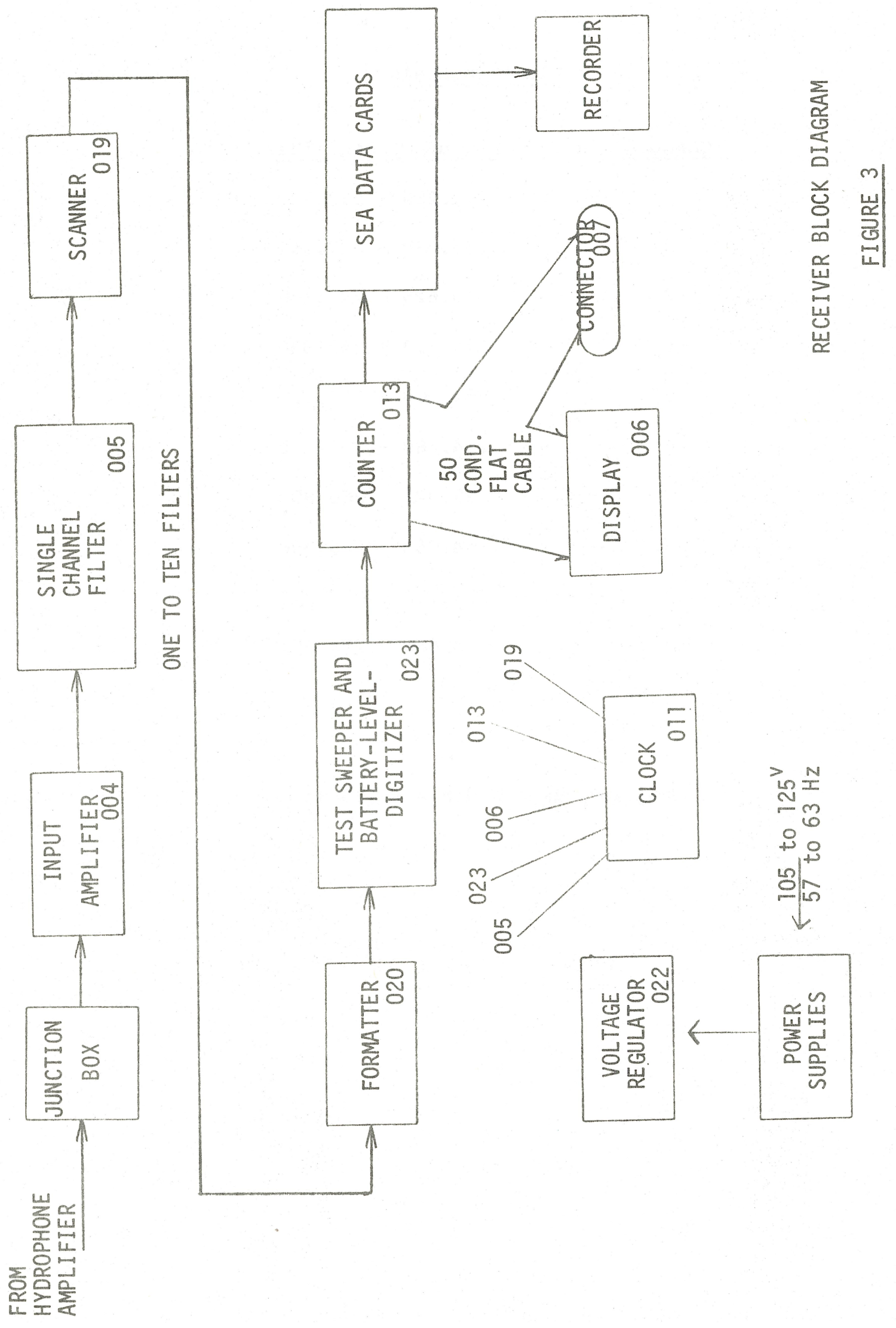


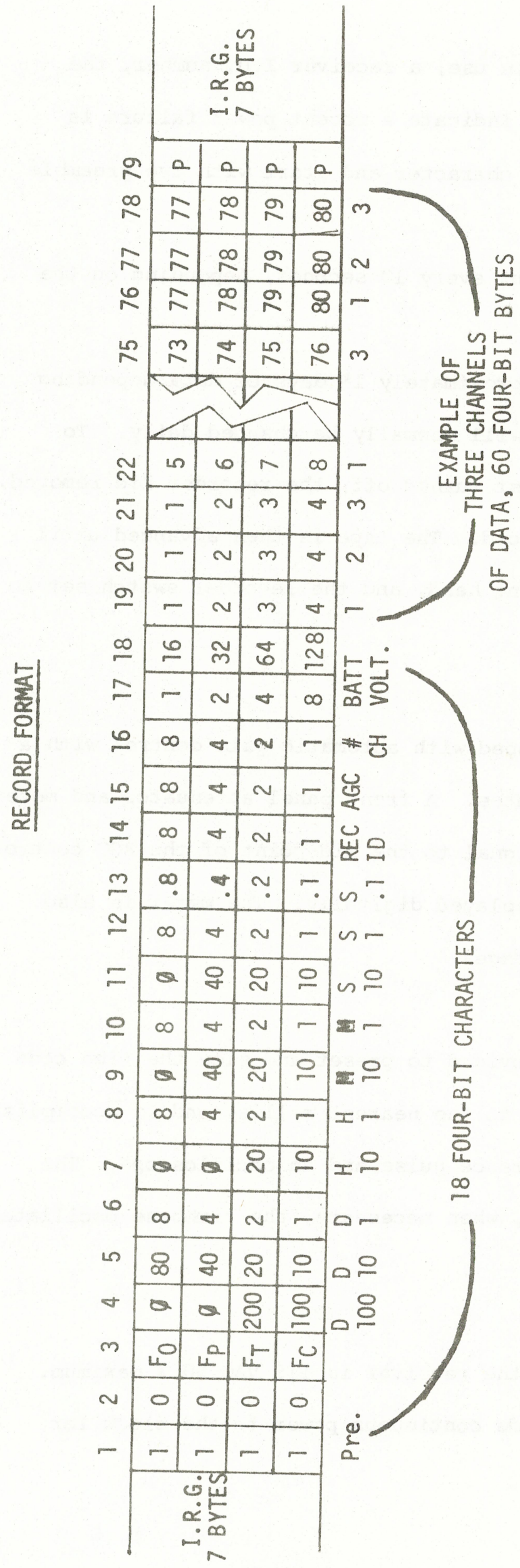


information on the number of channels in use, a receiver I.D. number, the standby battery voltage, and a flag to indicate a recent power failure is recorded. All blocks include 1 parity character and start with two preamble characters.

Data blocks are recorded about every 10 seconds, depending on the number of channels in use.

A tape cassette will hold approximately $1 \frac{1}{2}$ days of data depending on the number of channels in use, and will normally be changed daily. To change a cassette, the recorder is first turned off, the recorder lid removed, the cassette changed and the lid replaced. The tape is then advanced until the leader is seen to pass the recording head, and the recorder switch set to "run".

\subsubsection{Signal Level}

The input amplifier is equipped with automatic gain control with a time constant of approximately 30 minutes. A front panel attenuator and meter will permit adjustment of the input signal to the mid-point of the AGC control range, and the AGC setting will be displayed digitally. The meter is also used to monitor selected internal voltages.

\subsubsection{Time Code Clock}

Front panel controls are provided to preset and slew the time code clock to the nearest second. Setting to the nearest millisecond is accomplished with the aid of an external $1 \mathrm{~Hz}$ reference pulse and an oscilloscope. The clock is to be reset once a week; and, when necessary, the timebase oscillator may be adjusted from the front panel.

\subsubsection{Power Supply}

Normal operating power for the receiver is $115 \mathrm{VAC} 50 \mathrm{~W}$ maximum. An internal battery supply will provide continuous power to the clock for 
approximately 24 hours of main power failure. When on battery, the clock display will be blank to minimize drain. The auxiliary battery voltage will be recorded on the magnetic tape.

\subsubsection{Sweep Calibrator}

Every 24 hours the sweep calibrator replaces the normal input amplifier with a standard sweep signal which will permit an automatic measurement of the individual response of each channel.

\subsubsection{Description of Signaling System}

To explain the functions of the receiver, a brief technical description of the signaling system is necessary.

Each POLYMODE float transmits a signal that is unique in that it is always initiated at predetermined times and on a specific frequency within the $230 \mathrm{~Hz}$ to $275 \mathrm{~Hz}$ range.

In order to overcome the effects of most underwater propagation anomalies, the signal transmitted by a float (the process is the same for all floats) is lengthy and of a known pattern.

The duration of a transmitted signal is 80 seconds. While the signal is being transmitted, its frequency is incremented by 40 steps of $0.039 \mathrm{~Hz}$ every 2 seconds or $1.56 \mathrm{~Hz}$ through its assigned frequency range. This signal is propagated through the ocean and reaches a receiving transducer attached to a receiver input, where it is amplified, filtered, and heterodyned to a low frequency band of approximately 0.75 to $2.25 \mathrm{~Hz}$ by the receiver. Finally, this signal is hard-limited so that instead of a low frequency sine wave, whose frequency is slowly increasing, there is a square wave, whose period is the same as that of the sine wave.

The square wave is sampled by a local clock at 10 samples per second during each square wave period such that samples during the high 
half-period are converted to logical "ones" and samples during the low halfperiod are converted to logical "zeros".

Thus, a digital approximation of the original sine wave transmitted signal is recorded by a digital recorder and later on correlated against the expected digital approximation during analysis.

The purpose of the frequency incrementing or sweeping during transmission is to generate a known pattern, having a more distinct code or signature for correlation than would exist for a tone burst of constant frequency for the same length of time and, therefore, better arrival time correlation.

\subsubsection{Functions of Panel Controls, Front Panel}

\subsubsection{The Meter}

The meter is an off-the-shelf 0 to 100 uamp movement.

\subsubsection{Meter Function Select Switch}

The function select switch is mounted below the meter. The switch selects resistances chosen to make a full scale reading for the various supply voltages and for a fresh battery.

The Fast Signal Level position will show a reading of about 20 on the meter with a nominal input signal level and the input attenuator adjusted for a mid-range reading of 8 on the AGC digit display.

The Slow Signal Level position will show a reading of 50 on the meter and will not vary much about this mid-reading unless the AGC becomes inoperative. When on a channel position, the meter will show a reading of about 50, mid-scale. This is the level at the output of the second mixer before limiting on a single channel filter.

\subsubsection{Oscillator Trim Control}

The Oscillator Trim control is used to set the internal crystal oscillator frequency to \pm 1 part in $10^{7}$ by phase comparison with a laboratory 
standard. The range of adjustment will allow for crystal aging over a period of one year of service.

\subsubsection{Input Attenuator}

The Input Attenuator is capable of attenuating the input signal in 2-decibel steps from $0 \mathrm{db}$ to $40 \mathrm{db}$.

\subsubsection{AGC Run/Preset Switch}

With the Run/Preset switch in the preset position, an internally set, fixed amount of attenuation is set into the AGC. In the run position, the AGC is completely automatic.

\subsubsection{Real Time Display Preset Select Switch}

The Preset select switch allows a choice of days digits, hours digits, minutes digits or seconds digits for preset advance in conjunction with the run/preset switch and the advance pushbutton.

These switches are used for initial clock setting for local time.

\subsubsection{Clock Adjust Selector Switch}

The Clock Adjust switch is used in conjunction with an external standard to set the clock to real time $\pm 10^{-3}$ seconds. The one-pulse-per-second clock waveform, available at the BNC under the 1 PPS LED, is used for this adjustment which is controlled by the slew pushbutton.

\subsubsection{Advance/Reload/Run Switch}

The Advance/Reload/Run switch, under the recorder cover, is used to advance the tape to a point beyond the leader and to check the recorder transport. This is a three-position switch. This switch also resets the Formatter Memory whenever a new cassette is installed. The cover cannot be closed without a "fail-safe" wedge moving the switch to the run position. An IED over the recorder is on whenever a record is being made. 


\subsubsection{Rear Panel}

\subsubsection{Channel Select Switch}

The Channel select switch and Limiter Out BNC make the limiter

output available by switch action from any one of up to ten Single Channel

Filters.

\subsubsection{Analog Outputs}

Ten BNC connectors make the analog signal before limiting available from any one of up to ten Single Channel Filters.

$3.1 .3 .2 \quad 1 \mathrm{MHz}$ and $100 \mathrm{KHz}$ BNC"S

One $\mathrm{MHz}$ and $100 \mathrm{KHz}$ square waves are available at these BNC's.

\subsubsection{Line Cord Connector Module}

The Line Cord Connector Module contains the line fuse and the standby

clock battery on-off switch.

3.1 .3 .4 Clock Digital Output

A 50-pin Blue Ribbon connector provides outputs to drive a digital

clock display or other equipment needing this kind of information for operation or synchronization, duplicating that on the front panel with the addition of seconds $\times 0.1$ and seconds $\times 0.01$.

\subsubsection{Other Controls}

There are other controls on the individual printed circuit cards

within the receiver.

3.1.4.0 Input Amplifier, Card 004

SW 1 allows the fixed gain of the input amplifier to be set to unity, times 10 or times 100.

SW 2 allows the AGC Preset attenuation to be any value in 3 db increments from $0 \mathrm{db}$ to $45 \mathrm{db}$. 
R40 allows the AGC to be set to insert attenuation whenever the signal level at the card output goes higher than 100 millivolts peak to peak, approximately $0.35 \times 10^{-3}$ volts RMS, and to reduce attenuation where the signal falls below 100 millivolts peak to peak.

\subsubsection{Single Channel Filter, Card 005}

R8 allows adjustment of overall gain of the filter. RI7 and R20 adjust $Q$ and frequency for the $22.79 \mathrm{~Hz}$ filter. R23 and R26 adjust $Q$ and frequency for the $24.17 \mathrm{~Hz}$ filter. Foil-cuts on the four-decade, count-down Integrated Circuit to set the heterodyne frequency for the channel to be used.

\subsubsection{Clock Counter Board, Card 013}

SW 1 allows a Binary Coded Decimal number to be selected for the Receiver Identification section of the data block recorded by the Sea Data Recorder subsystem.

\subsubsection{Ten-Channel Scanner, Card 019}

The ten-step thumbwheel switch allows the setting of the number of channels, from "one" to "ten", to be scanned during each scanning cycle. This number corresponds to the number of Single Channel Filters installed.

\subsubsection{Voltage Regulator, Card 022}

R2 allows setting of the voltage at which the emergency clock-power battery takes over in case of main power failure.

RI8 adjusts the regulated output voltage.

\subsubsection{Battery-Voltage A/D and Sweeper Generator, Card 023}

R26 and R28 provide fine adjustment for the two most significant bits of the battery-voltage network.

R6 provides adjustment for the frequency-offset of the Phase-LockedLoop voltage-controlled oscillator. 
The Sweeper Disable switch assures that the Sweeper can be turned off during the receiver bench testing.

\subsection{Technical}

\subsubsection{Specification}

\subsubsection{Power Reguired}

The power required is 50 watts or less. The line voltage may be between $105^{\mathrm{V}}$ and $125^{\mathrm{V}}$ with a single phase line frequency between $57 \mathrm{~Hz}$ and $63 \mathrm{~Hz}$.

\subsubsection{Frequency Range Covered}

The acoustic frequency range covered is from $230 \mathrm{~Hz}$ to $275 \mathrm{~Hz}$. The ten

frequency bands within this range are listed on Table 1, Float Channels.

\section{2 .0 .2 Overall Voltage Gain}

The available voltage gain is 154 db from the receiver input to the analog output of any Single Channel Filter (available on the back panel). The overall attenuation available is 165 ab which allows the recelver to be set up in a varying acoustical environment.

\subsubsection{Manual Gain Control Range}

The Manual Gain Control Range is 120 db as follows:

(a) 40 db in 2-db steps from the front panel Input Attenuator

(b) 40 db in two 20-db steps from a switch on the Input Amplifier PC board

(c) $40 \mathrm{db}$ continuously variable from a potentiometer on each single Channel Filter board.

\subsubsection{AGC Range}

The AGC attenuator covers a $45 \mathrm{db}$ range in 3-db steps. There are 15 steps and any one of these may be switch selected as the normal AGC level. Midrange is usually chosen.

\subsubsection{Clock Backup Battery}

The Clock Backup Battery has been chosen with discharge characteristics to provide clock power for approximately 24 hours of main power failure. 


\subsubsection{Sea Data Recording Subsystem}

The Sea Data Model 610 Recording Subsystem records a data block about every 10 seconds. Each block contains 78 four-bit characters with a 7-character inter-record gap.

The Phillips-type tape cassette will hold approximately $11 / 2$ days of data, depending upon the number of channels in use (Table 2).

\subsubsection{Printed Circuit Cards}

The printed circuit cards are discussed individually except where it is appropriate to consider the interface with other cards. The generic number is used; for example, the schematic for Card 004 is numbered 004C, its historic number. Section 3.2.1.1 contains the schematics and layouts. 3.2.1.0.0 Input Amplifier, Card 004 (Figure 5a and 5b)

The hydrophone signal after amplification in a separate pre-amplifier enters a shielded box at the rear of the receiver, where the signal is $A C$ coupled and low pass filtered to a length of coaxial cable connecting the shielded box to the Daven attenuator on the front panel (included on 004 schematic).

There are two protective zener diodes in the shielded box to shortout voltage spikes or any other accidentally high voltages from damaging the attenuator or input operational amplifier.

The input amplifier proper begins with pins 29 and 31 on the schematic. The signal, well shielded from external perturbations, come from the Daven attenuator to an LM308 operational amplifier, Al. The amplifier gain may be fixed at unity, times 10, or times 100 by switch SWI, an AMP dip switch mounted on the card.

The output of amplifier Al passes through a UTC FHH-200 Hz highpass filter. The purpose of the filter is to filter out the very noisy 


\section{TABLE 2}

\section{RECORDING TIME VS. NUMBER OF CHANNELS}

\begin{tabular}{cc}
$\begin{array}{cc}\text { NUMBER OF } \\
\text { CHANNELS }\end{array}$ & $\begin{array}{r}\text { PER } \\
\text { HOUR }\end{array}$ \\
\cline { 2 - 2 } 1 & 150 \\
2 & 300 \\
3 & 450 \\
4 & 600 \\
5 & 750 \\
6 & 900 \\
8 & 1200 \\
10 & 1500
\end{tabular}

DURATION OF RECORDING

$300^{\prime}$ TAPE $450^{\prime}$ TAPE

223 hours $\quad 334$ hours

111 hours $\quad 167$ hours

74 hours 171 hours

55 hours 83 hours

44 hours $\quad 66$ hours

37 hours $\quad 55$ hours

27 hours 42 hours

22 hours $\quad 33$ hours 
low frequency spectrum of the oceans, eg. steaming ships, sea state, earthquake.

The filter output goes to four T-pad attenuators. The resistance values for the T-pads were chosen to give a constant $10 \mathrm{~K} \Omega$ impedance load on the FHH-200 filter as the various stages are switched in and out of the circuit as demanded by the AGC logic.

The T-pads are designed to change the attenuation between $200 \mathrm{~Hz}$ filter and the following operational amplifier, A2, in 3-decibel steps from no attenuation to 45 decibels of attenuation.

The 4 relays, Teledyne \#732-1000, are shown on the schematic in the unenergized full-attenuation position.

Operational amplifier A2, an LM308 set to a gain of 100, feeds the Single Channel Filter cards (card 005) from card pin 18 and also drives the delay section of the delayed AGC.

The signal from pin 18 feeds operational amplifier A2, an LM308 set for a gain of 10 which places a nominal one volt peak to peak (approximately 0.35 volts RMS) signal at the input of the full wave rectifier/averaging filter section (for $100 \mathrm{mV}$ at pin 18).

The operational amplifier $\mathrm{A} 4$ is a full wave precision rectifier which feeds two operational amplifiers A5 and A7 configured as averaging filters. Averaging filter $\mathrm{A} 5$ has a time constant of 4.7 seconds and its DC output feeds the front panel meter when Meter Slow is selected.

Potentiometer R40 adjusts bias on operational amplifier A5 in order to cause the output of comparator operational amplifier A6 to switch down when the level at pin 18 rises above 100 millivolts, and to switch up, when the level falls below 100 millivolts. 
The 4.7 second delay provided by the averaging filter 25 filters out abrupt changes in level that might appear at pin 18 and which could cause the digital time delay following the comparator to be overly active.

The AGC decision logic is set to add (or remove) attenuation in $3 \mathrm{db}$ steps. If continuous attenuation change is called for, that is, two or more 3 db steps, the minimum time between steps is 16 minutes. The criterion for continuous attenuation would be for as long as the voltage level at pin 18 remains above 100 millivolts $p-p$ ( 35 millivolts RMS).

It is of course possible for the signal level to cause the voltage level at pin 18 to wander above and below 100 millivolts allowing the attenuation to remain at the last position for hours.

Whenever the output of comparator $A 6$ is high, transistor $Q 5$ conducts and its collector is low holding the $D$ input of the lower half of dual flipflop IC (6), a 4013, also low.

The one minute clock pulse, coming into the card from pin 7 through a section of the quad dual NOR IC(5), a 4001, acting as an inverter clocks $\bar{Q}$ of the flipflop high. $\bar{Q}$ is connected to the Up/Down control inputs of 4 stage up/ down counters IC(7) and IC(8). two 4029's, which are wired for their binarycounting mode.

When the Up/Down control line is high, the counters increment. The counters are clock incremented or decremented by the $\overline{\mathrm{Q}}$ output of the upper half of dual flipflop IC(6), which is configured as a one-shot multivibrator.

$\overline{2}$ is normally high so that the clock input to the first stage of the 4029 will always be high when the Up/Down control input changes state.

The first 4029, IC(7), is used as a digital delay. IC(7) is incremented (or decremented) by one count each minute by the regenerated one minute clock, which means that a complete cycle of delay will be a minimum of 16 minutes. 
When the carry out of IC(7) comes up, IC (8) is allowed to increment by one count on the next clock pulse.

Assuming that SW 2 had been set for a preset AGC setting of 8 (hexidecimal) in the IC (8), the next clock would change the count to 9.

Relay RY I had been energized by the "8" output of the IC (8)which disconnected the $24 \mathrm{db} \mathrm{T}$-pad, leaving in $21 \mathrm{db}$ of attenuation. With the count of 9, RY 2 will be energized, thus, taking out 3 db more and reducing the attenuation to $18 \mathrm{db}$.

Assume now that the signal level at pin 18 rises above 100 millivolts. After some portion of the 4.7 second delay in averaging filter A5, the comparator A6 switches and its output going low turns off transistor 25.

The collector of 25 is pulled high through $\mathrm{R} 56$ to $+12 \mathrm{~V}$ and simultaneously pulls D of the Up/Down control flipflop (lower half of IC (6)) high. Shift from up to down and vice-versa cannot occur in the middle of the one millisecond one-shot output because the regenerated leading edge of the one minute clock changes the Up/Down flipflop, and the trailing-edge 12 seconds later triggers the one-shot.

With the Up/Down control input now high, the next one minute clock pulse will start the counters counting down. When the carry occurs (depending upon what the up-count was), 3 db of attenuation will be added, thus, changing the $18 \mathrm{db}$ back to $21 \mathrm{db}$.

By the above process, the input to the Single Channel Filters is kept within a dynamic range that can be handled by the filters without appreciable distortion.

Whenever the attenuation is a maximum or a minimum, the Q's of IC (8) have a direct bearing upon the function of the Up/Down control flipflop, IC (6).

There are two wired-AND matrices attached to the $Q^{\prime} \mathrm{s}$ of IC (8). The upper AND goes high when all Q's are high and pulls the set input of the 
Up/Down control flipflop high. This action forces $\overline{2}$ low causing the $4029^{\prime} \mathrm{s}$ to count-down.

Likewise, when all $\mathrm{Q}^{\prime \prime} \mathrm{s}$ are low, the lower matrix is low and through the inverter (4001, part of IC(5)), the reset input of the Up/Down control flipflop goes high. This action forces $\overline{2}$ high causing the 4029 's to count up. The $Q^{\prime}$ s of IC (8) also go to pins 14, 15, 16, 17 which control the hexadecimal AGC display on the front panel.

3.2.1.0.1 Single Channel Filter, Card 005 (Figure 6a and 6b)

The Single Channel Filter is a tuned input double-conversion intermediate frequency (IF) filter amplifier with a hard limited output.

The nominal input voltage across pins 30 and 29 is 100 millivolts peak-to-peak ( $35 \mathrm{millivolts} \mathrm{RMS)}$ in the band of approximately $200 \mathrm{~Hz}$ to $300 \mathrm{~Hz}$. The frequency range over which the filter can be fixed tuned is $230 \mathrm{~Hz}$ to $275 \mathrm{~Hz}$.

The parallel tuned L-C Carrier Frequency Filter is tuned to the center frequency of one of the ten channels by chosing a combination of three fixed capacitors.

The filter passes the band chosen to the input operational amplifier

Al.

R8 is the overall single Channel Filter gain control. The mixing of the carrier frequency and the local frequency is accomplished by inverting the carrier frequency waveform at the input to amplifier A1. Transistor 22 is switched on and off by a square-wave whose frequency is about $24 \mathrm{~Hz}$ higher than the lowest transmitted frequency for the channel (see Table 3).

This difference frequency, which sweeps from about $24 \mathrm{~Hz}$ to $22.5 \mathrm{~Hz}$ during a float signal transmission matches the bandpass of the first IF filter. 
TABLE 3

\section{FILTER TUNING SUMMARY}

\begin{tabular}{|c|c|c|c|c|}
\hline $\begin{array}{l}\text { Channel } \\
\text { Number }\end{array}$ & $\begin{array}{c}\text { Signal } \\
\text { Sweep Range } \\
\end{array}$ & $\begin{array}{c}\text { Carrier Frequency } \\
\text { Filter } \\
\text { Center Frequency }\end{array}$ & Loca 1 Osc. & $\begin{array}{c}\text { Divisor } \\
1 \mathrm{MHz} \\
\end{array}$ \\
\hline 1 & $\begin{array}{r}231.250 \text { to } \\
232.773\end{array}$ & 232.01 & 255.4931 & 3914 \\
\hline 2 & $\begin{array}{r}235.938 \text { to } \\
237.461\end{array}$ & 236.70 & 260.1457 & 3844 \\
\hline 3 & $\begin{array}{r}240.625 \text { to } \\
242.148\end{array}$ & 241.39 & 264.8305 & 3776 \\
\hline 4 & $\begin{array}{r}245.313 \text { to } \\
246.836\end{array}$ & 246.07 & 269.5418 & 3710 \\
\hline 5 & $\begin{array}{r}250.000 \text { to } \\
251.523\end{array}$ & 250.76 & 274.2732 & 3646 \\
\hline 6 & $\begin{array}{r}254.688 \text { to } \\
256.211\end{array}$ & 255.45 & 278.8622 & 3586 \\
\hline 7 & $\begin{array}{r}259.375 \text { to } \\
260.898\end{array}$ & 260.14 & 283.6075 & 3526 \\
\hline 8 & $\begin{array}{r}264.063 \text { to } \\
265.586\end{array}$ & 264.82 & 288.3506 & 3468 \\
\hline 9 & $\begin{array}{r}268.750 \text { to } \\
270.273\end{array}$ & 269.51 & 293.0832 & 3412 \\
\hline 10 & $\begin{array}{r}273.438 \text { to } \\
274.961\end{array}$ & 274.20 & 297.6190 & 3360 \\
\hline
\end{tabular}


The mixing frequency is generated by counting down from one $\mathrm{MHz}$ in a 4059 programmable divide by "N" counter.

Amplifier $\mathrm{A} 2 \mathrm{a}$ is coupled to the first stage of a stagger-tuned active filter by a low pass RC combination which reduces the higher unwanted frequencies (signal, local oscillator, sum and higher harmonics). The stagger-tuned filters are KTI FS-60'S, F1 and F2. The first filter is tuned to $22.79 \mathrm{~Hz}$ with a nominal bandwidth of $0.98 \mathrm{~Hz}$. The second filter is tuned to $24.17 \mathrm{~Hz}$ with a nominal bandwidth of $1.0 \mathrm{~Hz}$. The alignment procedure and an alignment page for each of the ten channels is in Section 3.2.2, Alignment.

The output of the first IF filter is $\mathrm{AC}$ coupled to amplifier $\mathrm{A} 3 \mathrm{a}$, a section of another LI44 triple operational amplifier. This amplifier has a gain of 10.

The mixing waveform coming into the second mixer is a square wave whose fundamental component is $25 \mathrm{~Hz}$.

The difference frequency for the second IF, from amplifier A3b, sweeps from $1 \mathrm{~Hz}$ to $2.5 \mathrm{~Hz}$ during a float transmission.

The mixer amplifier output available at pin 22, second mixer test, drives L144-A2b configured as a low pass Butterworth filter, the second IF filter.

Analog Signal output from this filter is available at pin [10]. This signal also drives $\mathrm{A} 2 \mathrm{C}$ having a gain of 50 which is $\mathrm{AC}$ coupled to the hard limiter $\mathrm{A} 3 \mathrm{C}$.

Transistor 24 is a level changer to change the limiter output which switches between $+12 \mathrm{~V}$ and $-12 \mathrm{~V}$ to a hard limited signal switching between ground and $+12 \mathrm{~V}$ at pin 28 , limiter output. 
A NOTE OF CAUTION:

The only control on this card that can be considered field adjustable is R8 Gain Adjust. Even so, this should only be used as a last resort. Trimpots R17, R20, R23, and R26 are laboratory adjustments made during initial channel tuning. Their functions are explained under section 3.2.2. Do not change these adjustments without the complete test equipment. 3.2.1.0.2 Display Board, Card 006 (Figure 7a and 7b)

The Display Board is unique in that it does not plug-in as do the other printed circuit cards. The Display Board is attached to the inside of the Front Panel.

This card mounts the Hewlett Packard \#5082-734 Digital Display's (shown as IC's (3) to (12) inclusive); one pulse per second LED; the Real Time Display Preset Select Switch S1, which is used in conjunction with the Run/Preset switch S3 and the Advance Pushbutton S4; the Clock Adjust Switch S2, used in conjunction with the Slew Pushbutton S5; and the AGC Run/Preset Switch.

To hold the above controls and displays firmly behind the front panel, the card is securely bolted into position.

The digital displays are driven by 4050 Hex Buffer Drivers which are connected to the $\mathrm{BCD}$ counter chain on the Clock Counter Board, Card 013, via a 50-conductor Scotchflex flat cable. The 4050's also act as level changers to convert COSMOS logic-levels to 5 volt TTL-levels. Dale CSP 10, 1 megohm resistor networks are used to protect all COSMOS inputs from static charge buildup. Each display has self-contained decoding and is powered by the +5 volt regulator, Fairchild $7805 \mathrm{KC}$.

To set real time into the Hewlett Packard displays, the BCD countdown chain on Card 013 (interconnected by 4019 AND/OR Select Gates) is disabled by placing $\mathrm{S} 3$ on Card 006 in the Preset position. A display is then selected by 
switch SI on Card 006, and switch S4 is depressed. As long as switch S4 is hold depressed, a once-per-second pulse is sent through the selected wire on a 20 conductor flat Scotchflex cable to Card 013. At Card 013, the pulse is gated into the Enable input of the selected 14566 Time Base Generator or 14518 Dual BCD Up Counter through the selected section of a 4019.

The display on the front panel is observed while the selected section is progressing through its count. When the desired numeral appears, the Advance Switch, S4, is allowed to return to its normal position and the next section of the display to be changed is selected by switch $\mathrm{Sl}$.

The 1 PPS waveform brought into Card 006 on pin 18 from Card 013 is used to trigger a 47 usecond one-shot multivibrator. This pulse is used to clock the Enable inputs of the selected $14518^{\prime \prime} \mathrm{s}$.

When the desired time has been set into the display to within \pm 1 second, the Run/Preset Switch $\mathrm{S} 3$ is immediately placed in the RUN position. The next step is to correct the occurrence of the 1-second pulse to within $\pm 10^{-3}$ seconds of a laboratory standard.

A way of correcting the 1-second pulse is to connect the 1 PPS signal (Card 013, pin 7 is the source) from the BNC connector on the front panel to the trigger input of an oscilloscope and to connect a 1 PPS signal from the laboratory standard or a WWV receiver to the vertical input of the scope. Use a one to two second sweep to discover the difference in time between the two waveforms and select an appropriate number from $100 \mathrm{~ms}$ advance, $100 \mathrm{~ms}$ retard, or $10 \mathrm{~ms}$ retard to bring the front panel waveform close to but in advance of the triggering waveform. Work down to the point where the sweep rate can be increased to a few milliseconds display and retard in one-millisecond increments until the one millisecond or less difference exists. The corrections take place once each second as long as the Slew Pushbutton 55 is held in. 
The correction takes place on Card 011, Clock Board, and effects the counter chain on Card 013 through the 100 PPS waveform from Card 011.

\subsection{Clock Board, Card 011 (Figure $8 \mathrm{a}$ and 8b)}

The Clock Board, Card 011 consists of a stable $1 \mathrm{MHz}$ crystal oscillator (temperature compensated to \pm 1 part in $10^{7}$ over the range of $+20^{\circ} \mathrm{C}$ to $+30^{\circ} \mathrm{C}$ ) which can be trimmed with a precision of better than one part in $10^{7}$; a countdown chain; and logic for retarding or advancing the phase of its 100 pulse-persecond output relative to the phase of an external time standard. The Oscillator Trim Control has a range that allows correction for more than a year of normal aging. When the range of the Fine-Trim Control (mounted on front panel) is exceeded, the oscillator is course-tuned with an internal slug-tuned coil accessed through a hole in the side of the oscillator case.

The $1 \mathrm{MHz}$ output frequency of the crystal oscillator is buffered by six parallel sections of a 4050 Hex Buffer Converter. This buffering is required because the $1 \mathrm{MHz}$ not only must be capable of driving up to $10 \mathrm{CD} 4059^{\circ} \mathrm{s}$ on up to 10 Single Channel Filters but is also connected to a rear panel BNC connector for external use.

On the card, the $1 \mathrm{MHz}$ drives a 14518 Dual BCD Up-Counter IC (1a). The $100 \mathrm{KHz}$ pulse is available at a BNC connector on the rear panel and drives the other divide by ten IC (10). $21,22,23$ and 24 of this second section of IC(1) are available on the backplane, but are not used. Q4, which provides the 10 KHz pulse drives a 4017 Decade Counter/Divider, IC(2).

Five outputs of IC(2) are available on the backplane and provide five sequential one-millisecond pulses with one-millisecond interstices. The repetition rate of each of the five pulses is at $1 \mathrm{KHz}$. The 0,2 , and 4 one$\mathrm{KHz}$ pulse outputs are used on Card 019 and Card 020 for logical reasons as will be explained. The $1 \mathrm{kHz}$ carry-out pulse of IC(2) drives IC (32) a 14518. 
21, 22,23 and 24 of this section are available on the backplane, but are not used. The $100 \mathrm{~Hz}$ pulse from $\mathrm{Q} 4$ drives one input of a dual input NOR IC (6), part of a 4001 guad Dual NOR. The gated $100 \mathrm{~Hz}$ pulse from this NOR is available on the backplane and is used by Card 013, as will be explained. This same $100 \mathrm{~Hz}$ pulse also drives the two sections of IC(5), a 4013 Dual "D" flipflop configured as a two-stage binary counter.

The $50 \mathrm{~Hz}$ pulse on pin 14 is used on Card 023 as will be explained. The $25 \mathrm{~Hz}$ pulse on pin 16 is used on the Single Channel Filters, Cards 005 at the second mixer as has been explained, and on Card 023 as will be explained. The function of the advance and retard logic must be considered in conjunction with the Advance/Retard selection Switch S2 and the Slew Pushbutton S5 on Card 006 and appearing on the front panel.

When S2 is in the "100 MS ADV" position and the Slew Pushbutton S5 is depressed, pin I ADVANCE SLEW is held high. Via a flipflop IC (80) and two sections of IC (6). flipflop IC (7a) is prepared to change state on the next following rising edge of $\overline{1 \text { PPS }}$ to arrive at pin[8]. When the rising edge arrives, IC (7a) changes state allowing the next following $100 \mathrm{~Hz}$ pulse feeding pin 12 to change the state of the second flipflop IC (70). This action opens the NOR gate IC (6). allowing the $1 \mathrm{KHz}$ pulses to bypass the $100 \mathrm{~Hz}$ countdown and appear at pin [10]. The $100 \mathrm{~Hz}$ countdown continues counting, however, and its output resets the second flipflop IC (76) inhibiting the $1 \mathrm{KHz}$ pulses through IC (6) and allowing just 10 extra pulses to have appeared at pin 10 . These 10 pulses have advanced all counters driven by pin 10 by 100 milliseconds.

The above action will repeat once each second as long as the Slew Pushbutton is held depressed.

When S2 is in the "100 MS RET" position and the Slew Pushbutton S5 is depressed, pin 5 Retard slew is held high. This action causes 2 of flipflop 
IC (101) to go high. In going high, the $Q$ holds one input of a NOR IC 9 high, and through a second section wired as an inverter holds the D input of IC (82) high.

The next following rising edge of $\overline{1 \text { PPS }}$ clocks the first section of IC (8) causing its $Q$ to go high and inhibiting IC(2) from counting. Simultaneously, the $R$ inputs of a section of IC(3) and both inputs of IC (4) are lowered by $\bar{Q}$ and these divide-by-ten counters start counting the $10 \mathrm{KHz}$ pulses.

When Q4 of the third section of 14518, IC(4) goes high at the end of 1000 pulses, this rising edge goes from pin 9 through switch s2 to pin 6 and clocks $Q$ of IC (10) high which resets the first section of IC (8). IC(2) now continues counting and all counters driven by IC(2)have paused for 100 milliseconds.

Similar operations as described above cause 10 millisecond and 1 millisecond pauses in counting, depending upon the position of $\mathrm{s} 2$.

The above selected retards will repeat once each second as long as the Slew Pushbutton is held depressed.

\subsection{Clock Counter Board, Card 013 (Figure 9a and 9b)}

The Clock Counter Board contains eleven $\mathrm{BCD}$ counters arranged to give in increasing orders of magnitude, seconds times 0.01 through days times 100.

The front panel time displays day of the year, hours, minutes and whole seconds. Tenths of seconds are recorded in addition to days, hours, minutes and seconds in order to determine correlation times precisely. All of this time information plus hundredths of seconds appears at the back panel Blue Ribbon, 50 pin connector.

In addition to the AND-OR Select Gates for presetting time-of-day as explained under Card 006, Card 013 also contains a 56-stage shift register comprised of IC's (12), (16), (15), (13), (11), (10, (9). These IC's are 4021 8-stage static shift registers, parallel or serial input/serial output types. 
Data are read into the shift register in parallel. A "one" or "zero" logic level is presented at a parallel input and then a parallel data load pulse from Card 020 is applied at pin 4. Some inputs are static, once initially set, like Receiver ID or the manually preset Receiver No. and these levels are transferred with every parallel data load pulse.

The four flag bits come out of the shift register first and are, therefore, the first 4-bit character to be recorded on the Sea Data tape recorder. The purpose of placing the flag character first is to allow the computer program to make important decisions immediately as each 76-character record (Figure 4) is played back. These flag bits indicate odd/even record, test sweep ON, power fail and a presently hard wired "one".

The serial data shift clock pin 5 is generated by the sea Data logic. This clock shifts the contents of the shift register to the serial data output, pin 34 in groups of four bits. Each group of four bits, a character, moves from pin 34 to the Sea Data serial data input, Sea Data Board CR-2I pin 13 . These serial characters go to the Sea Data longitudinal parity generator and to the Sea Data serial to parallel input shift register, a 4015, where each fourbit character is converted to parallel prior to being recorded. (A description of the Sea Data logic is included with the sea Data manual which is shipped with each receiver).

The Serial Data Input, pin 6 is connected to the Serial Data Output of Card 020, pin 32. As each group of four bits is read out of pin 34 to the Sea Data logic, a group of four bits is read into the shift register from the storage registers on Card 020 .

Card 020 also provides the odd record flag and the power fail to Card 013. The test sweep flag comes from Card 023. 
The 1 PPS pulse on pin 7 is connected to the front panel BNC connector. Figure 14 is a flow chart showing the interrelation between Card 013, Card 020, and Card 023. Connections to Card 004 and Card 019 are also indicated. 3.2.1.0.5 Ten Channel Scanner, Card 019 (Figure 10a and 10b)

The ten channel scanner will sample from one to ten single channel filter hard limited outputs at a sampling rate of 10 samples per second for each selected channel.

Every 400 milliseconds, the four previous samples from each filter are transferred into the FIFO buffer storage on Card 020. The transfer is in sequence starting with filter number one. Figure 15 is a timing diagram for three channels selected. The example is further illustrated by the dotted line on Figure 10a (Schematic 019B) which is the EECO switch selection for three channels.

Each time at end-of-scan the number of channels scanned is latched into IC (19). This number is read into IC (12) on Card 013 each time a record is read into the sea Data recorder.

A $10 \mathrm{~Hz}$ pulse continuously clocks the ten serial to parallel shift registers in IC(1). (2), (3), (4), (5), 4015's. The "D" inputs to the shift registers connect to the ten single channel filter connectors at their hard limiter outputs.

If a high logical level exists at a hard limiter output at clock time, a "one" is read into the associated serial-to-parallel shift register. If a low level exists at the output, a "zero" is read into the shift register. Simultaneously with sampling the hard limiter outputs, the $10 \mathrm{~Hz}$ pulse is being counted by IC (23), a 4024 binary counter. On every fourth count, the $\mathrm{Q} 2$ output of IC (23) clocks IC (21) a 4013 flipflop, causing its $\bar{Q}$ to go low starting a scan. 


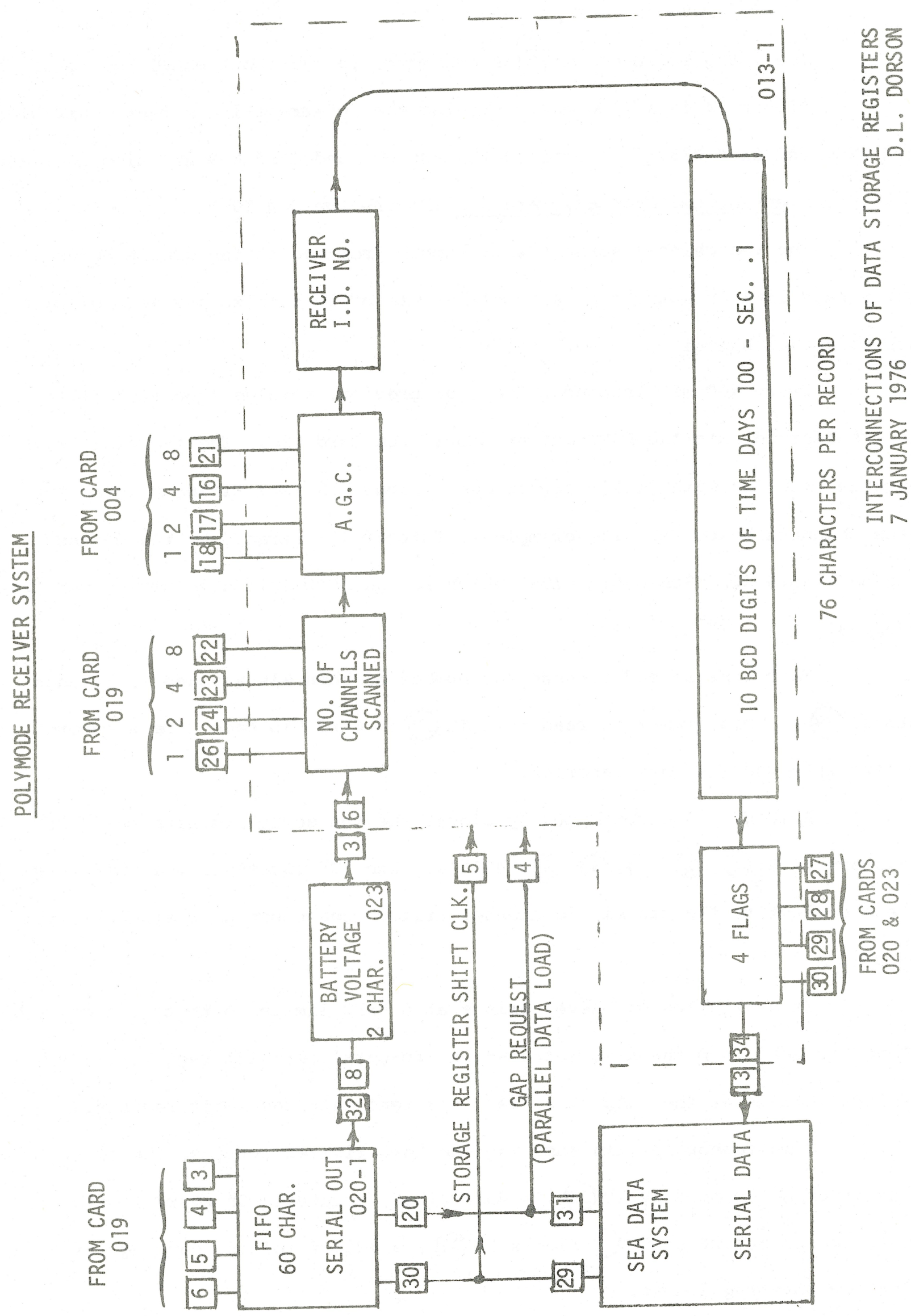




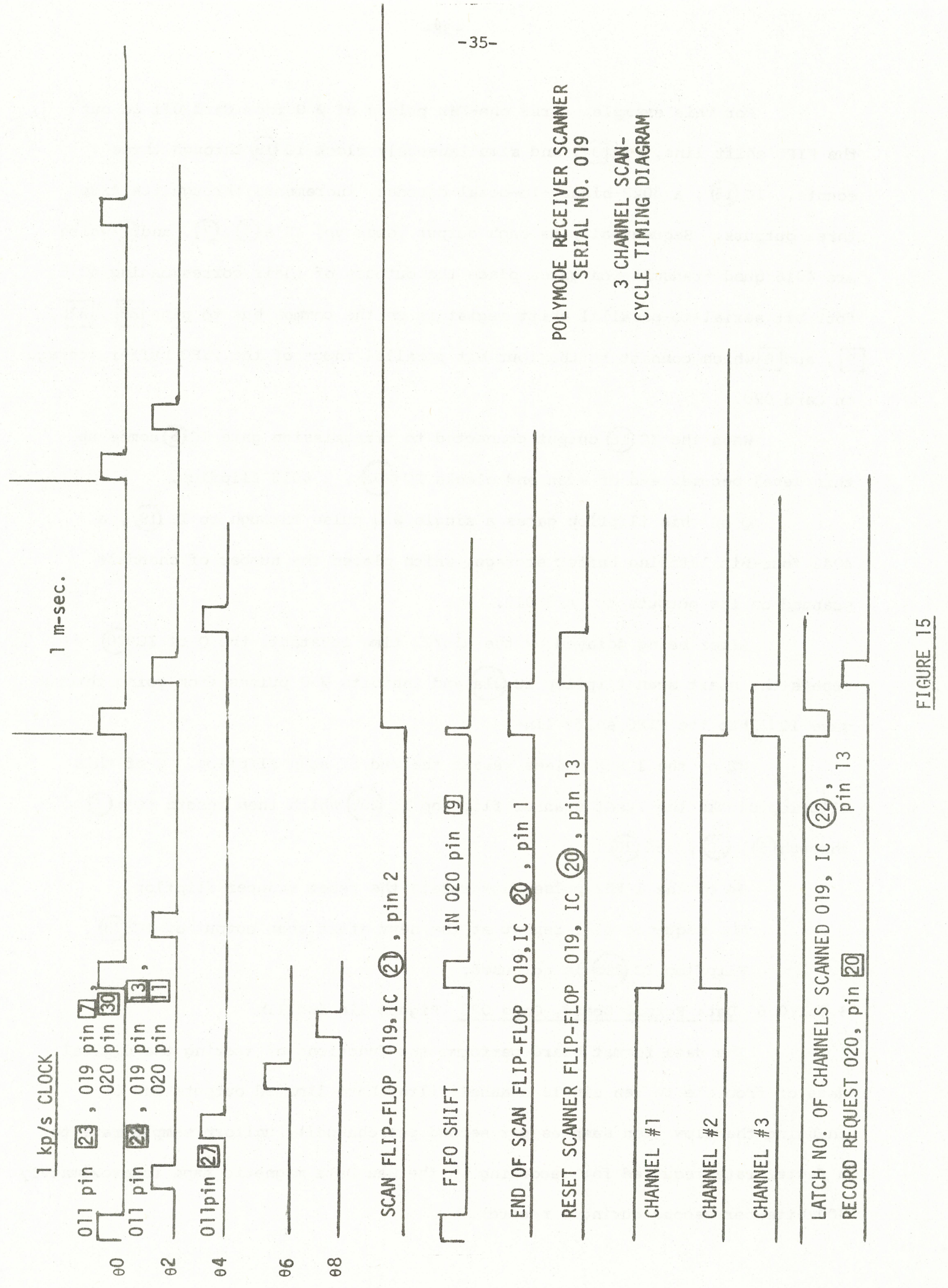


For this example, three one-KHz pulses of $\varnothing 0$ from Card 011 go out the FIFO shift line, pin 3, and simultaneous Iy clock IC (18) through three counts. IC (16), a 4028 binary-to-octal decoder, increments through its first three outputs. Sequentially as each output comes up, IC's (6), (7), and (8) which are 4016 quad transmission gates place the outputs of their corresponding 4015 four bit sexial-to-parallel shift registers on the common bus to pins 28, 32 . 9]. and 8] which connect to the four bit parallel input of the FIFO buffer storage on Card 020.

When the IC (16) output connected to transmission gate IC (6) comes up, this level becomes end of scan and clocks IC 202 , a 4013 flipflop.

$Q$ of this flipflop gates a single $\varnothing 0$ pulse through to IC (19). a 4042 four-bit latching buffer storage, which places the number of channels scanned on its outputs to Card 013.

After being delayed by the R38/C2 time constant, the 2 of IC (20) resets the start scan flipflop IC (21a) and inhibits $\varnothing 0$ pulses from going through gate IC (22) to the FIFO shift line.

$\emptyset 2$ of the $1 \mathrm{KHz}$ pulses resets the end of scan flipflop. $\bar{Q}$ of this flipflop clocks the reset scannex flipflop IC (20b) which then resets IC's (1) through (5). (18), and (23.

94 of the $1 \mathrm{KHz}$ pulses now resets the reset scanner flipflop. The sequence will repeat at the next start scan output of IC (23). Flipflop IC (210) is not used.

3.2.1.0.6 Data Format Board, Card 020 (Figure 1la and 11b)

The data format board performs the functions of storing the digital data of from one to ten single channel filter hard limited outputs and of changing the slow (ten samples per second per channel), uniform sample rate to a faster rate required for recording on the sea Data magnetic tape (approximately 400 bits-per-second during a record). 
Data are transferred in parallel in 4-bit bytes by the $1 \mathrm{KHz} \varnothing 0$ pulses through the FIFO (Fairchild 34703 First In First Out, FIFO, $16 \times 4$ Parallel/Serial buffer memory) Shift-In line. The time constant Rloc2 delays the transfer signal until the input lines from the scanner have settled down. Data are shifted out serially in short bursts at 500 bits per second by the Storage Register Shift Clock generated by the Sea Data recorder logic. This same shift clock connects to Card 013 pin 5 and to Card 023, pin 6 making the Serial Data Out, pin 32 of the FIFO's an extension of the shift register on Cards 013 and Card 023 where connection is made to pin 8, Serial Data Input. The general principle of First In First Out (FIFO) operation is that of a stack where a byte is put into the top and then sinks to the bottom or output end by internal circuitry. The sink rate is much faster than the data transfer rates used in this system.

When the FIFO fills up to 15 of the 16 four-bit storage levels, the Input Register, IRF, line drops indicating that the register is full. This is because when the fall through stack is full, no automatic "initialize" signal is generated and, therefore, IRF remains low.

The IRF level on IC (2) is named Full Flag and is used to gate one pulse of the $1 \mathrm{KHz} \varnothing 2$ pulses through gates (8c), (8d), and (6b) to pin 20 for a Gap Request to the Sea Data logic.

Flipflop (9b) closes gate (6b) after one pulse.

The IRF on IC (2) indicates that 61 characters have been transferred into the FIFO's and the sampling of this level by the phase 2 clock 0.2 milliseconds after transfer allows time for IRF to come back to the "not full" level as a character "falls through".

The Gap Request, pin 20, to the sea Data logic starts the recording sequence. After generating an Inter Record Gap and a two character Preamble, the Serial Data Shift Clock is generated by Sea Data and appears on pin 30 . 
The clock is at a $500 \mathrm{~Hz}$ rate, but comes in groups of 4 with every fifth $500 \mathrm{~Hz}$ pulse missing. The purpose of groups of four is to form the 4-bit character just prior to recording in the sea Data recorder.

In ordex to read just 60 characters out of the FIFO's the "O-units" and "6-tens" outputs generated on the Sea Data Record Length counters are brought in on pin 27 and pin 28 where they are ANDed in IC (6) to reset flipflop (70). whose $Q$ output then inhibits the shift pulses in AND IC (60). Shift pulses from Sea Data continue, however, to Card 023 and Card 013 so that by the time that 64 more bits ( 16 characters) have been shifted out to Sea Data, the shift registers on Card 013 and Card 023 contain all "zeros".

A complete record on the Sea Data tape consists of 79 characters: 2 Preamble, 1 Flag, 10 Time Characters, 1 Receiver Identification, 1 Automatic Gain Control Level, I Number of Channels Being Scanned, 2 Battery Voltage, 60 Hard Limited Outputs of from one to Ten Single Channel Filters, I Longitudinal Parity. Figure 4 presents the format of a single record.

The odd Record Flag is generated by flipflop IC (7a). After either starting a new tape in the sea Data Recorder or a Power Fail Restart, IC (7a) is reset. Reload Switch and Power Fail Restart are ANDed in IC (62) and must both be high for the FIFO to function. When a new tape is started, the Odd Record Flag is low. At the end of the first Gap Request, the flag is clocked high and from then on toggles at the end of each Gap Request. For all oddnumbered records, the flag will be low.

The cormuter program, when the tape is being played back, keeps track of the Odd Record Flag and the Number of Channels being recorded. When the Number of Channels is eight, the sorting process that reassembles the interleaved channel information from the tape is different from that used for Number 
of Channels exactly divisible into 60 , since sorting must go into $1 / 2$ of each 8th record out of every 15 records.

For similar reasons, the programming to handle 7 or 9 channels would be more complicated due to the precession of the record length and the number of characters in 7 or 9 channels.

The Power Fail Restart Flag appears whenever power is brought up after a power failure and the following LCC shift from the Sea Data resets the flag flipflop IC (9a). LCC shift also resets the Gap Request flipflop IC (9b) and Storage Register, Shift Clock inhibit flipflop IC (7b) each time LCC shift occurs. 3.2.1.0.7 Voltage Regulator, Card 022 (Figure 12a and 12b)

This Voltage Regulator is powered from two sources. The primary power for the regulator is the unregulated output of the PMC Model RAI2-3.0 power supply, which is modified during the receiver construction (as indicated on the schematic, Figure 16) to bring out +27 volts.

When line power fails, the regulator is automatically powered by the stand-by battery which connects to pins 29 and 30 , the battery current flows through isolation diode D2.

The section of the schematic to the left of diodes D4 and D5 is the switchover section. When the PMC power supply is supplying the regulator, transistors $\mathrm{Q} 1$ and $\mathrm{Q} 2$ are conducting and are powered by a small portion of the current flowing through diode Dl.

Transistors $\mathrm{Q} 3$ and $\mathrm{Q} 4$ are not conducting and the battery is isolated from the regulator by the back resistance of diode D2.

The Switchover Adjust potentiometer R2 is set so that when the voltage at pins 31 and 32 falls to +15 volts, transistors $Q 1$ and $Q 2$ are turned off. The base of transistor $\mathrm{Q} 3$ is now pulled positively through R10, R9 and R8 causing $Q 3$ to turn on and pull the base of transistor 24 negatively turning 24 on. The battery now powers the regulator section, to the right of diodes D4 and D5, 


\section{FIGURE 16}

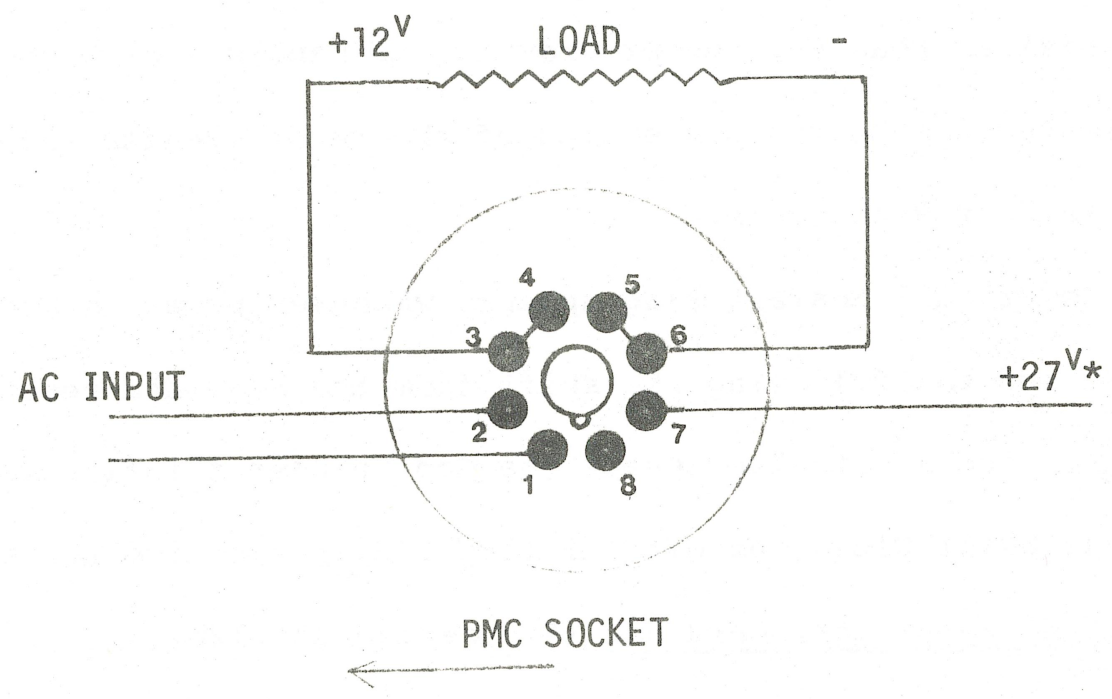

*IN THESE RECEIVERS, INTERNAL WIRES HAVE BEEN REMOVED FROM 7 \& 8 AND TIED TOGETHER ON THE PC BOARD. NO. 7 IS NOW + UNREGULATED, APPROXIMATELY $27^{\mathrm{V}}$. 
through diode D2 and transistor $\mathrm{Q4}$. There is hysterises of about $1 / 2$ volt between turn off and turn on.

Diodes D3 and D4 are current regulator diodes. Diode D3 assures that a constant current holds $Q 4$ turned on as it takes over the load through the regulator and also limits the current through the zener diode D5 when $\mathrm{Q} 3$ is on. Diode D4 assures that there is always at least a minimum current through the zener.

The regulator is a conventional series regulator with output current limiting due to the forward voltage drop across diodes D6 and D7, which limits the base/emitter potential of $Q 7$.

The schematic (Figure 12a) shows the connections for the Lambda LZD-32 $\pm 12 \mathrm{~V}$ Analog Devices power supply mounted on Card 022. Connections for the PMC supply which plugs into an octal socket mounted on the receivex chassis are given and connections for the Fairchild $7805 \mathrm{KC}+5$ volt regulator which is also mounted on the chassis.

3.2.1.0.8 Battery Voltage A/D and Sweeper Generator, Card 023 (Figure 13a and 13b)

This card performs two functions:

The Battery Voltage Analog to Digital section of the card, the left

half of the schematic, Figure 13a, converts battery voltage to a binary number for recording on the sea Data tape.

The other section of the card is the Sweeper Generator, which is turned on once each twenty-four hours at twenty hours GMT, 4 p.m. for most stations.

For the $A / D$ a counter converter is used.

Every eight minutes, IC (12) is reset along with the R-S flipflop comprised of NOR gates IC (10b) and 100 . When the R-S flipflop is reset, a battery load of approximately $10 \mathrm{~K}$ ohms is switched on by transistors $\mathrm{Q} 1$ and $\mathrm{Q} 2$ and $25 \mathrm{~Hz}$ square wave is gated to the eight stage binary counter IC (12), an SCI 4404 . 
Approximately $1 / 2$ of the voltage across the battery load is connected to the inverting input of comparator Al, a 3130 operational amplifier and the summing point of the binary weighted resistor network on the counter outputs is connected to the non-inverting input.

The counter increments at the $25 \mathrm{~Hz}$ rate until the ladder voltage equals the voltage on the comparator inverting input, at which point the comparator output goes high. This output differentiated by C10/R36 sets the R-S flipflop which inhibits the $25 \mathrm{~Hz}$ clock through NOR $10 \mathrm{a}$ and turns off the battery load.

The binary number in the counter is transferred to IC (13), 4021 parallel in serial out shift register, at the next Gap Request. Figure 17 is a typical graph of Battery Voltage vs. Binary Number.

The Sweeper Generator is a frequency synthesizer comprised of a 4046 Phase Locked Loop, IC (6), and a 4059 programmable Counter, IC (7). The 4059 is programmed by the BCD outputs of the four decade counter made up of a 14518, IC(2), and two $4029^{\prime} \mathrm{s}$, IC(3) and(4). The counter is clocked by a one-every-two-seconds square wave from flipflop IC (10) which is toggled by the one Hz pulse through NAND IC (5a).

The sweep is started by the 20 hour pulse on pin 30 which sets flipflop IC (1a) gating the one Hz pulse through IC (5a). Q of IC (1a) is the Test Sweep Flag.

As the counter increments, the synthesizer frequency increments through 1599 steps. At the end of 1599 steps, three decade counter outputs NANDed in IC (5b) reset flipflop IC (1a). A sweep lasts for 53.3 minutes.

The synthesizer output (whose frequency range covers from about $295,000 \mathrm{~Hz}$ to $352,000 \mathrm{~Hz}$ ) is counted down by 10 in the 4017 Decade Counter Divider, IC(8), and by 128 in the 4024 Seven Stage Binary Counter. 


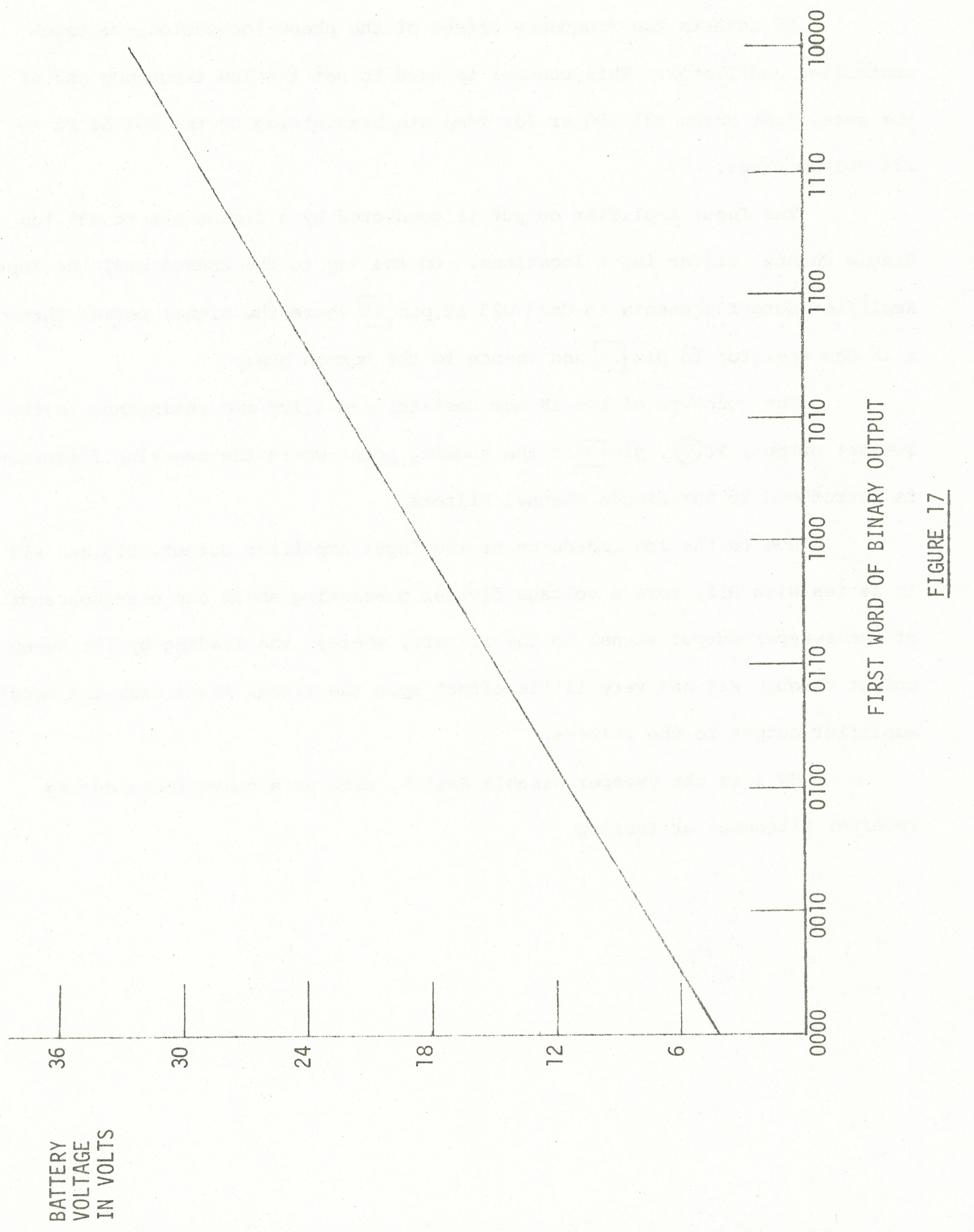

WOODS HOLE OCEANOGRAPHIC INSTITUTION WOODS HOLE, MASS. 02543

PROJ. BY

DATE
TITLE

TYPICAL BATTERY VOLTAGE VS. BINARY NUMBER, A/D ON CARD 023B 
R6 adjusts the frequency offset of the phase-locked-1oop-voltagecontrolled oscillator. This control is used to set the low frequency end of the sweep just below $231.250 \mathrm{~Hz}$ for complete bracketting of the $231.50 \mathrm{~Hz}$ to $274.961 \mathrm{~Hz}$ range.

The Input Amplifier output is connected by a common bus to all ten Single Channel Filter input locations. On the way to the common bus, the Input Amplifier Output connects to Card 023 at pin 26 where the signal passes through a $1 \mathrm{~K}$ ohm resistor to pin 25 and thence to the common bus.

The juncture of the $I K$ ohm resistor and $1.10 \mathrm{M}$ ohm resistance to the sweeper output, IC(9), pin 3 is the summing point where the sweeping frequency is introduced to the Single Channel Filters.

Due to the low impedance of the Input Amplifier output, RI3 and RI4 in series with RI5, form a voltage divider presenting about one one-thousandth of the sweeper output signal to the filters, whereas the loading by the sweeper output through RI4 has very little effect upon the signal level from the Input Amplifier output to the filters.

SW $I$ is the Sweeper Disable Switch, used as a convenience during receiver alignment or testing. 
$-45-$

3.2.1.1 SCHEMATICS \& LAYOUTS 


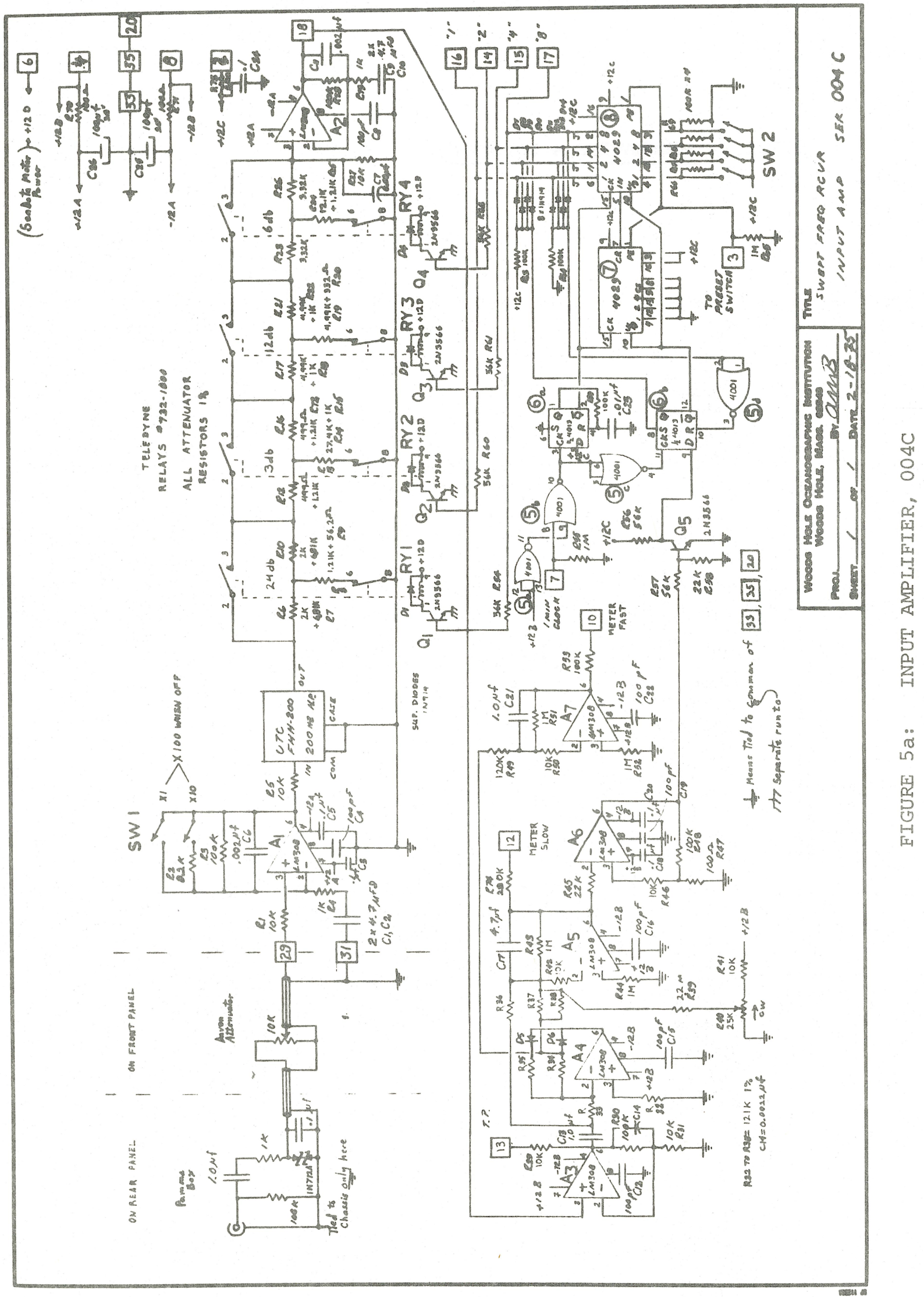




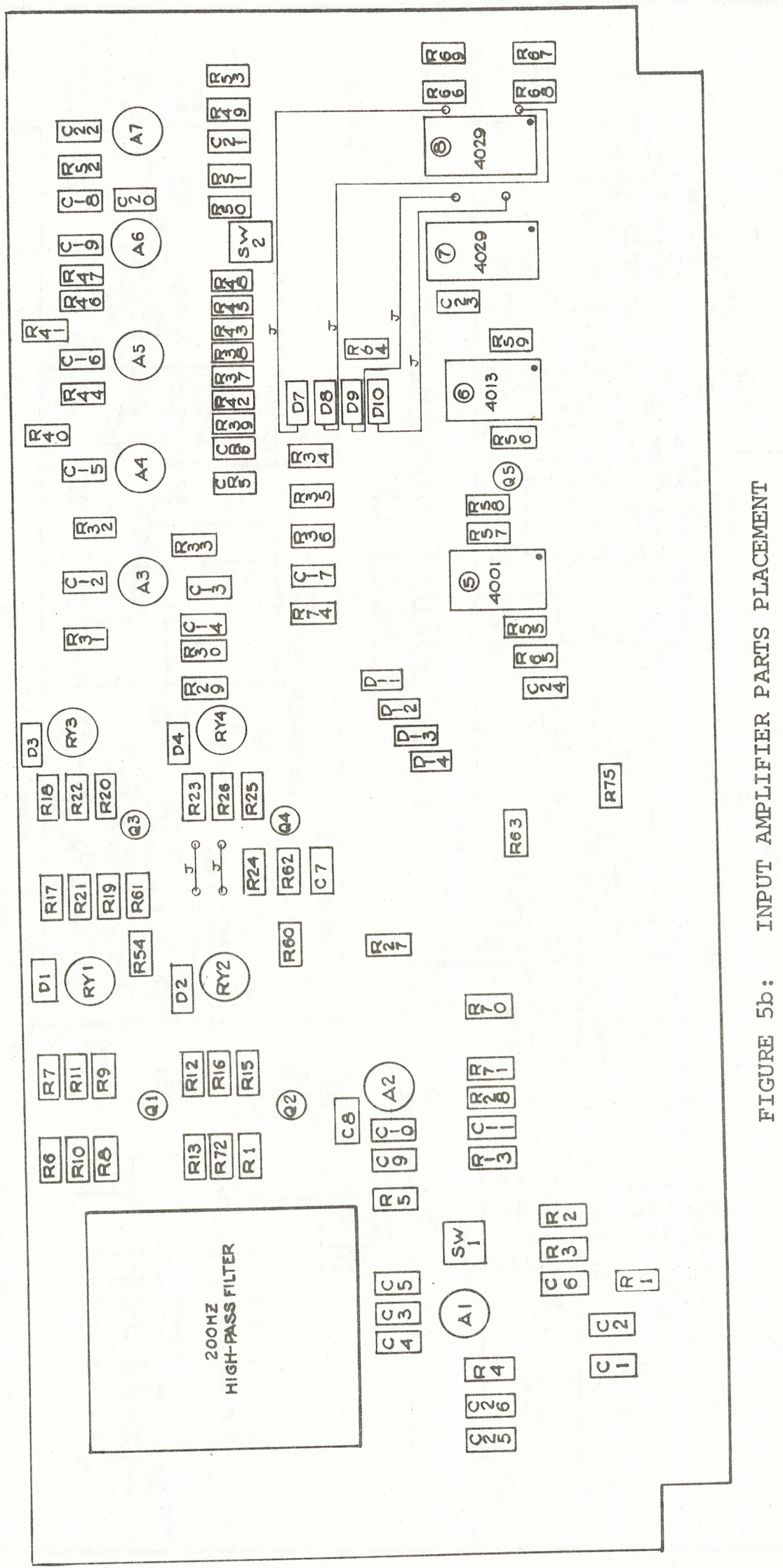




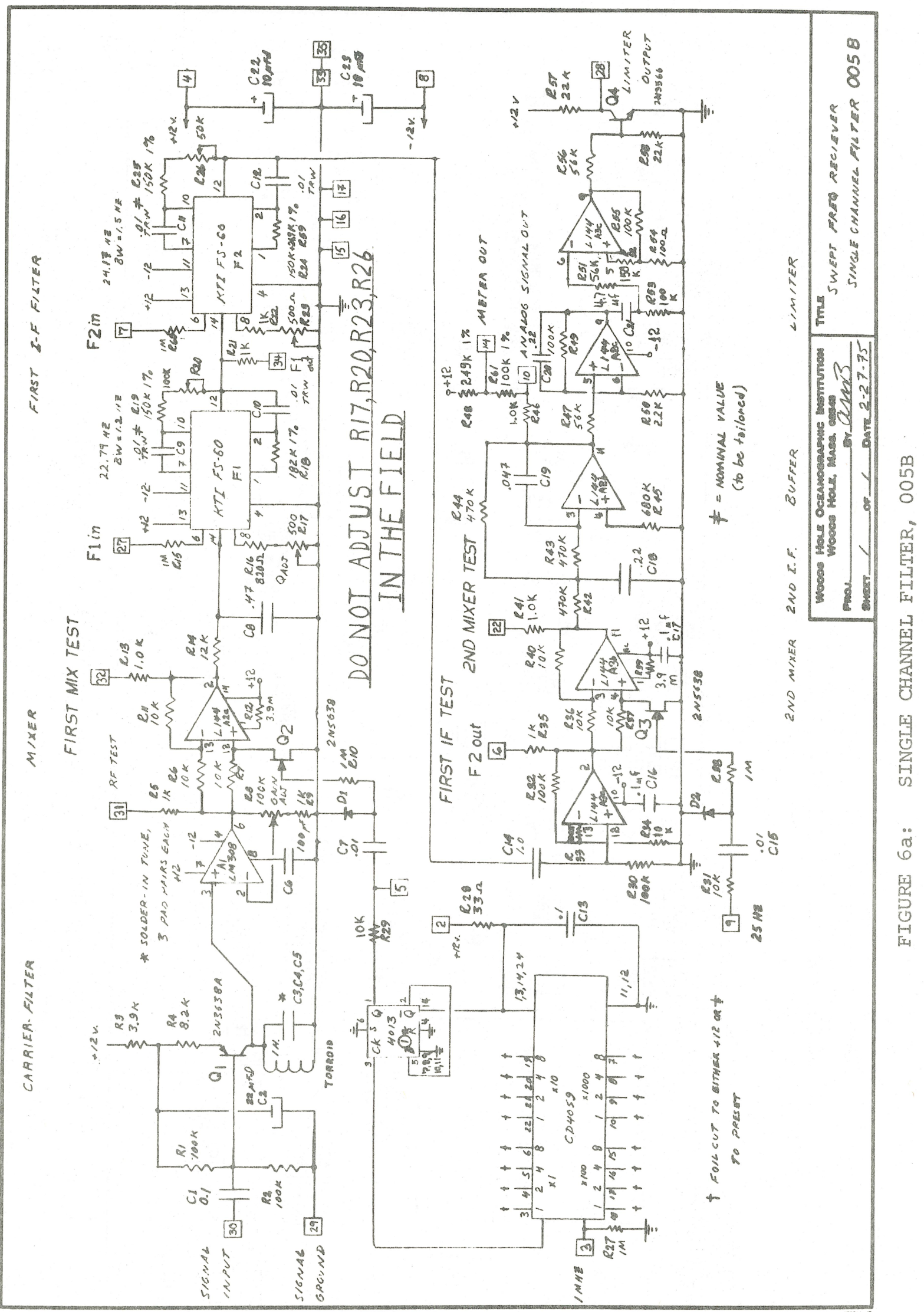




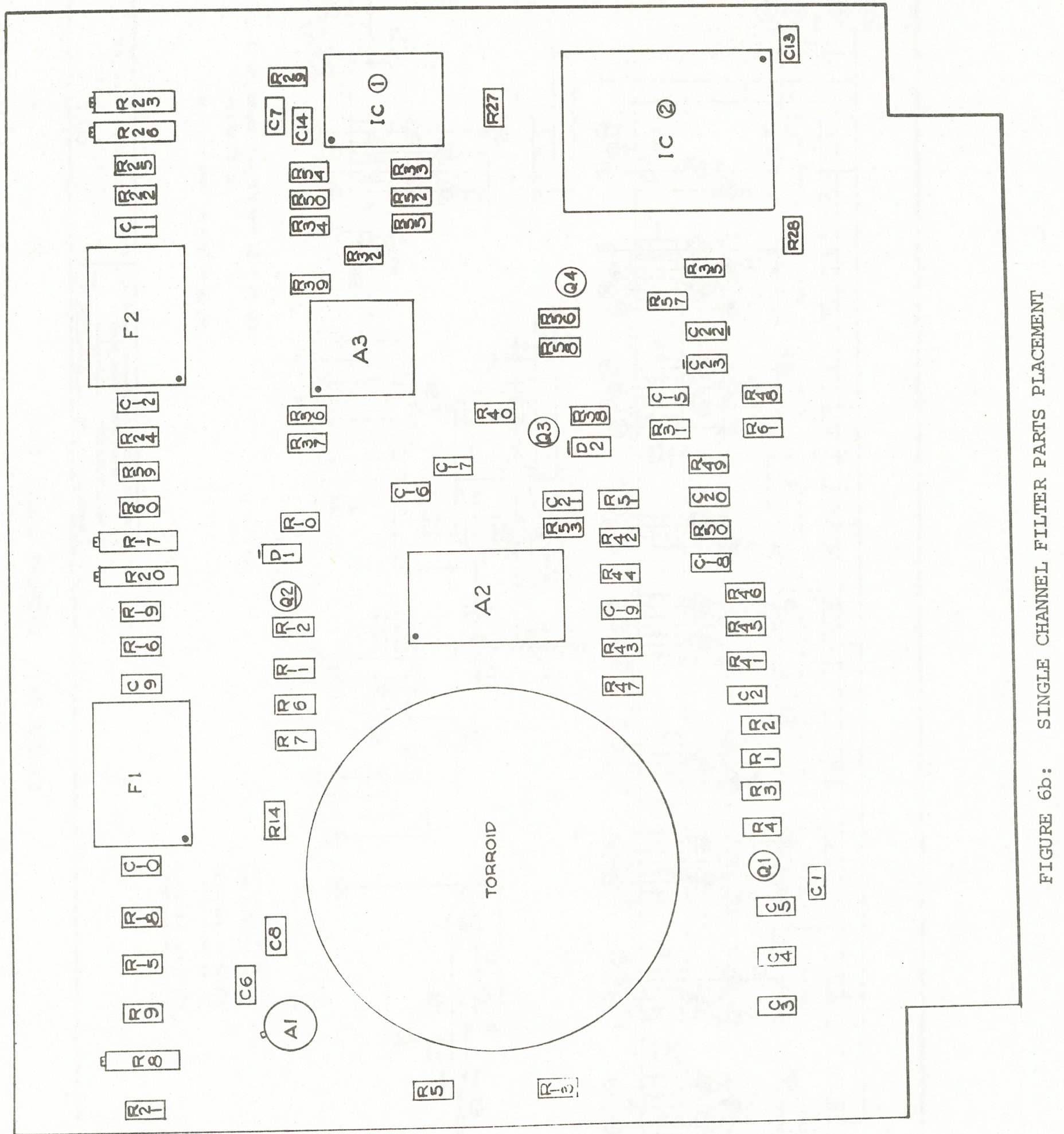




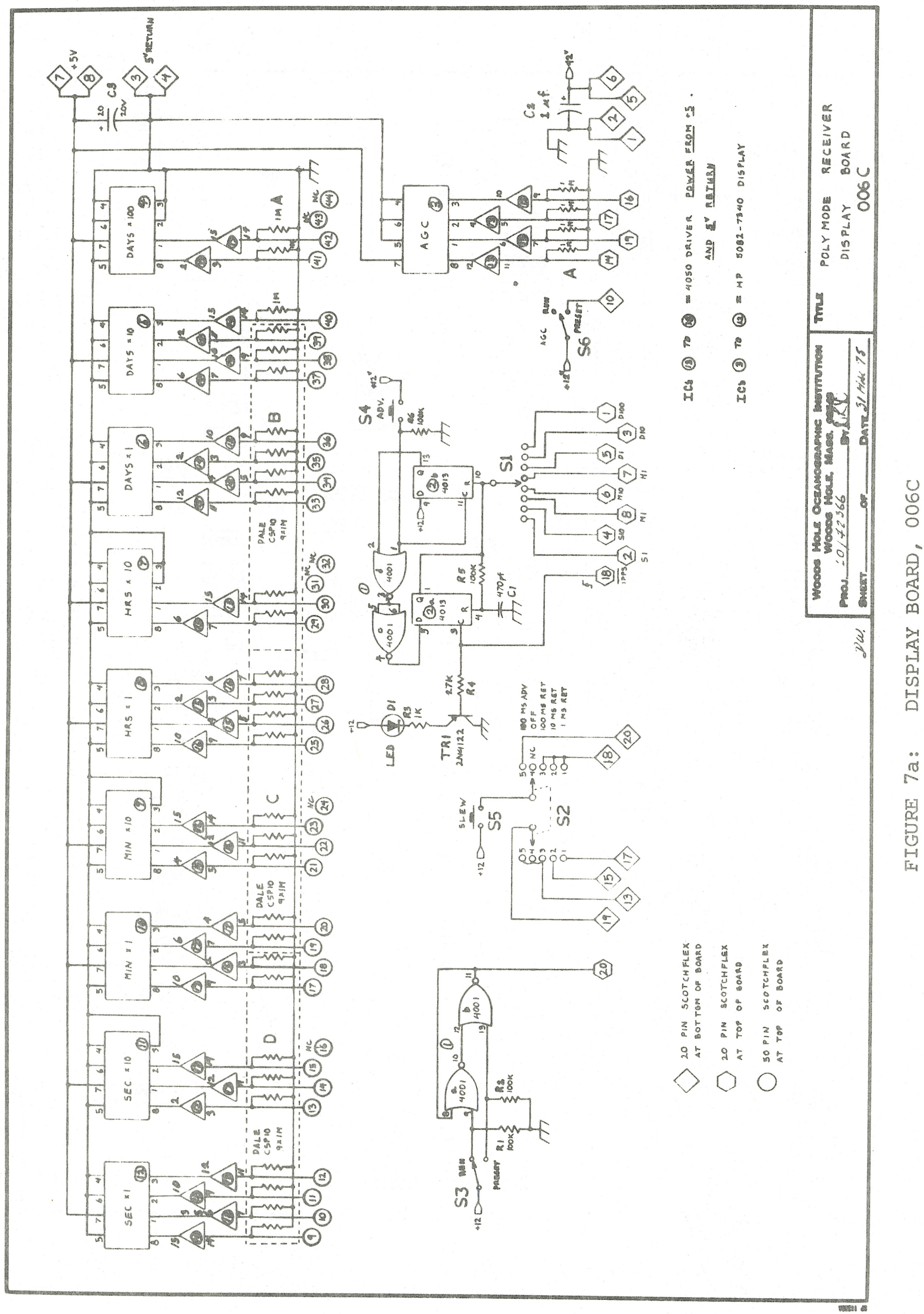




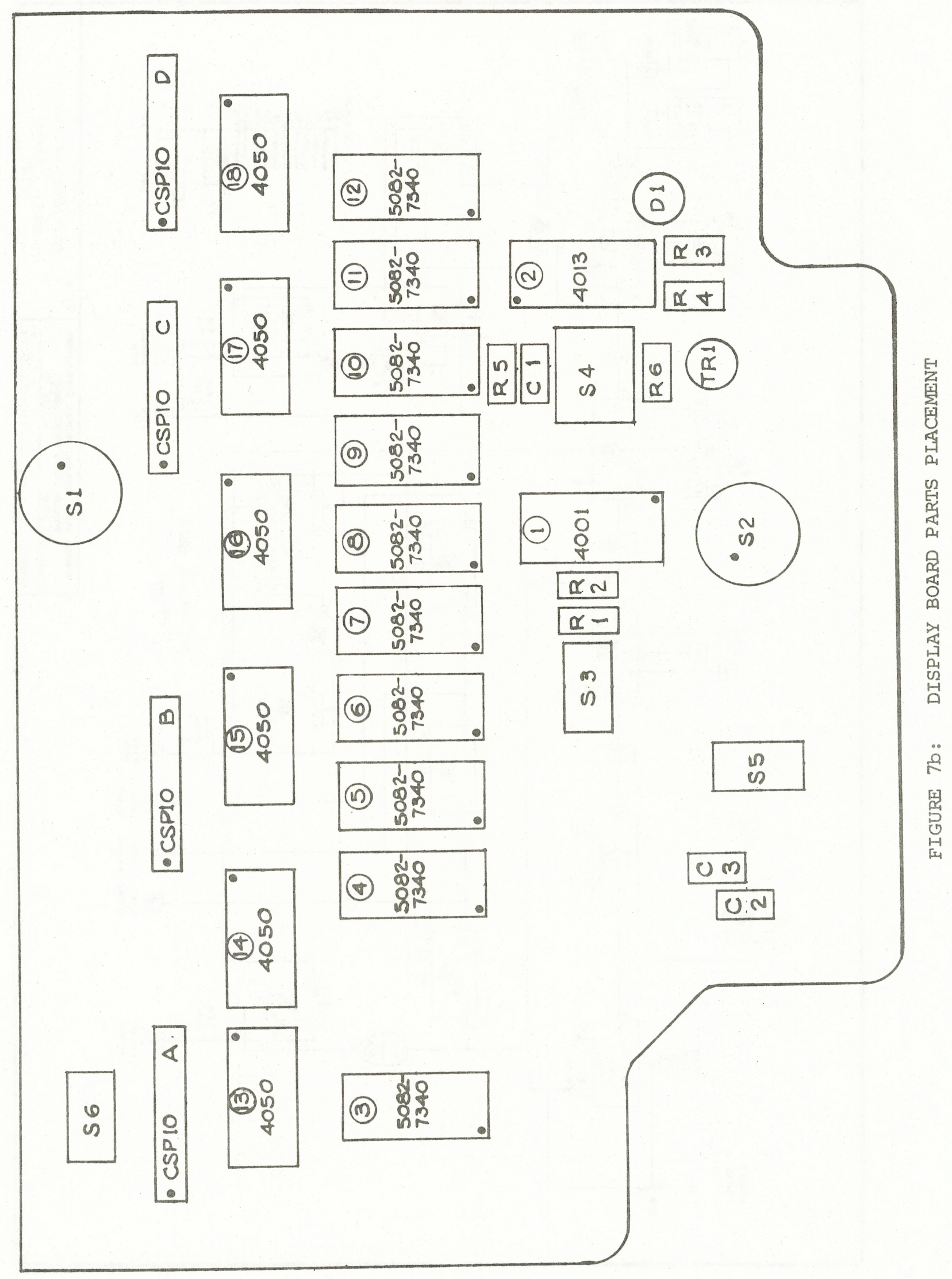




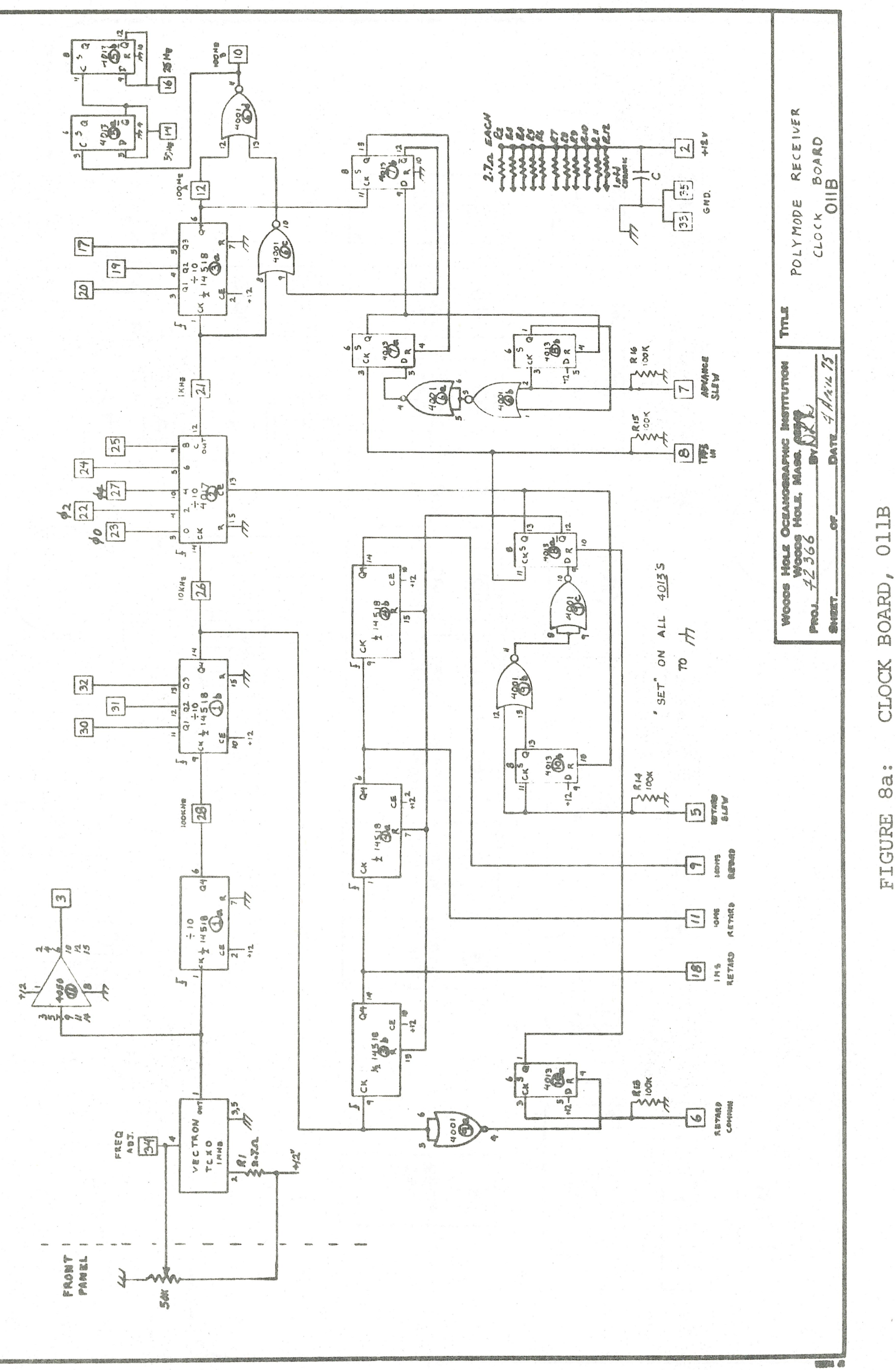



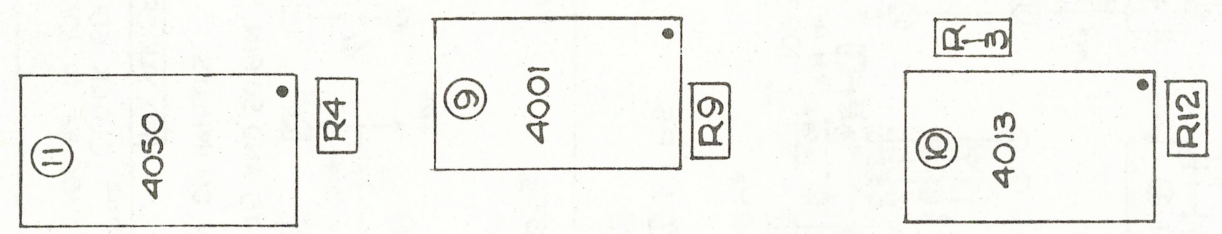

$$
a-8
$$

$0-$

$\alpha-6$

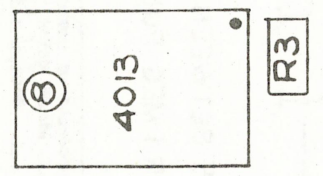

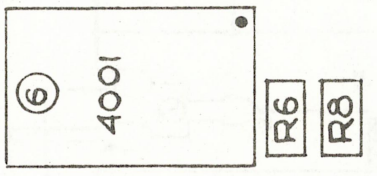

(t) $\frac{\infty}{ \pm}$

$[-10$

\begin{tabular}{|ll|l}
\hline 10 & $\frac{1}{0}$ \\
\hline
\end{tabular}

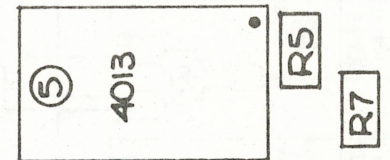

(1) $\frac{\infty}{10}$

$\bar{a}$
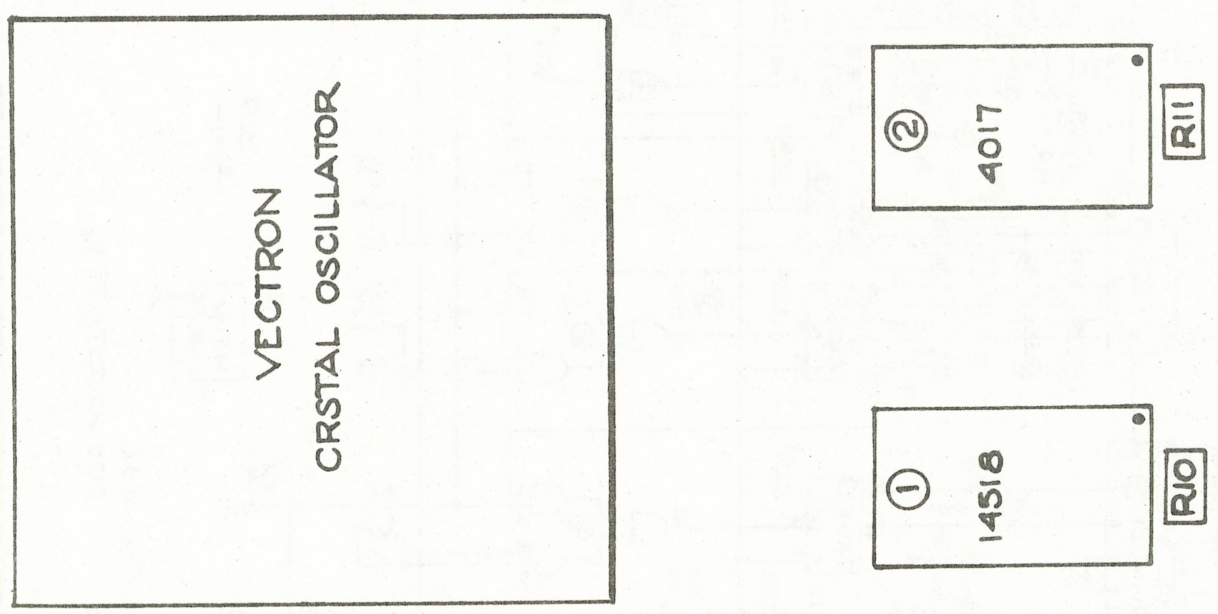


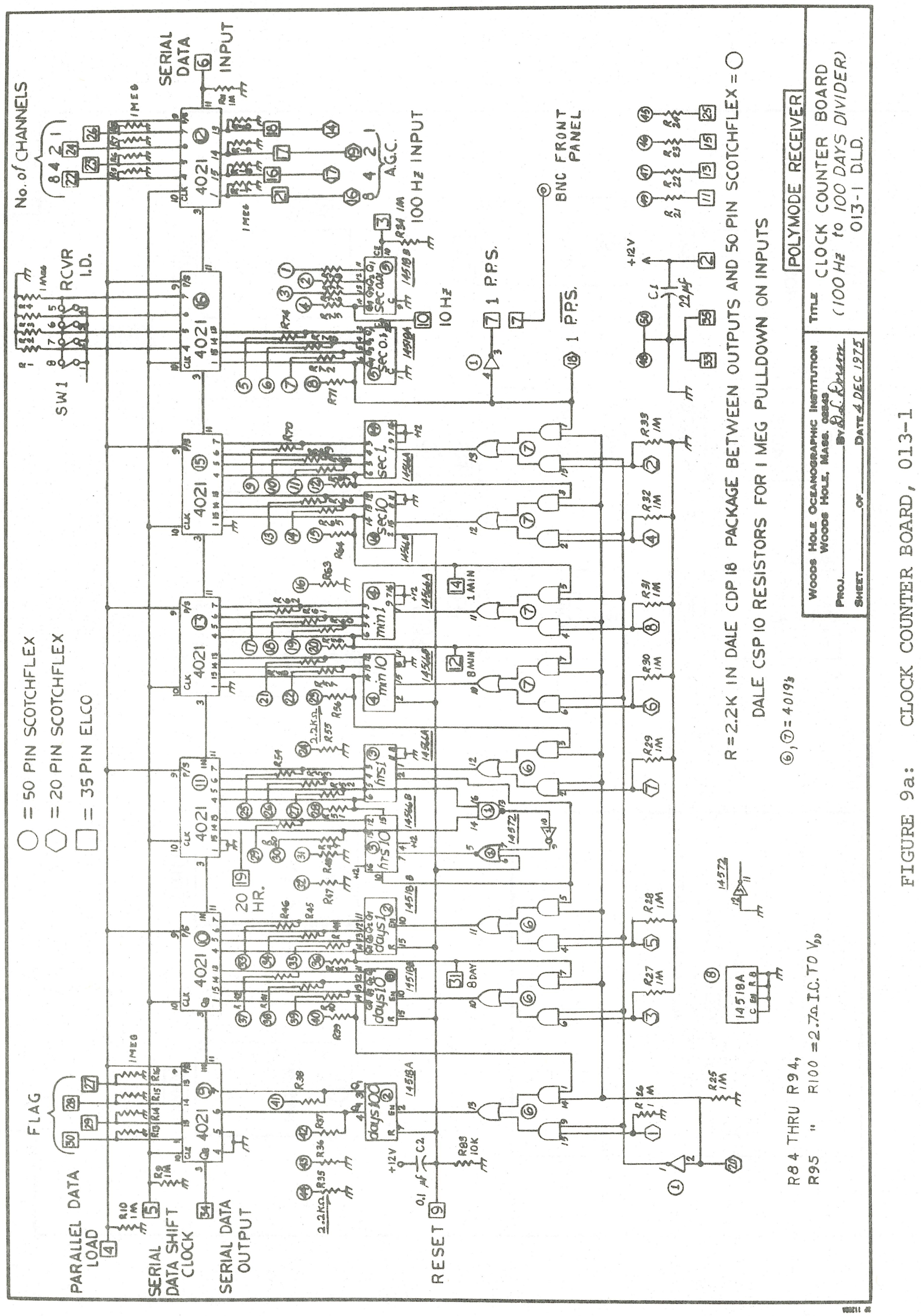




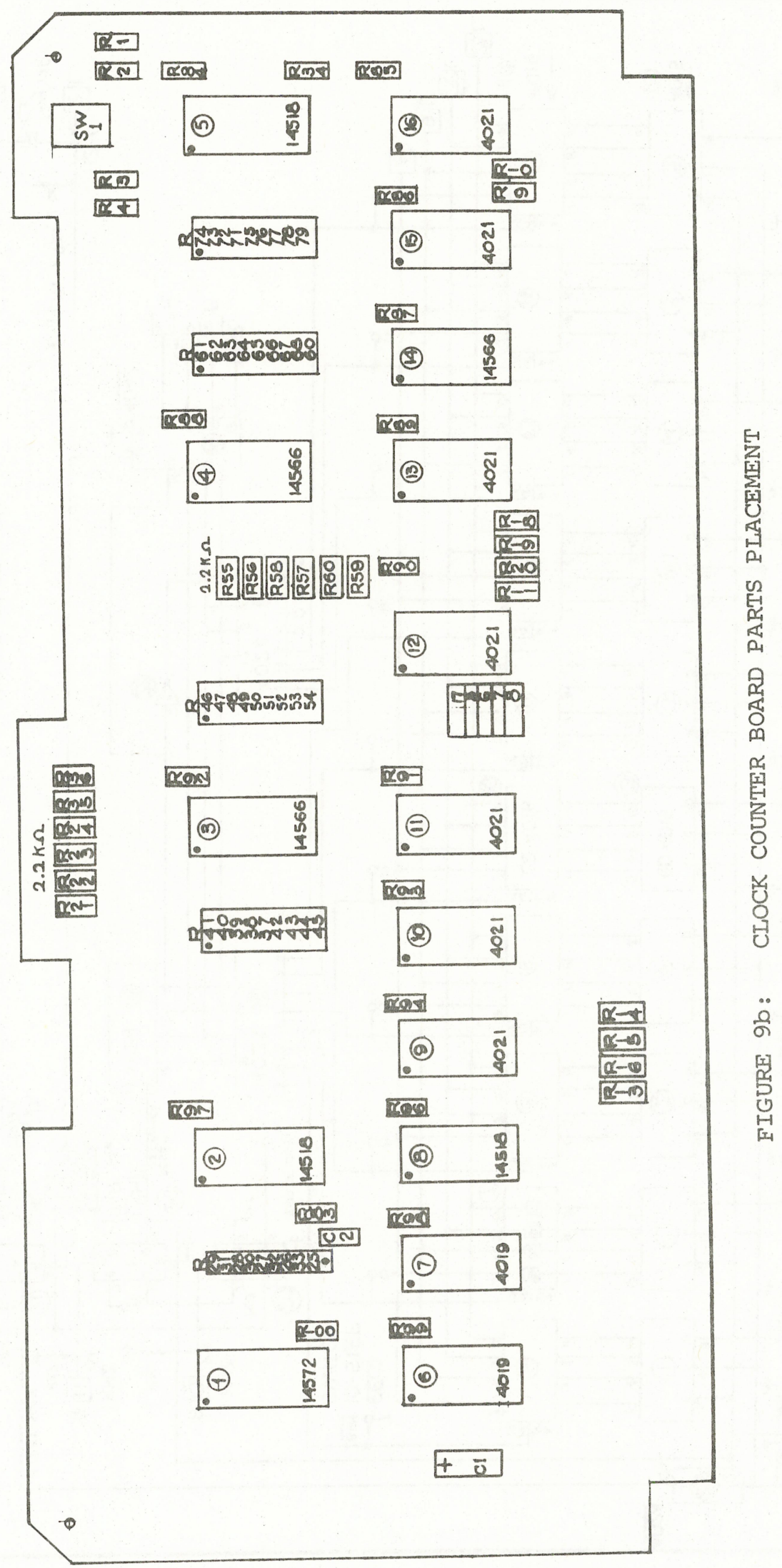




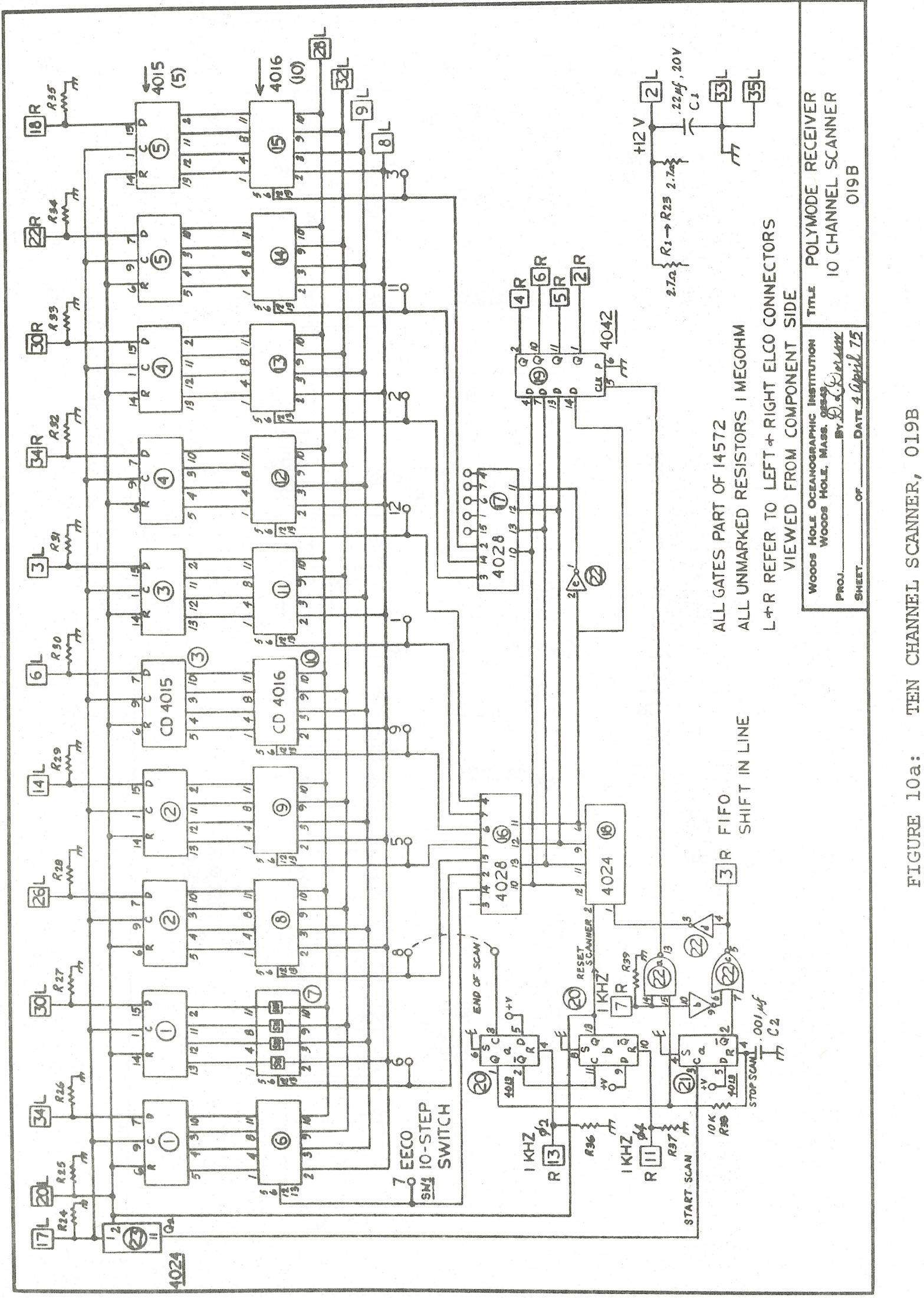




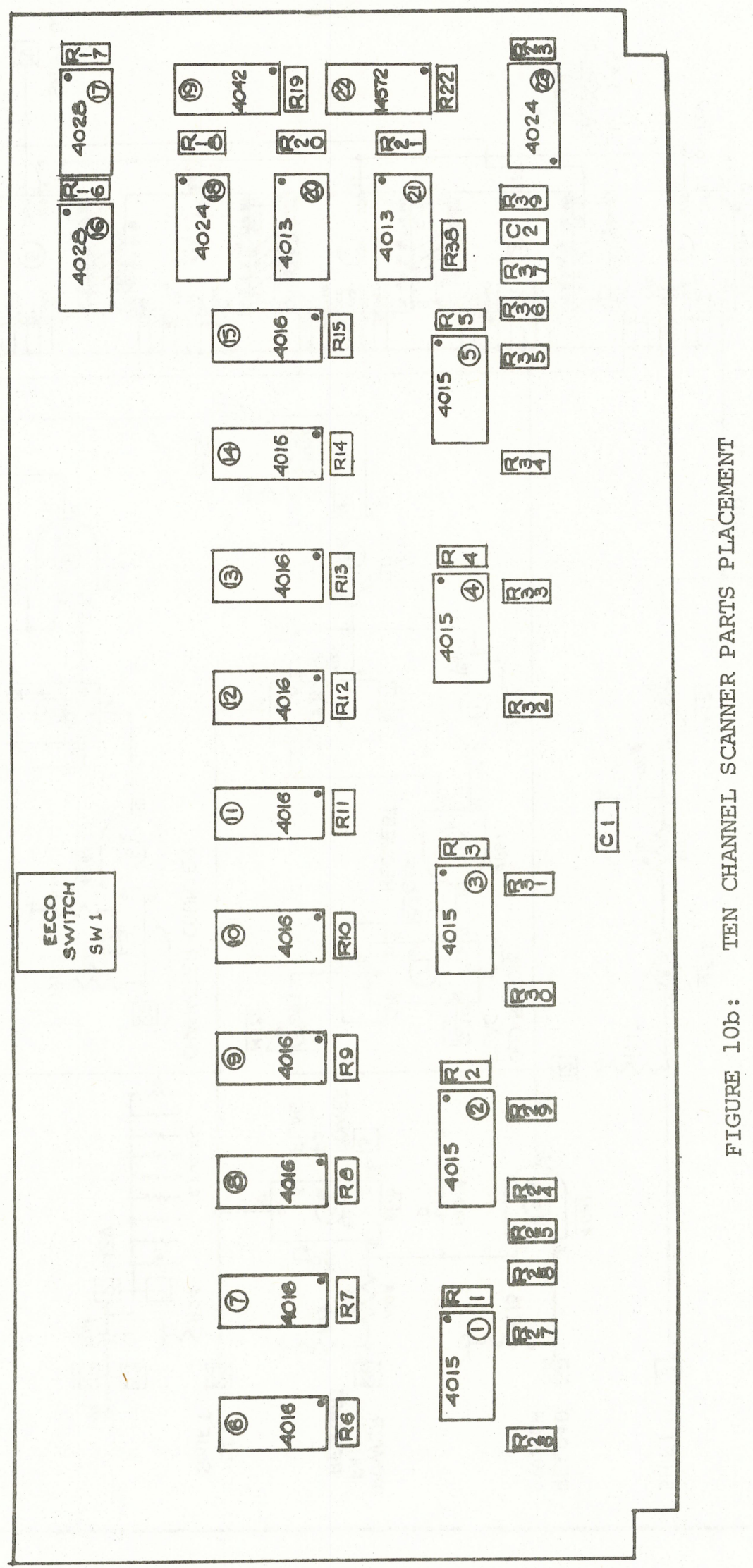




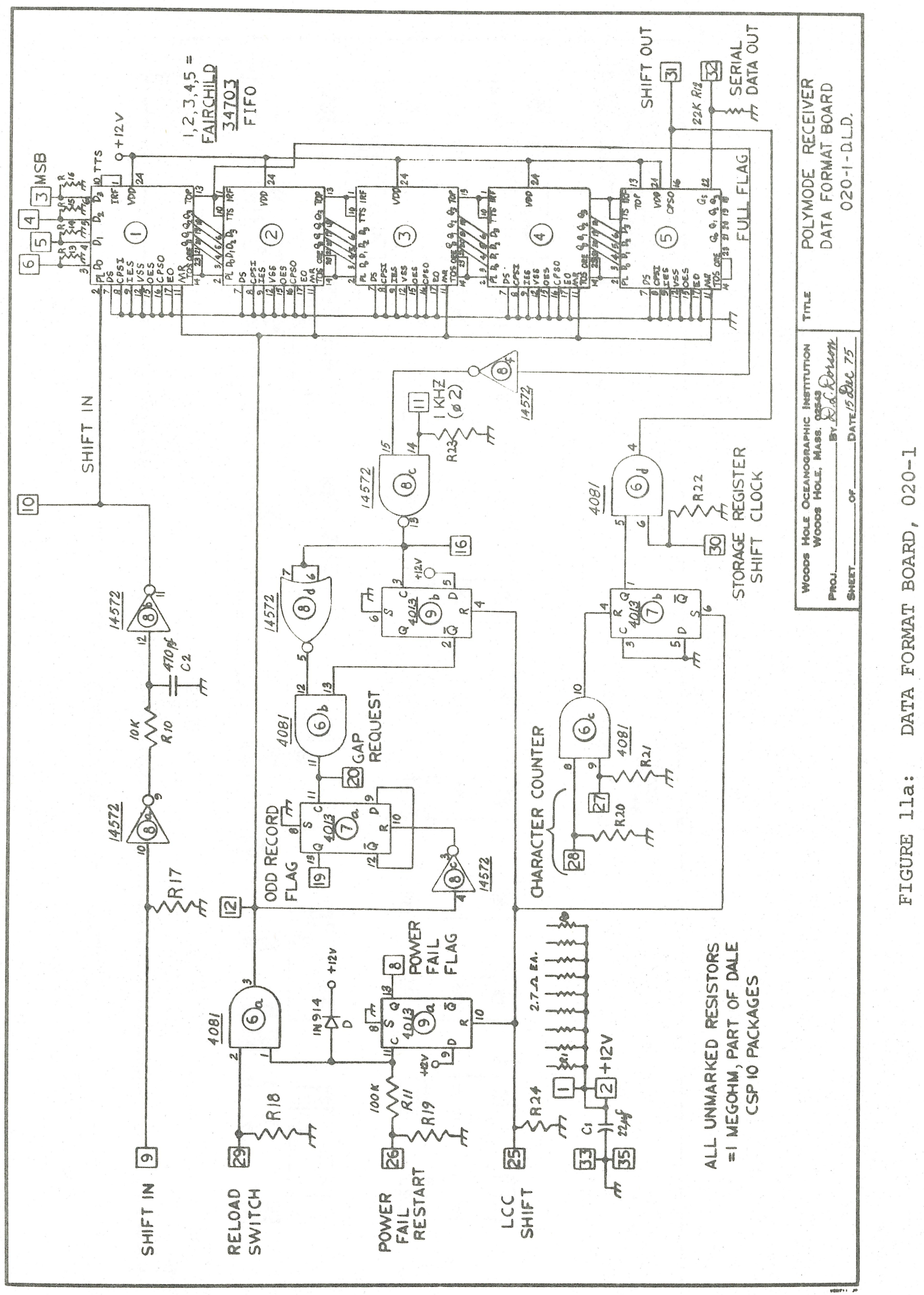




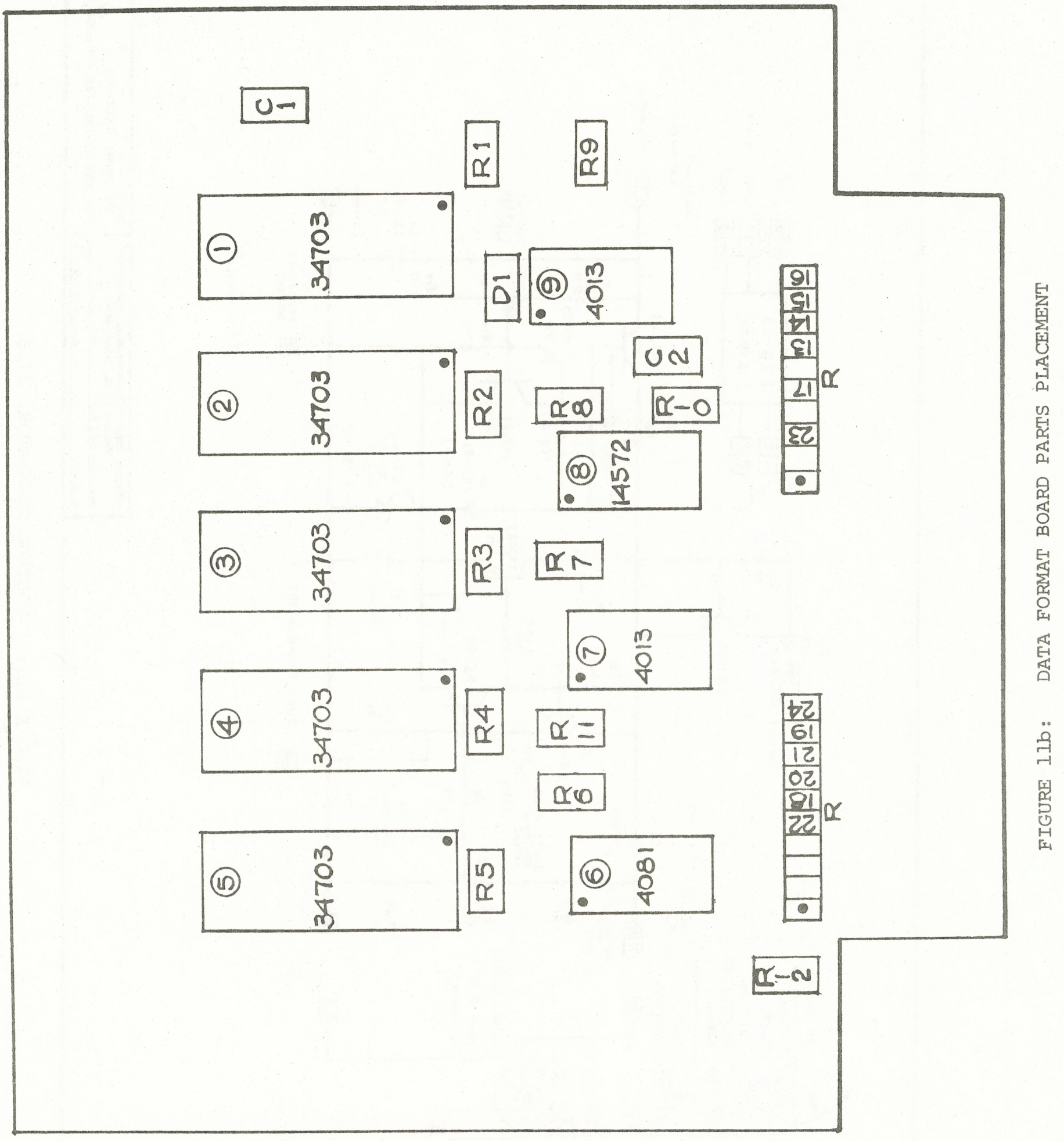




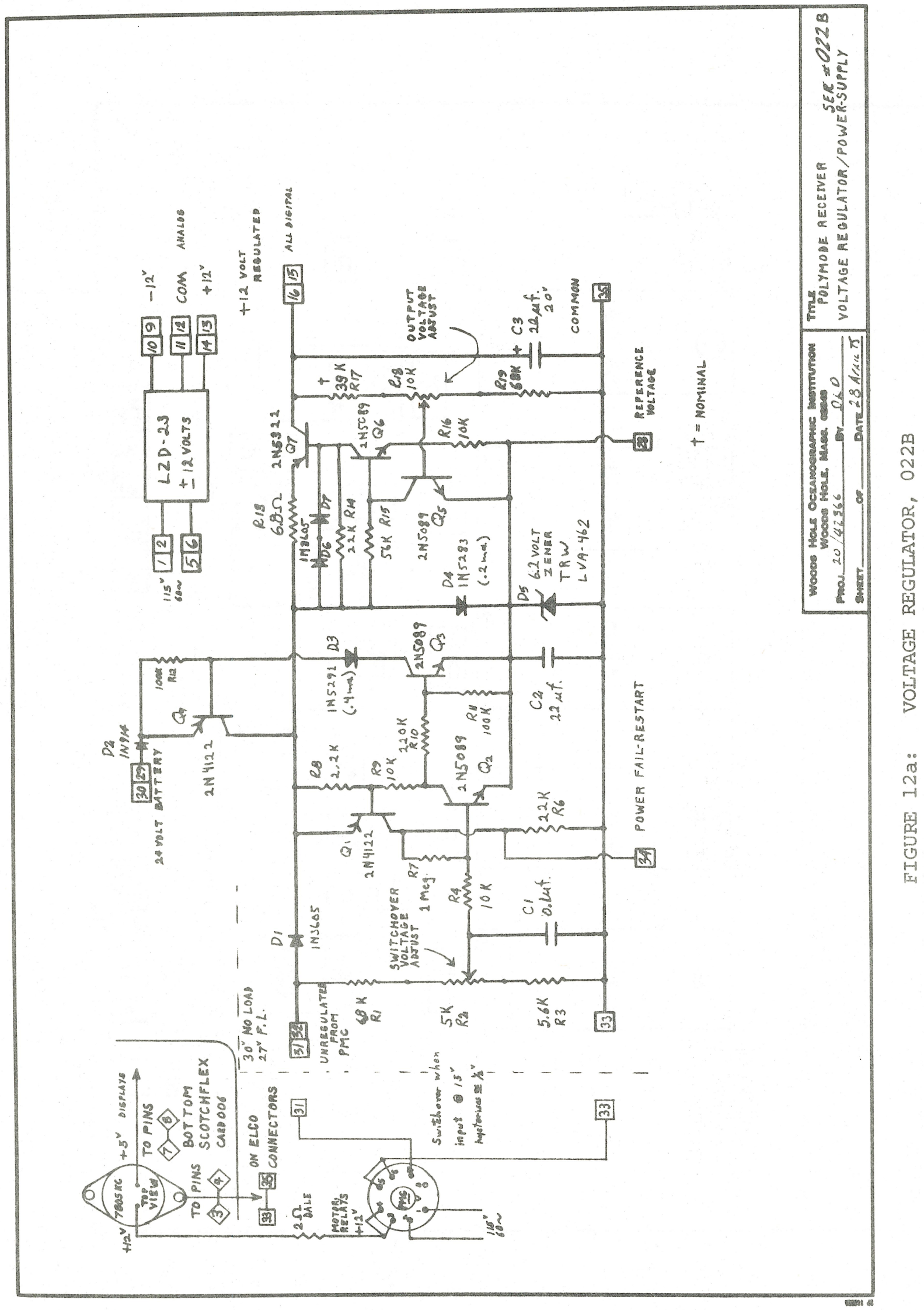




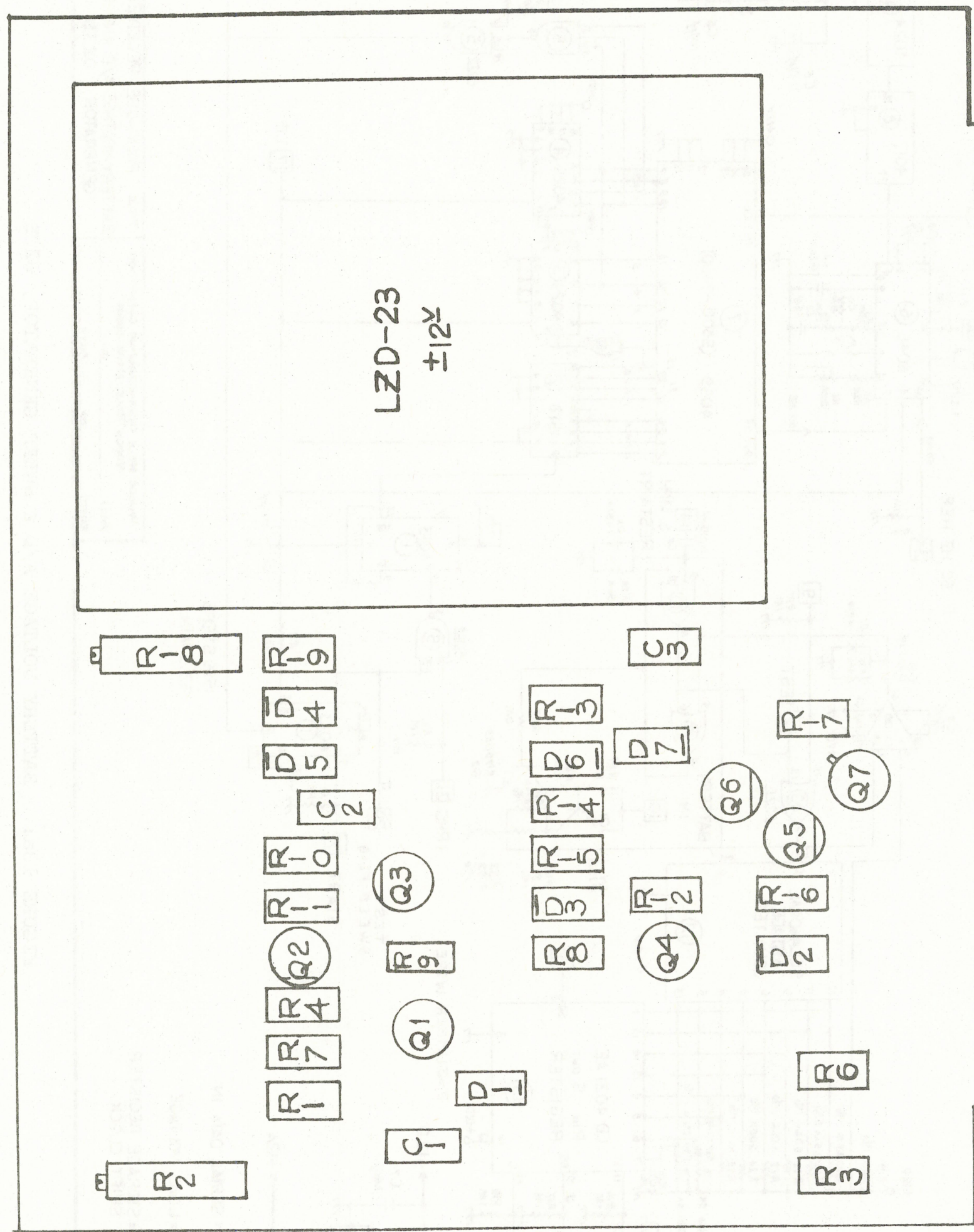

是 


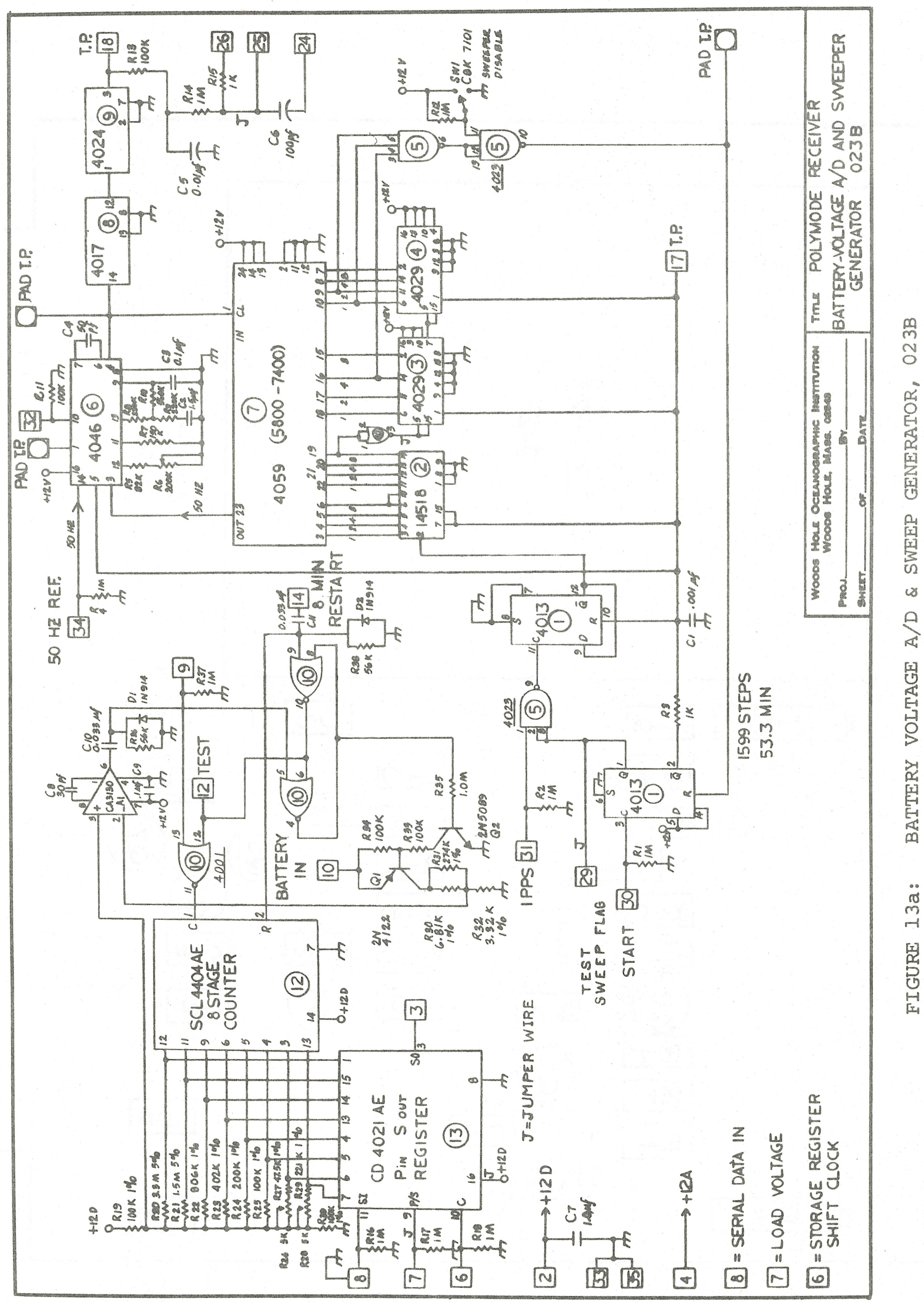




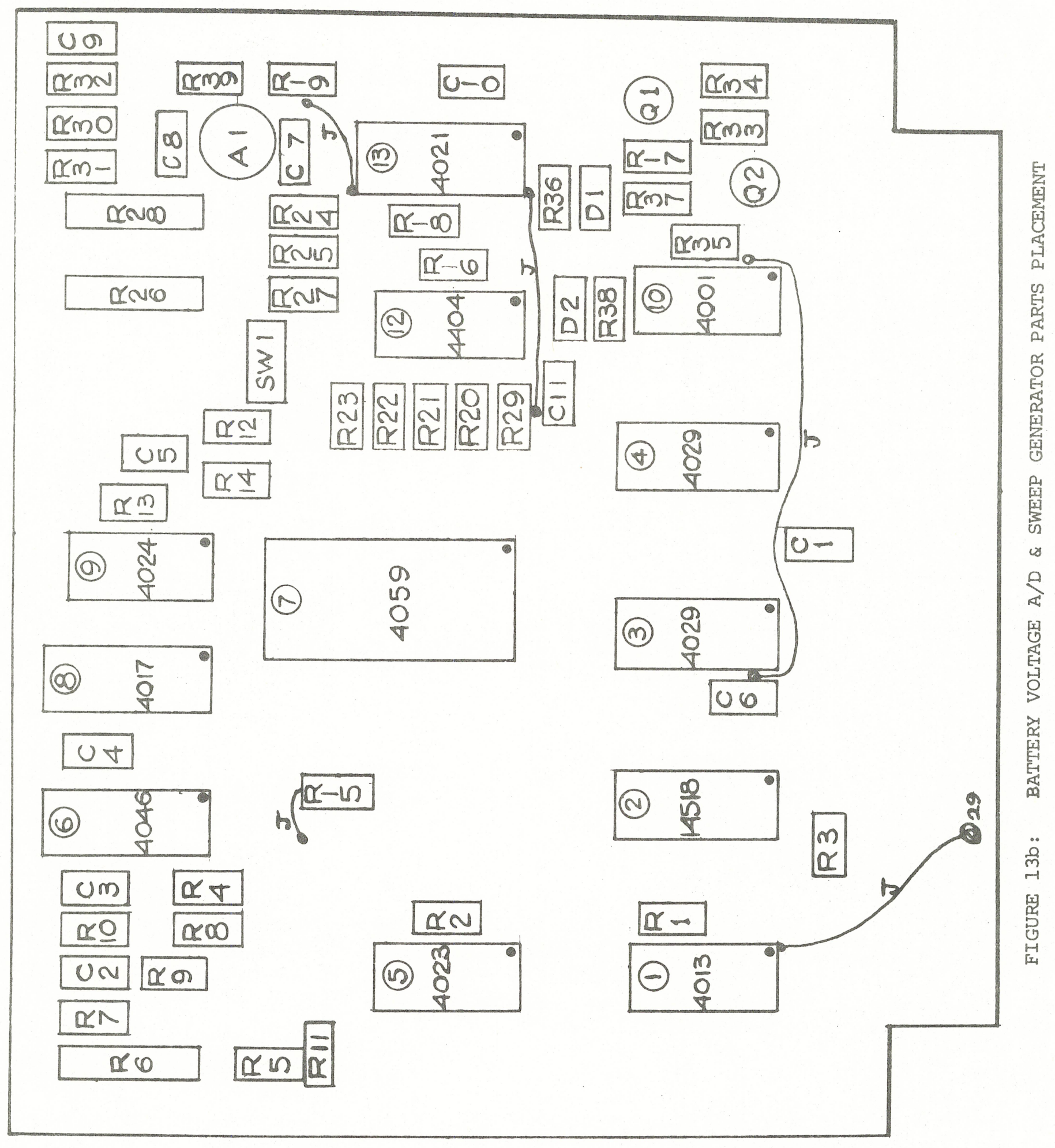




\subsubsection{Wiring List}

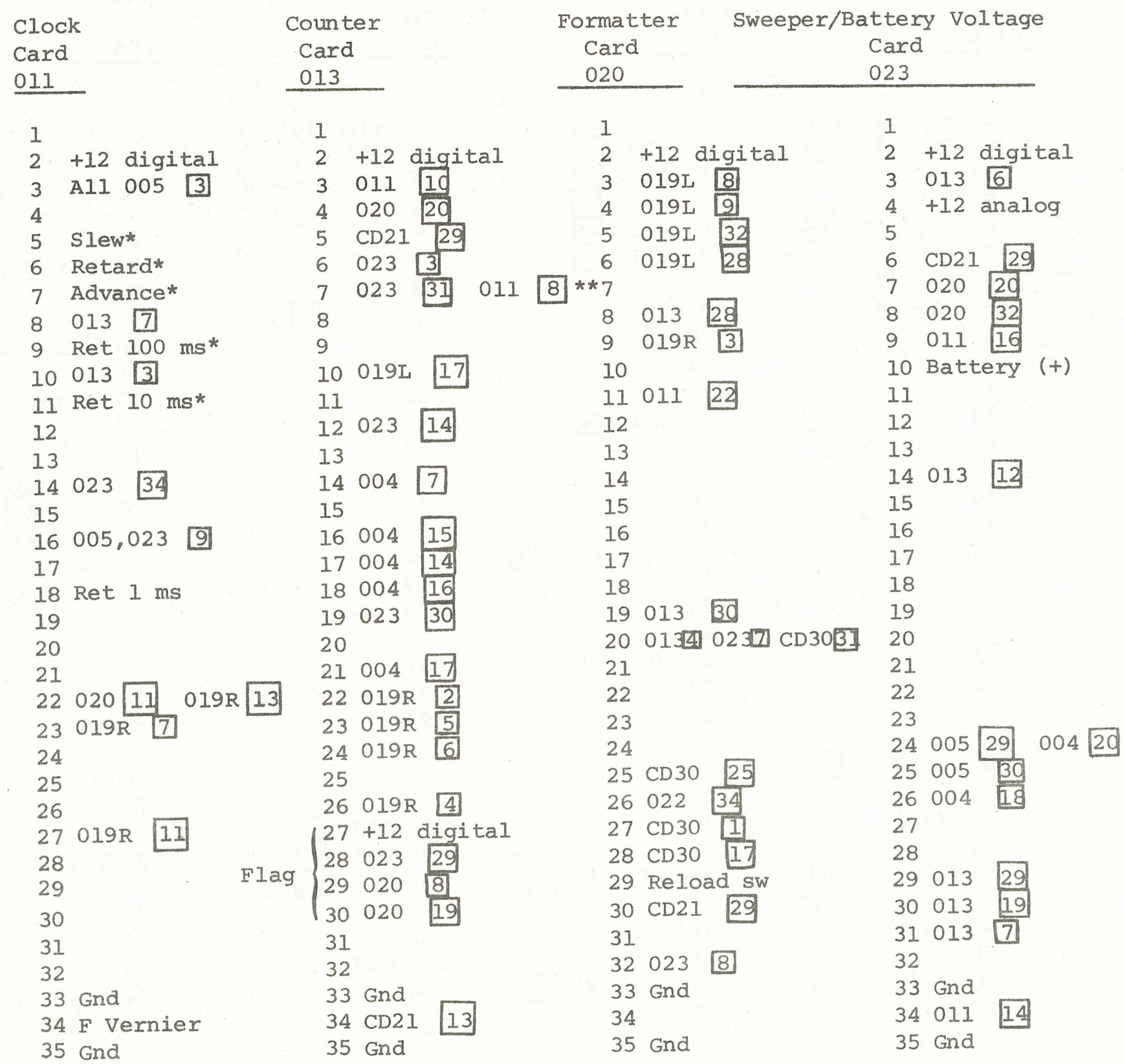

* Scotchflex from 006

**Front Panel 


\begin{tabular}{|c|c|c|c|c|c|c|c|}
\hline $\begin{array}{r}\text { Scann } \\
\text { Card } \\
0191 \\
\end{array}$ & & $\begin{array}{c}\text { Scanne } \\
\text { Card } \\
019 R \\
\end{array}$ & & $\begin{array}{c}\text { Filte } \\
\text { Card } \\
005 \\
\end{array}$ & & $\begin{array}{c}\text { Ampli } \\
\text { Carc } \\
004 \\
\end{array}$ & $\begin{array}{l}\text { fier } \\
\text { d } \\
\end{array}$ \\
\hline 1 & & 1 & & 1 & & 1 & \\
\hline 2 & +12 digital & 2 & $013 \quad 22$ & 2 & +12 digital & 2 & +12 digital \\
\hline 3 & $005, \# 628$ & 3 & 0209 & 3 & 0113 & 3 & Preset \\
\hline 4 & & 4 & 01326 & 4 & +12 analog & 4 & +12 analog \\
\hline 5 & & 5 & 01323 & 5 & & 5 & \\
\hline 6 & $005, \# 528$ & 6 & 01324 & 6 & & 6 & +12 motor \\
\hline 7 & & 7 & 01123 & 7 & & 7 & $013 \quad 14$ \\
\hline 8 & 0203 & 8 & & 8 & -12 & 8 & -12 \\
\hline 9 & 020 4 & 9 & & 9 & $011 \quad 16$ & 9 & \\
\hline 10 & & 10 & & 10 & & 10 & Meter fast \\
\hline 11 & & 11 & 01127 & 11 & & 11 & \\
\hline 12 & & 12 & & 12 & & 12 & Meter slow \\
\hline 13 & & 13 & 01122 & 13 & & 13 & \\
\hline 14 & $005, \# 428$ & 14 & & 14 & & 14 & 013 \\
\hline 15 & & 15 & & 15 & & 15 & $013 \quad 16$ \\
\hline 16 & & 16 & & 16 & & 16 & 01318 \\
\hline 17 & 01310 & 17 & & 17 & & 17 & 013 \\
\hline 18 & & 18 & 005, \#10 28 & 18 & & 18 & 02326 \\
\hline 19 & & 19 & & 19 & & 19 & \\
\hline 20 & & 20 & & 20 & & 20 & 02324 \\
\hline 21 & & 21 & & 21 & & 21 & \\
\hline 22 & & 22 & 005, \#9 28 & 22 & & 22 & \\
\hline 23 & & 23 & & 23 & & 23 & \\
\hline 24 & & 24 & & 24 & & 24 & \\
\hline 25 & & 25 & & 25 & & 25 & \\
\hline 26 & $005, \# 328$ & 26 & & 26 & & 26 & \\
\hline 27 & & 27 & & 27 & & 27 & \\
\hline 28 & 0206 & 28 & & 28 & 019 & 28 & \\
\hline 29 & & 29 & & 29 & 023 & 29 & Signal in \\
\hline 30 & $005, \# 2 \quad 28$ & 30 & 005, \#8 & 30 & 02325 & 30 & \\
\hline 31 & & 31 & & 31 & & 31 & Signal ground \\
\hline 32 & 0205 & 32 & & 32 & & 32 & \\
\hline 33 & Gnd & 33 & & 33 & Gnd & 33 & Gnd \\
\hline 34 & 005, \#1 28 & 34 & $005, \# 7$ & 34 & & 34 & \\
\hline 35 & Gnd & 35 & & 35 & Gnd & 35 & Gnd \\
\hline
\end{tabular}




\section{Display \\ Card \\ 006 \\ 50-Pin}

Scotchflex
1

2

3

4

5

6

7

8

9

10

11

12

13

14

15

16

17

18

19

20

21

22

23

24

25

26

27

28

29

30

31

32

33

34

35

36

37

38

39

40

41

42

43

44

45

46

47

48

49

50
Seconds $\times 1,1$

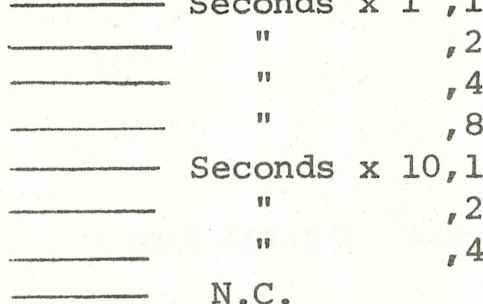

Minutes $\times 1,1$

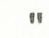

"

Minutes x 10,1

"

"

N.C.

Hours $\times 1$
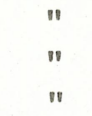

Hours $\times 10$

N.C.

N.C.

Days $\times 1$

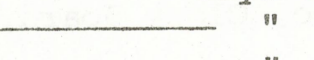

- "
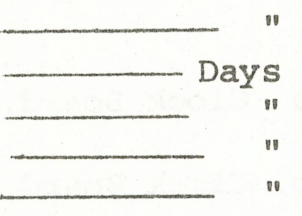

Days x 100

N.C.

N.C.

.1

.4

8

.1

$$
\begin{gathered}
\begin{array}{c}
\text { Counter } \\
\text { Card } \\
013 \\
\hline 50-P i n \\
\text { Scotchflex }
\end{array} \\
\hline
\end{gathered}
$$

Seconds $\times 0.01,11$

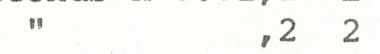

$"$

43

, 84

Seconds $\times 0.1,15$

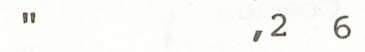

" $\quad .4 \quad 7$

.88
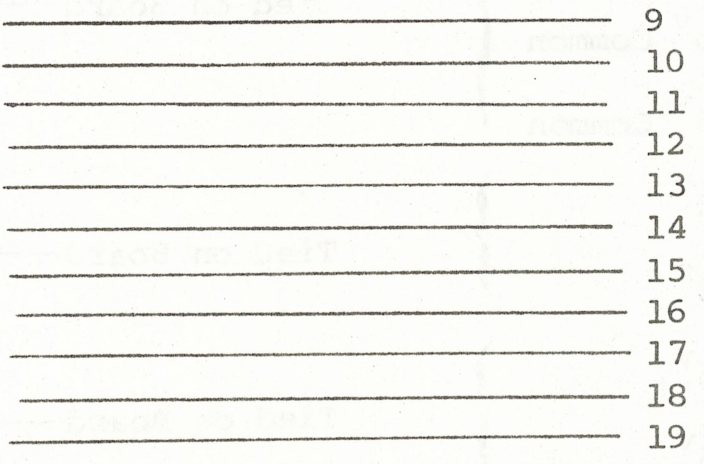

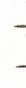

.

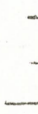

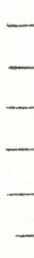

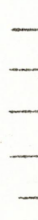
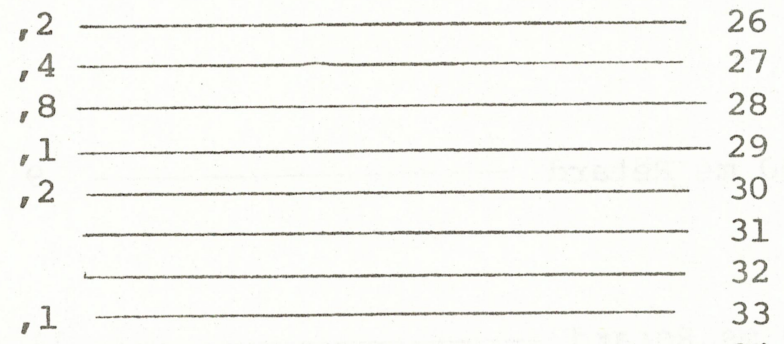

.4

, 8

, 1

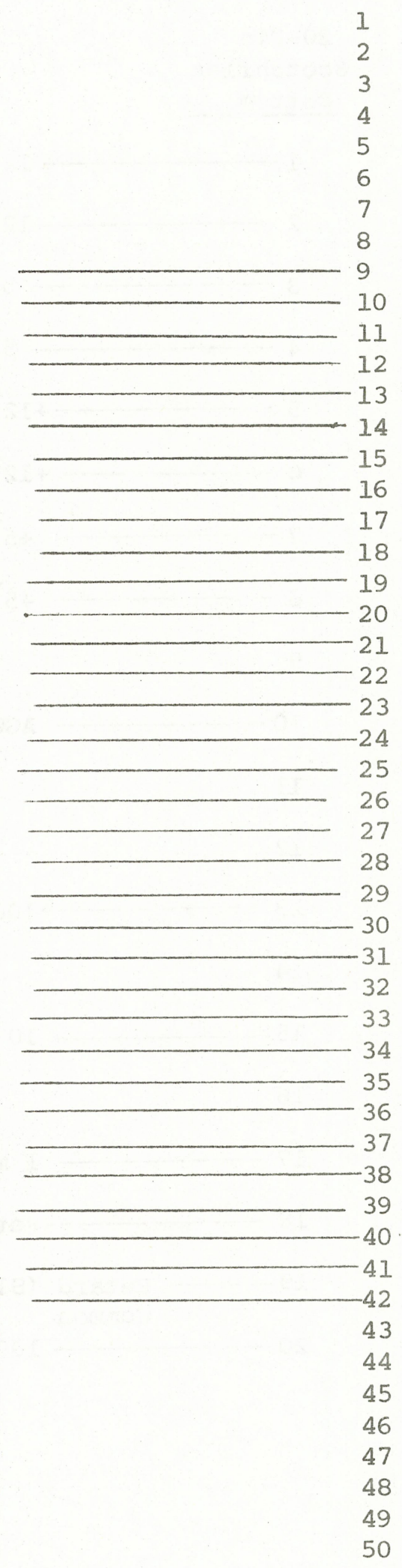

Connector

Card

007

50-Pin

Scotchflex

1 


\section{Display \\ Card \\ 006 \\ 20-Pin \\ scotchflex \\ Bottom}

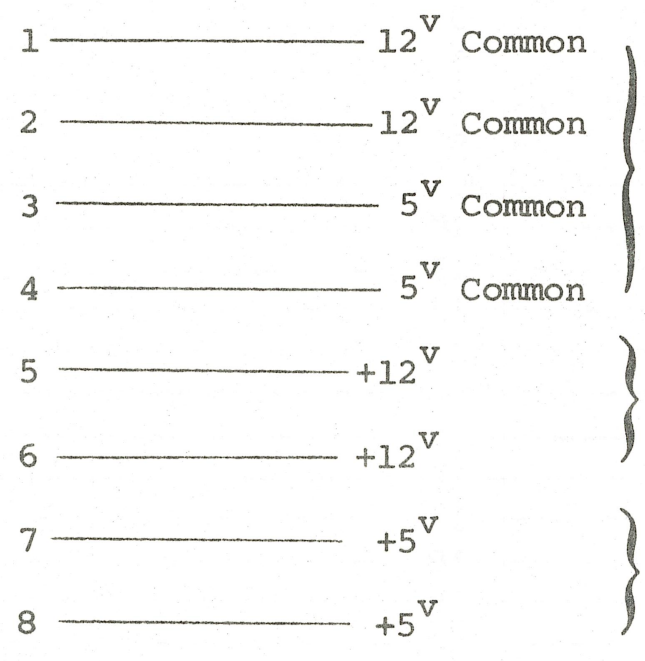

9

$10-$ AGC Preset

11

12

$13-100 \mathrm{~ms}$ Retard

14

15 $10 \mathrm{~ms}$ Retard

\section{Tied on Board-Common Bus}

Tied on Board $-12^{\mathrm{V}}$ Digital Bus

Tied on Board $+5^{\mathrm{V}}$ Bus

16

17

$1 \mathrm{~ms}$ Retard

18 on Elco, Clock Board, 011

18 Retard slew

5 on Elco, Clock Board, 011

19

Retard (Slew-Selector Switch Wiper)

Common

3 on ElCO, Input Ampl., 004

6 on Elco, Clock Board, 011 7 on Elco, Clock Board, 011 


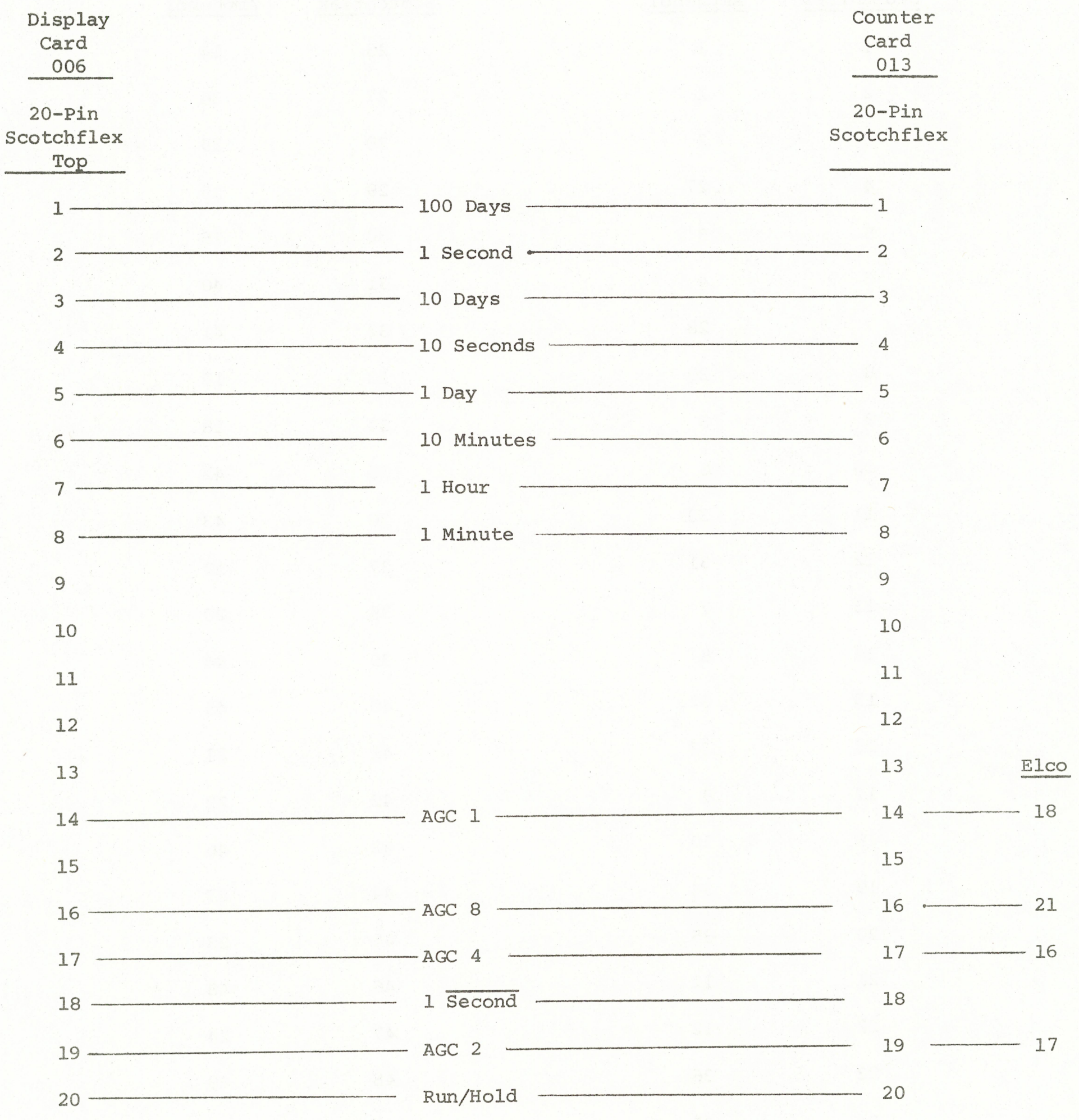


Card 007

2

3

4

5

6

7

8

9

10

11

12

13

14

15

16

17

18

19

20

21

22

23

24

25
Scotchflex 50-Pin

To

Amphenol Microribbon 50-Pin

Amphenol

1

2

3

27

3

4

28

29

5

6

30

31

7

8

32

33

9

10

34

35

11

12

36

37

13
Scotchflex Amphenol

26

14

27

36

28

39

29

15

30

16

31

40

32

41

33

17

34

18

35

42

36

43

37

19

38

20

39

44

40

45

41

21

42

22

43

46

44

47

45

23

46

48

47

24

48

49

49

25

50

50 


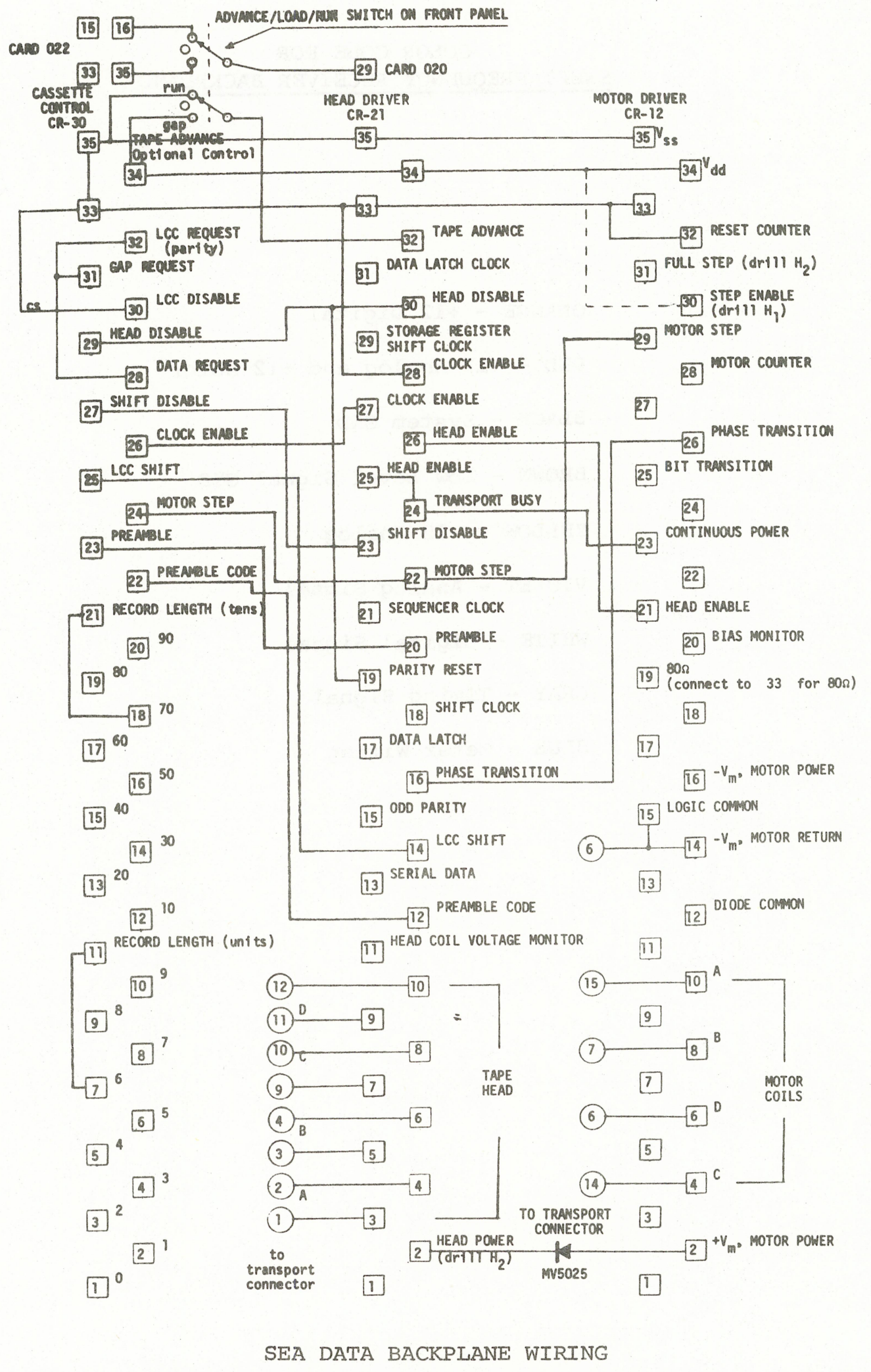


COLOR CODE FOR SWEPT FREQUENCY RECEIVER BACKPLANE

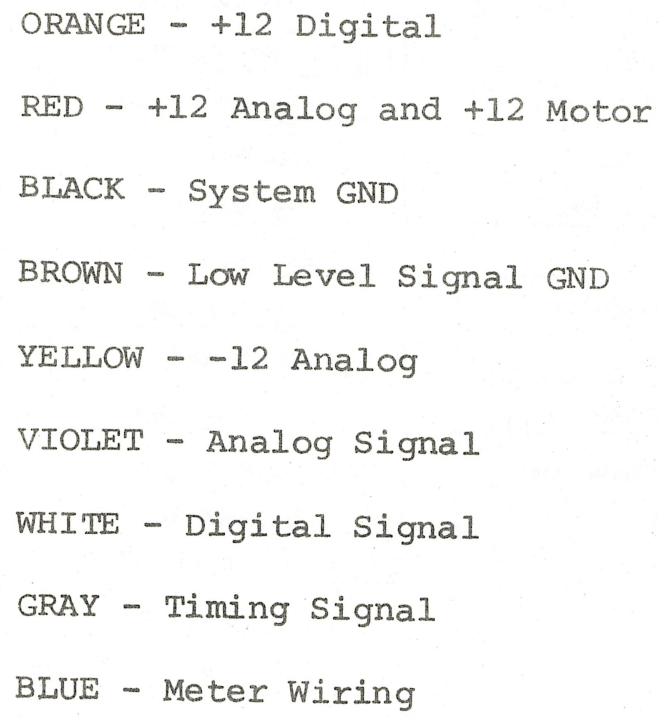




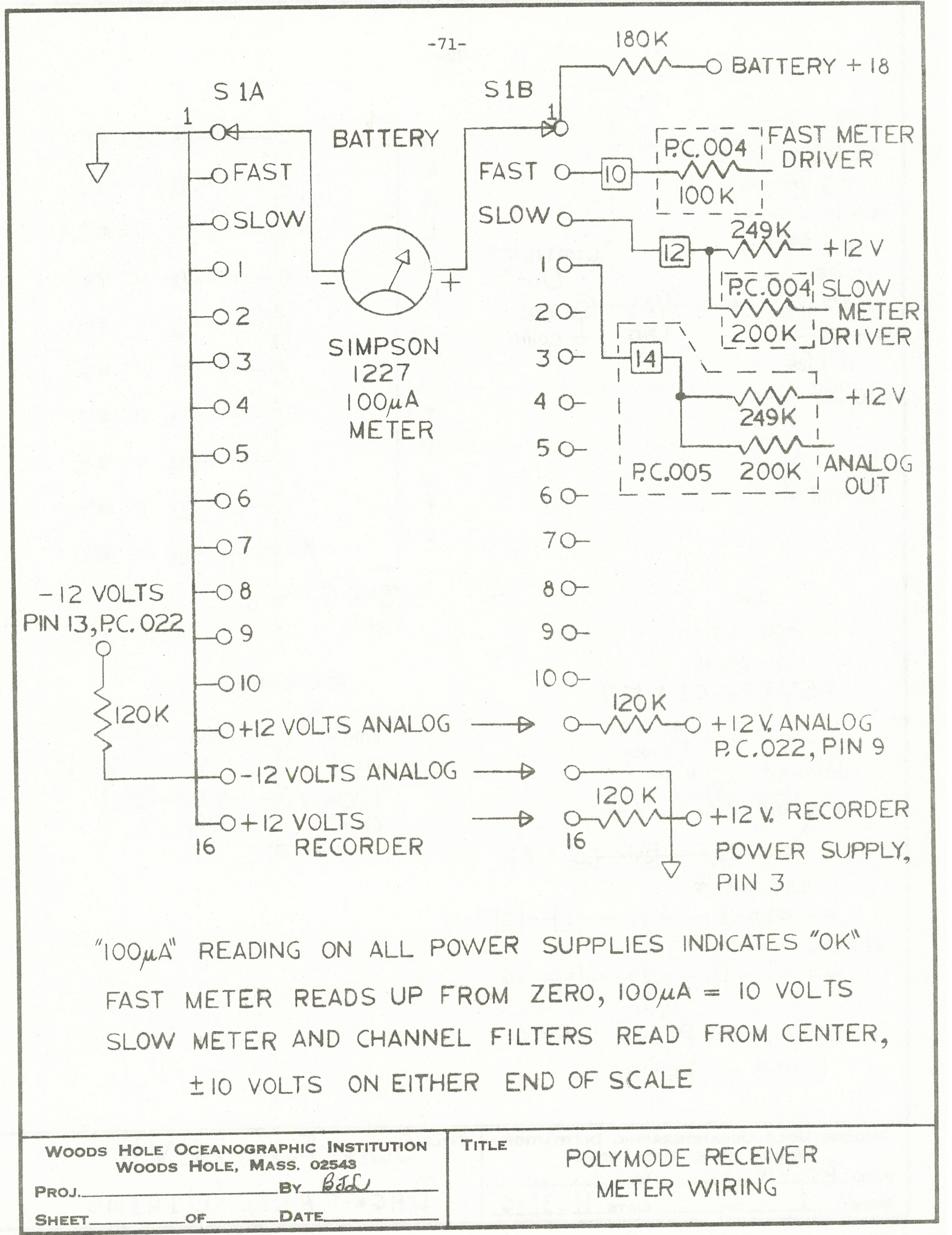


$005 \#\left[\begin{array}{ll}28 & 1\end{array}\right.$

H's 28 -

\# $3[28-0$

4 年4 28

$\# 5 \mid 28\}$

"Limirer

$\$ 6[28-\cdots$

Out"

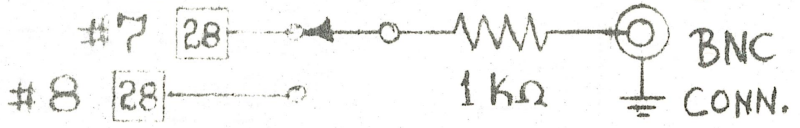

$+9128+$

$1 0 \longdiv { 2 8 } - \cdots$

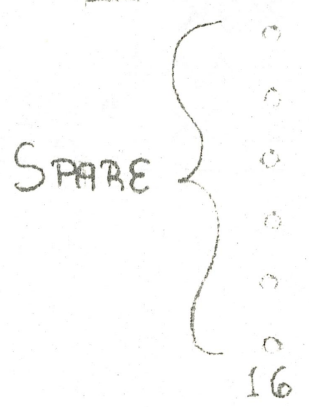

GRATHTLL

SWITCH

\#5rmaz-01-1-16N

BATTERY

"Battent"

"OFF"q

25 volr

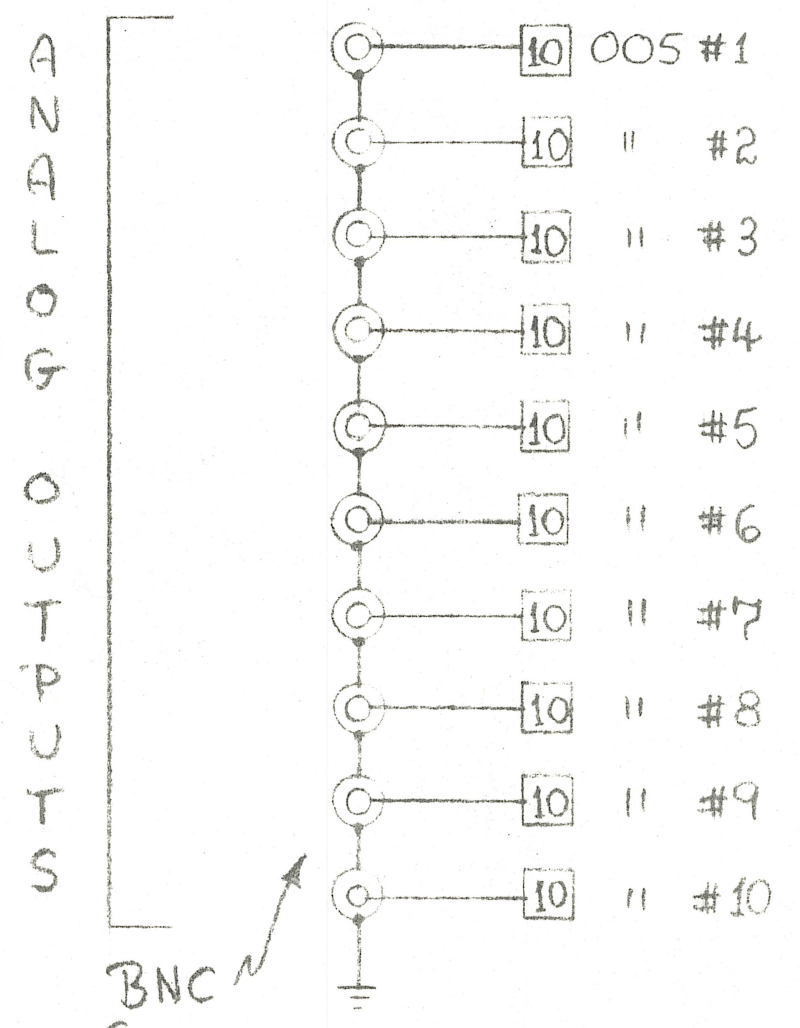

CONN.

C10 \#2

(c) -10 11 \#3

C) $-1011 \quad$ \#

$\rightarrow \quad 10$ " \#5

of - 10 11 6

c) 1011 \#?

6-[10] 11 \#8

$10+-10 \quad 11 \quad+9$

BNC CONN.

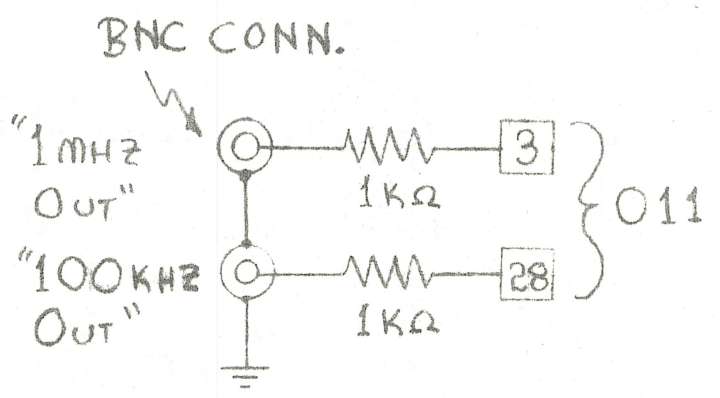

$117 V A C$

$0.5 \mathrm{~A}, \mathrm{AGC1/2}$

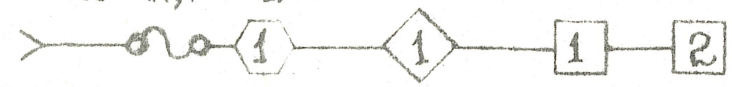

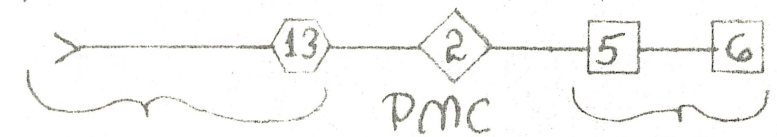

$$
\begin{aligned}
& \text { HP POERR POWER OZ2 } \\
& \text { CONN SUPPLY }
\end{aligned}
$$

\section{TITLE SwePt FreQ $R C V R$ \\ BaCK PanEL WIRING}


$-13-$

3.2.1.3 Parts Lists Input Amplifier, Card 004C

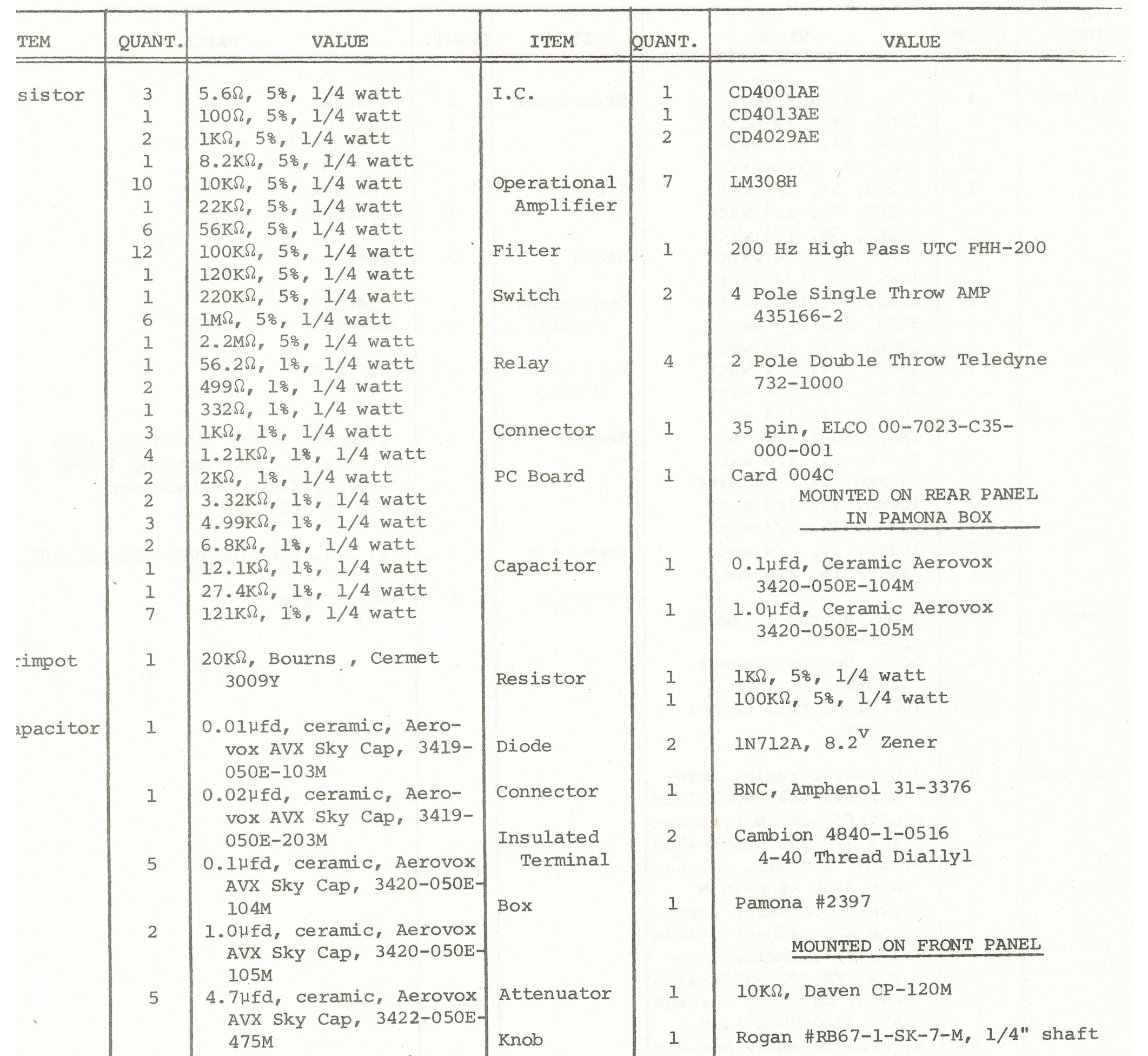


$-74-$

Single Channel Filter, Card 005B

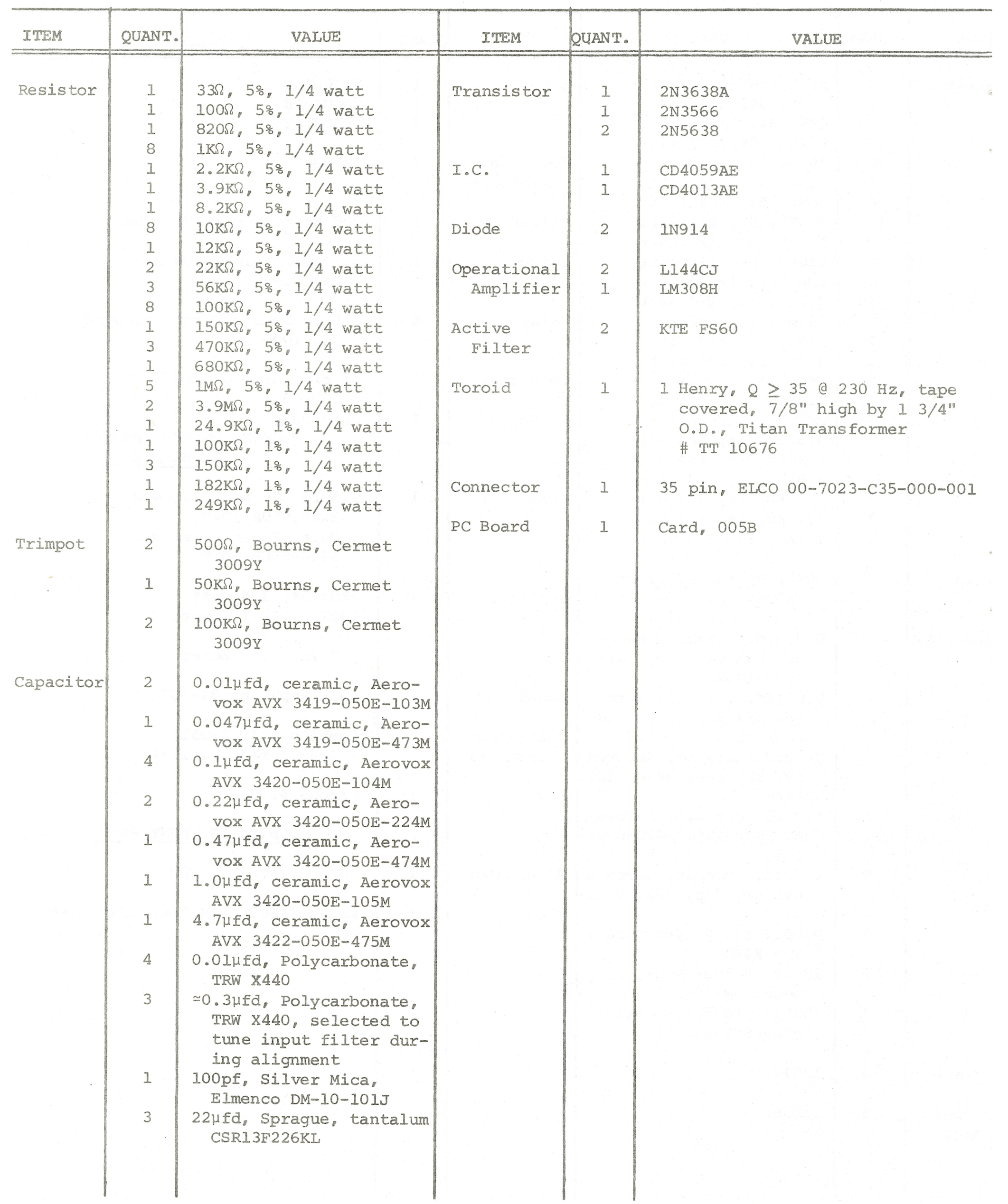




\begin{tabular}{|l|l|l|l|l|l|}
\hline ITEM & QUANT. & VALUE & ITEM & QUANT. & VALUE \\
\hline
\end{tabular}

\begin{tabular}{|c|c|c|}
\hline lesistor & $\begin{array}{l}1 \\
1 \\
4\end{array}$ & $\begin{array}{l}1 \mathrm{~K} \Omega, 5 \%, 1 / 4 \text { watt } \\
27 \mathrm{~K} \Omega, 5 \%, 1 / 4 \text { watt } \\
100 \mathrm{~K} \Omega, 5 \%, 1 / 4 \text { watt }\end{array}$ \\
\hline 'ransistor & 1 & $2 \mathrm{~N} 4122$ \\
\hline$\therefore$. C. & $\begin{array}{l}1 \\
1 \\
6\end{array}$ & $\begin{array}{l}\text { CD4001AE } \\
\text { CD4013AE } \\
\text { CD4050AE }\end{array}$ \\
\hline isplay IC & 10 & $\begin{array}{c}\text { 5082-7340 Hewlett Pack- } \\
\text { ard Hexadecimal Dis- } \\
\text { play and Electronics }\end{array}$ \\
\hline I.E.D. & 1 & $\begin{array}{l}\text { 5082-4880 Hewlett Pack- } \\
\text { ard LED and Clip }\end{array}$ \\
\hline $\begin{array}{l}\text { esistor } \\
\text { Package }\end{array}$ & 4 & $1 \mathrm{M} \Omega$, Dale CSP1OE-01-105K \\
\hline witch & 1 & $\begin{array}{l}\text { Grayhill 5lCDP30-01-2- } \\
\text { AJN } \\
\text { Grayhill 5lCDP30-01-1 } \\
\text { AJN } \\
\text { JBT MPC-LFH-126 Spring } \\
\text { Loaded Toggle with } \\
\text { MPC Terminals } \\
\text { JBT MPC-LL-123 Locking } \\
\text { Lever Toggle with MPC } \\
\text { Terminals } \\
\text { C\&K P-8121C Pushbutton }\end{array}$ \\
\hline $\begin{array}{l}\text { Iisplay } \\
\text { Socket }\end{array}$ & 10 & Augat \#508-AGAD \\
\hline :apacitor & 1 & 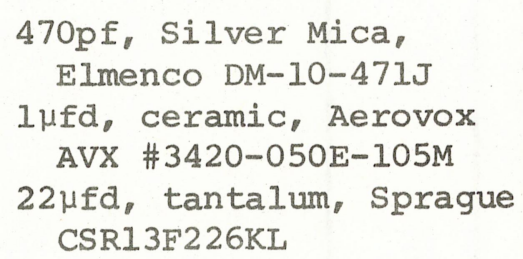 \\
\hline :onnector & 1 & $\begin{array}{l}20 \text { pin, Scotchflex } \\
\text { straight PC Header, } \\
\text { Wirewrap \#3428-4005 } \\
20 \text { pin, Scotchflex } \\
\text { straight PC Header, } \\
\text { solder Tail \#3428-2002 } \\
50 \text { pin, Scotchflex } \\
\text { straight PC Header, } \\
\text { Wirewrap \#3433-4005 }\end{array}$ \\
\hline nob & 2 & $\begin{array}{l}\text { Rogan RB67-0-SK-7-M, } \\
\text { I/8" shaft }\end{array}$ \\
\hline C Board & 1 & Card 006C \\
\hline
\end{tabular}


$-76-$

Clock Board, Card 011B

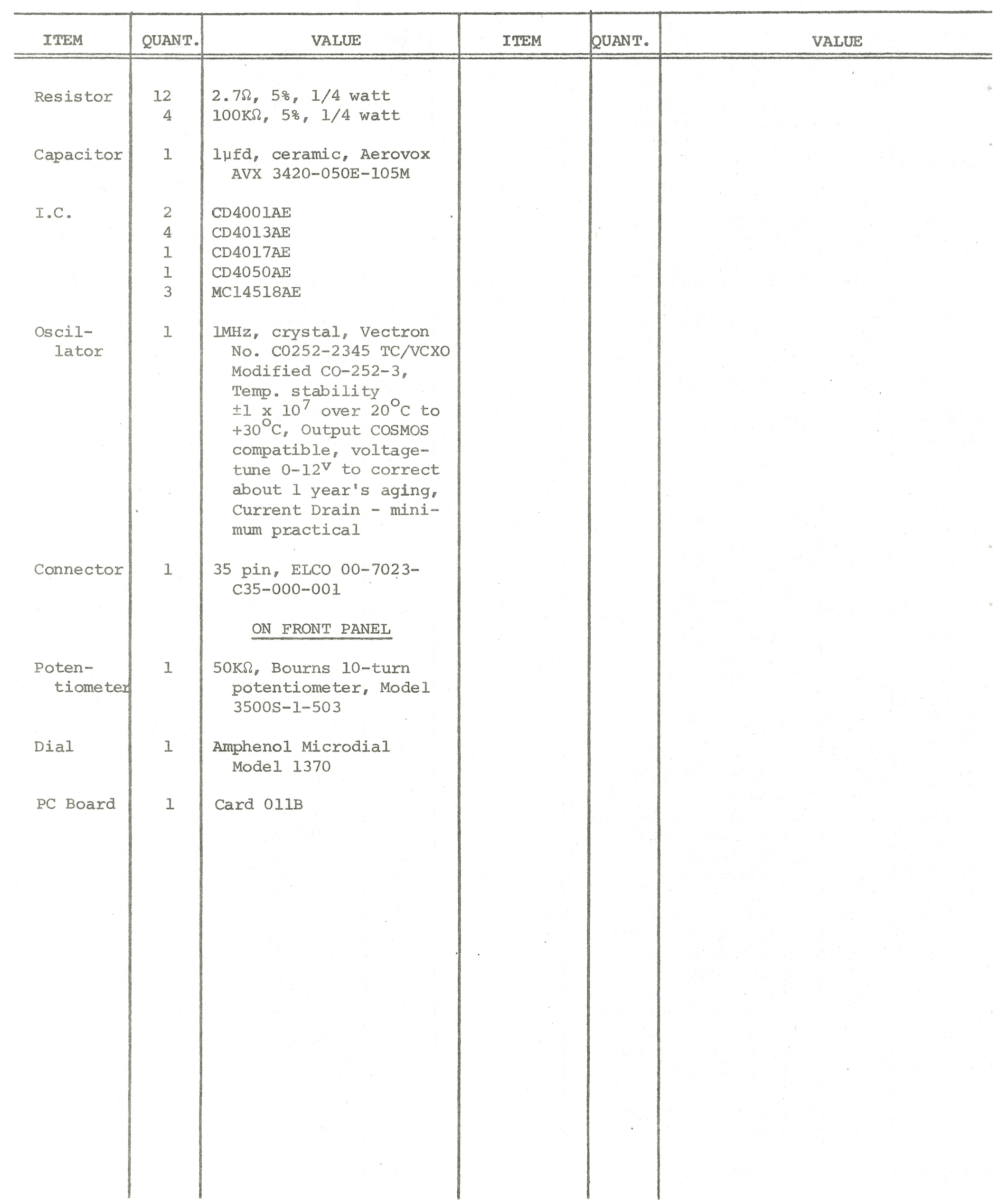


Clock Counter Board, Card 013-1

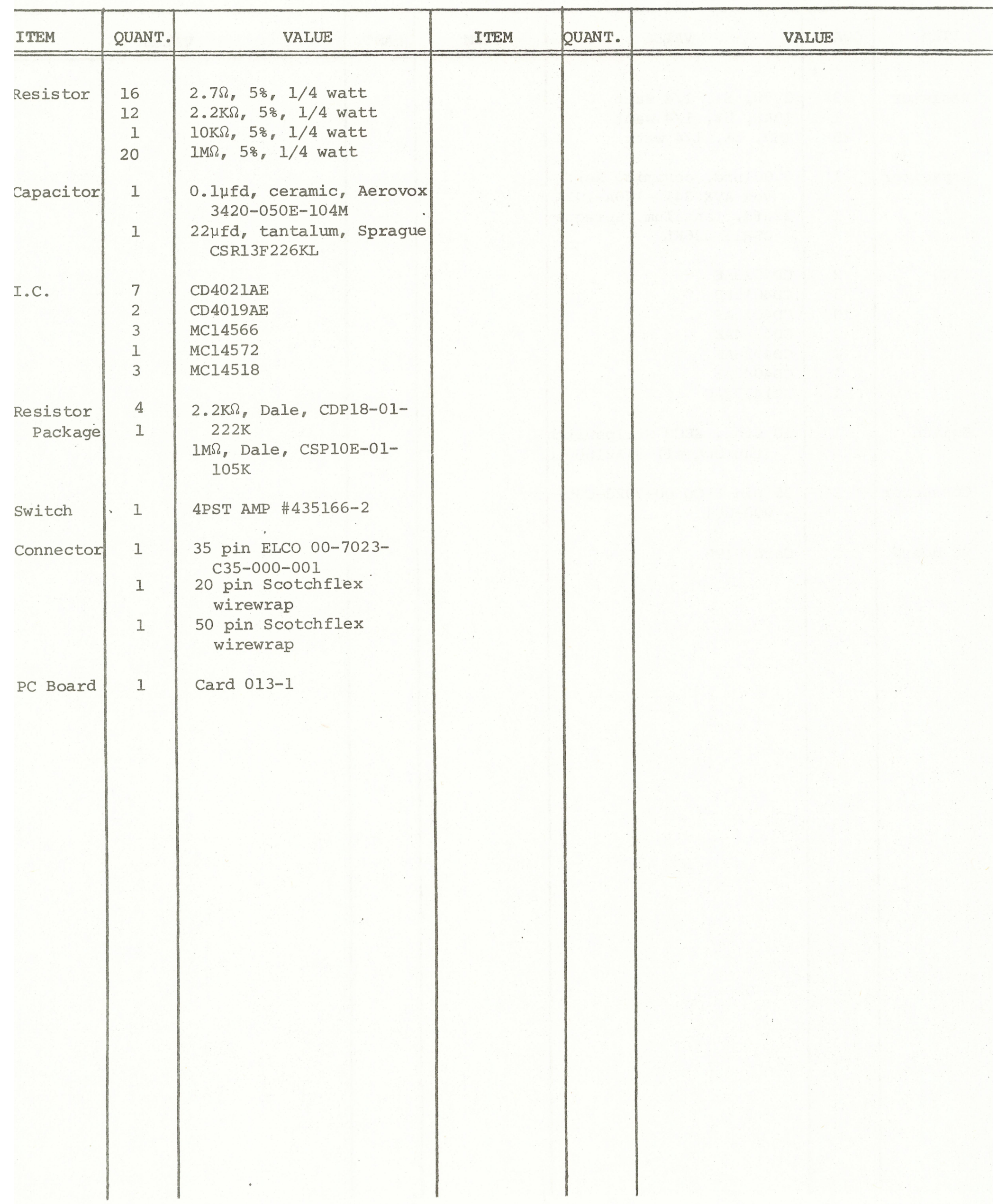


Ten Channel Scanner, Card 019B

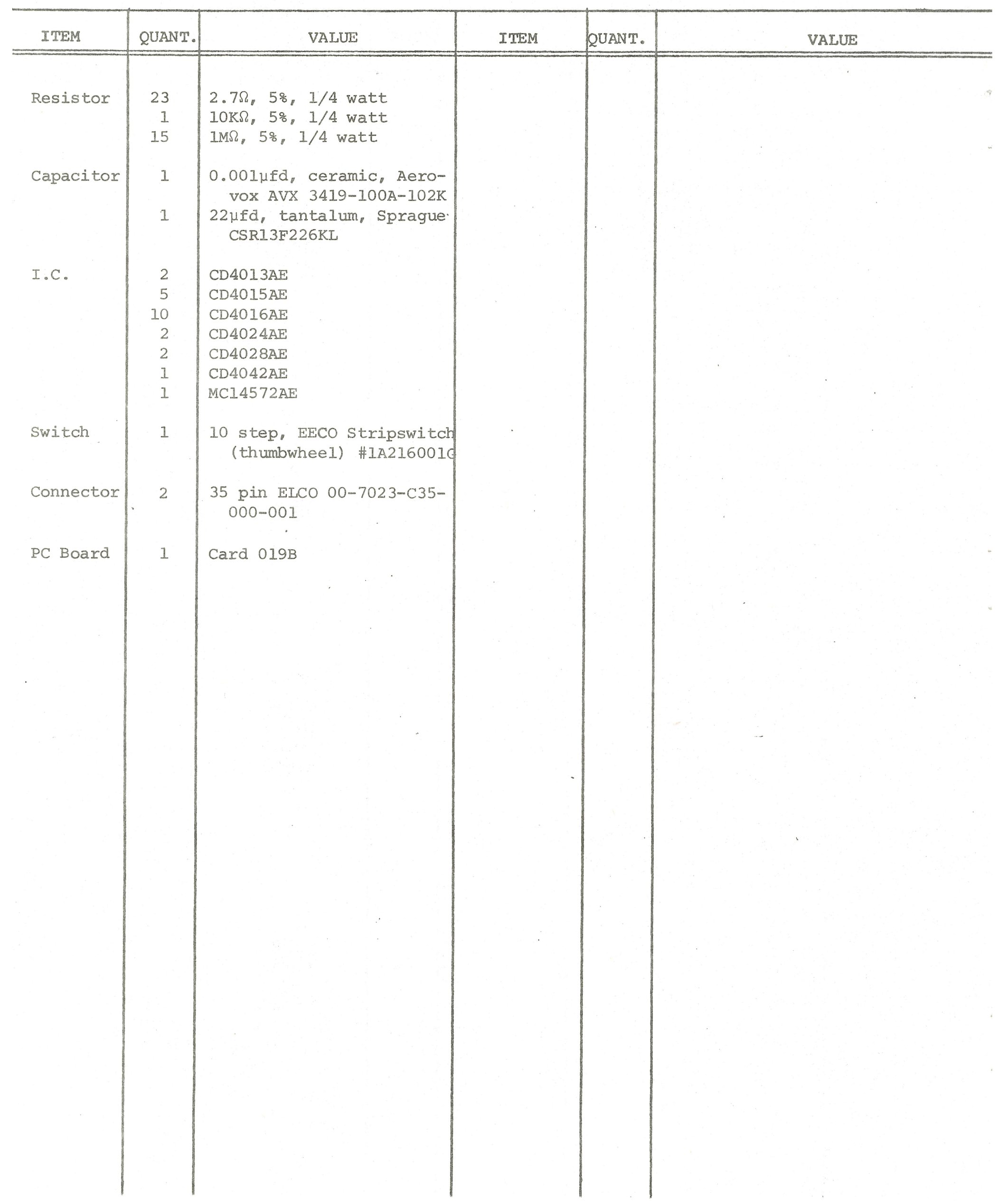


$-79-$

Data Formatter, Card 020-1

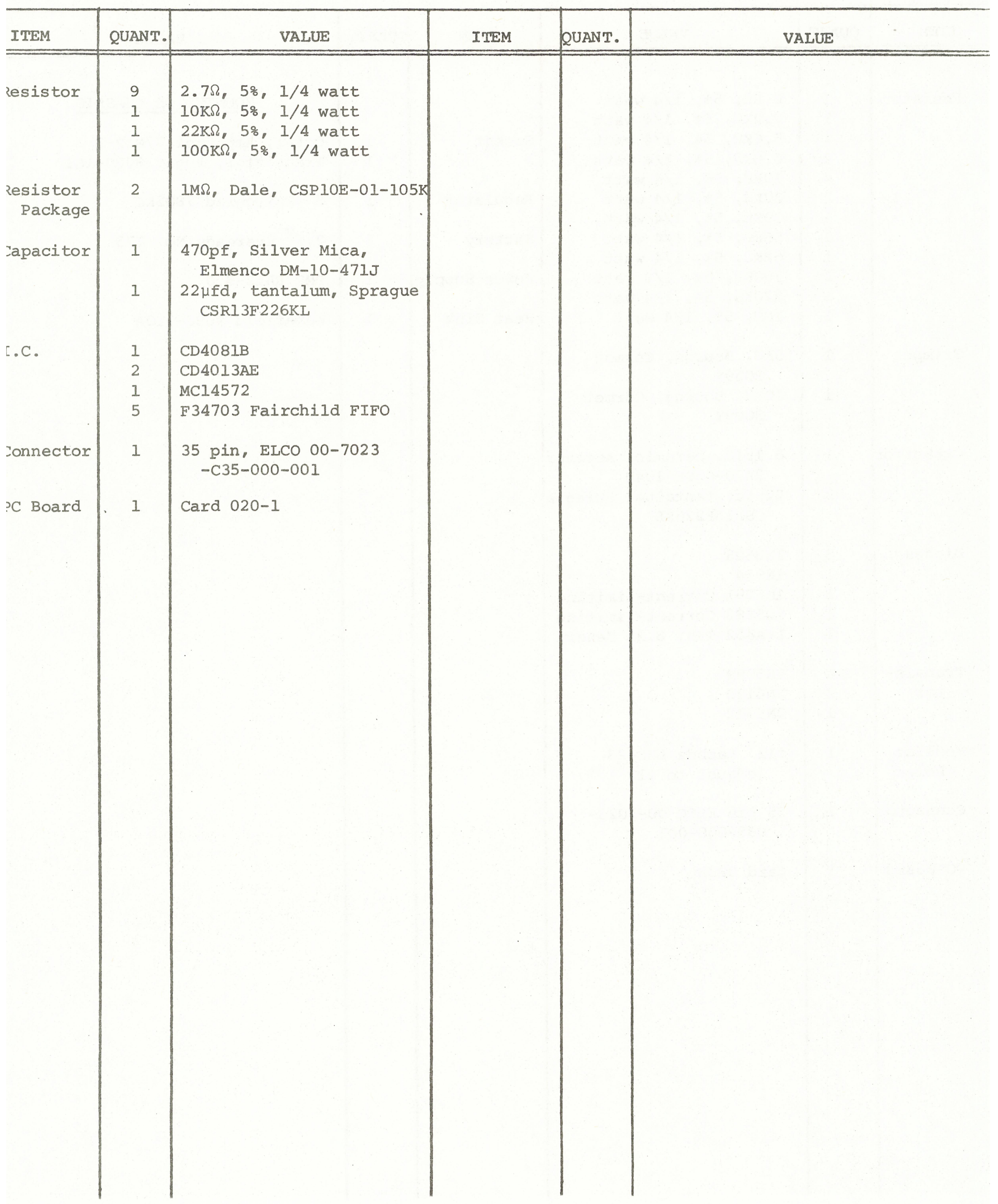




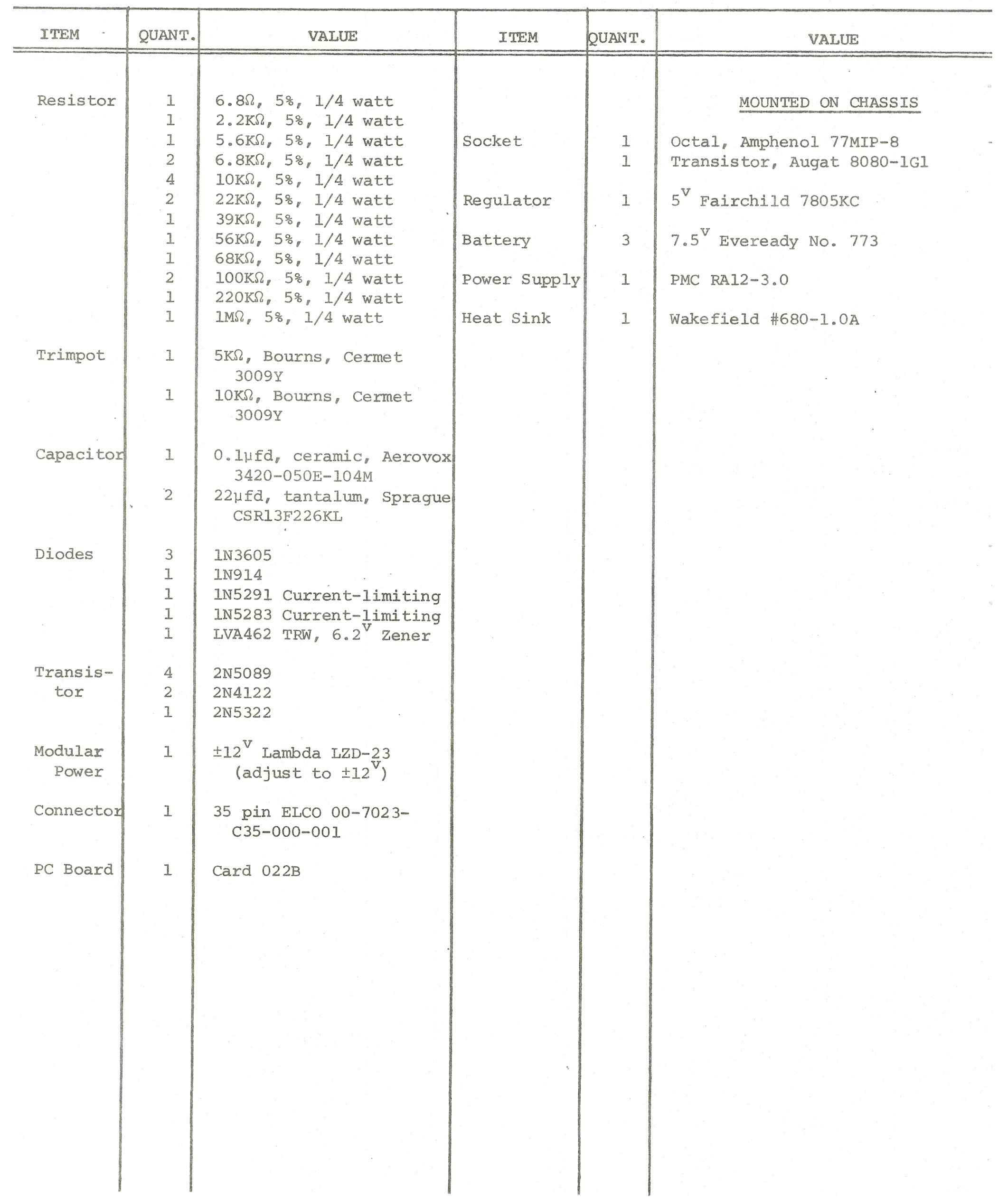


Battery Voltage A/D and Sweeper, Card 023B

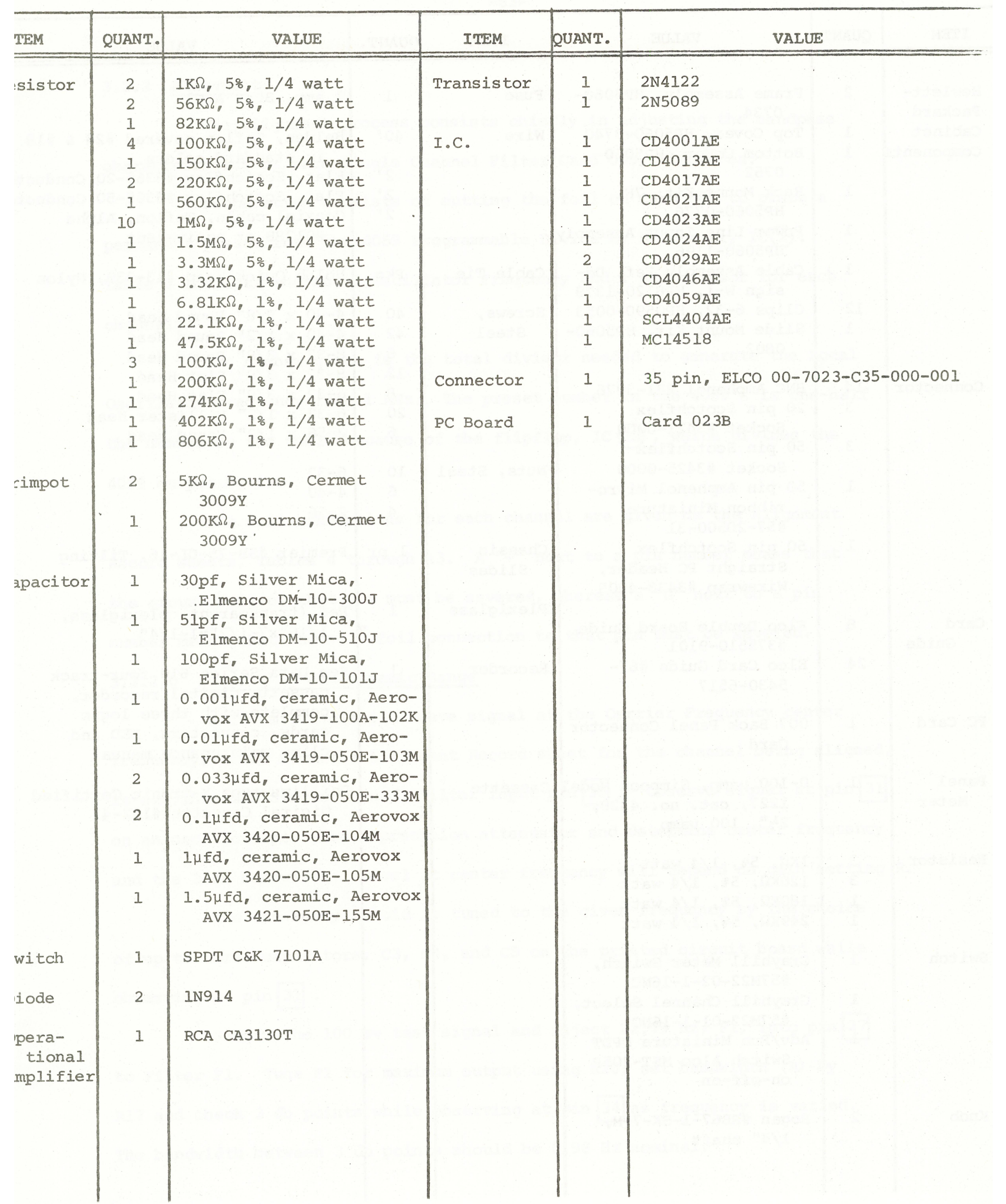




\subsubsection{Alignment}

The alignment process consists chiefly in adjusting the bandpass characteristics of each Single Channel Filter Card 005, Figure 6a.

Preparation consists of cutting the foil on Card 005 to place a

permanent preset into the 4059 Progranmable Divide By $\mathrm{N}$ Counter, IC(2).

Table 3 includes the Local Oscillator Frequency and $1 \mathrm{MHz}$ divisor for each channel.

The number given is the total divisor needed to generate the Local Oscillator-frequency-from-1-Mz. The preset number in the 4059's-is-one-half the number on the table because of the flipflop, IC (1a), which divides the 4059 output by two.

The foil connections for each channel are given on the Alignment Record sheets, Tables 4 through 13. A "+" next to a pin number means that the ground foil of that pin must be severed, whereas a "G" next to a pin number means that the $+12^{\mathrm{V}}$ foil connection to that pin must be severed.

\subsubsection{Setting Up and Dynamic Range}

A 100 milivolt sine wave signal at the Carrier Frequency center frequency, taken from the Alignment Record sheet for the channel being aligned, is set into the Single Channel Filter input pin 30 . Observe signal at pin 31 on an oscilloscope. Use a precision attenuator and determine center frequency and the 3 db bandwidth. Level at center frequency will depend on gain setting $R$. The one-Henry toroid is tuned to the given frequency by the choice of up to three capacitors, C3, C4, and C5 on the printed circuit board while observing at pin 31 .

Remove the $100 \mathrm{mv}$ tegt signal and inject $22.79 \mathrm{~Hz}, \mathrm{Fl}$, into pin 27 to Filter F1. Tune FI for maximum output using R20; set bandwidth (A) by RI7 and check 3 db points while observing at pin 34 as frequency is varied. The bandwidth between 3 db points should be $0.98 \mathrm{~Hz}$ nominal. 
Recheck and set frequency with R20. Several iterations may be required. $\mathrm{C} 9$ and $\mathrm{Cl} 10$ may need padding in order to keep frequency under control of R20.

The value of Rl6 may have to be reduced in order to keep control of 2 in the range of $\mathrm{R} 17$.

Tune $F 2$ in the same way that F1 was tuned, injecting $24.17 \mathrm{~Hz}$ at pin 7 and observing at pin 6 . R26 is frequency adjust. R23 is bandwidth adjust. The bandwidth between 3 do points should be $1.0 \mathrm{~Hz}$ nominal. Cll and C12 may require padding for $\mathrm{R} 26$ and $\mathrm{R} 23$ may need reduction for reasons stated above.

Set a $100 \mathrm{mv}$ mid-channel frequency into pin 30 and adjust gain R8 for just below observable clipping in first mixer observing at pin 32 . Observe second mixer at pin 22. and if needed pad R34 to adjust gain of A3 for just below observable clipping in second miser.

Synchronize oscilloscope internally and observe output square wave at pin 28. Reduce signal level at input pin 30 until display barely jitters. Record range in $\mathrm{db}$.

Reduce signal more until no signal evident on display. Record db range.

\subsubsection{Phase Measurement}

For this test, a Phase Reference Card must be used, Figure 18. The Phase Reference Card consists of an amplifier chain similar to that used in the Single Channel Filter. The Universal Phase-Frequency Chart, Figure 19, shows the phase-shift through the Reference Card and the expected phase-shift through the overall Single Channel Filter. Also given on Figure 19 is the formula for determining the lowed edge $f_{1}$ of each channel's frequency range. The formula relates to the frequency synthesizer which determines the frequency sweep in both the receiver and the individual floats. 


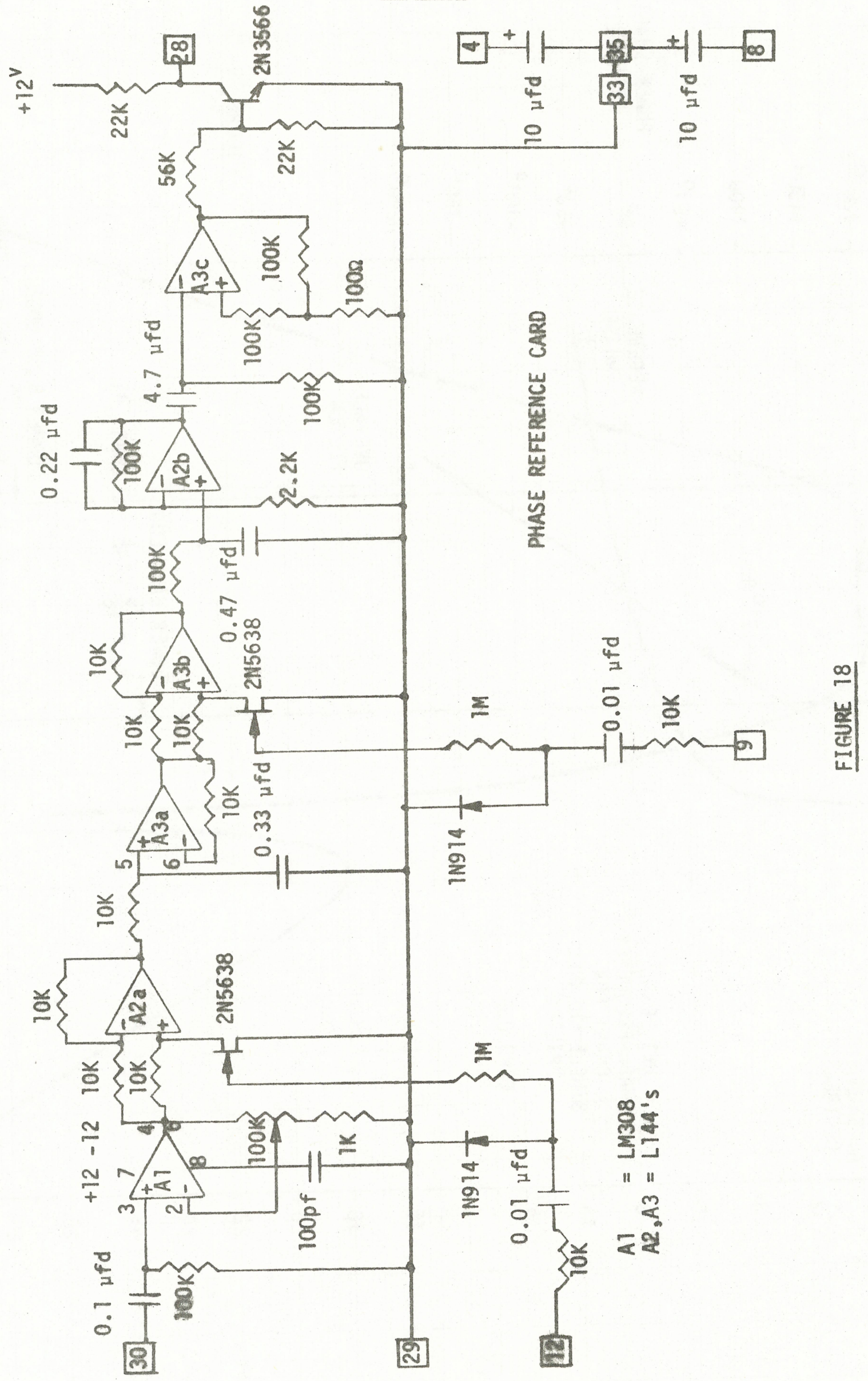




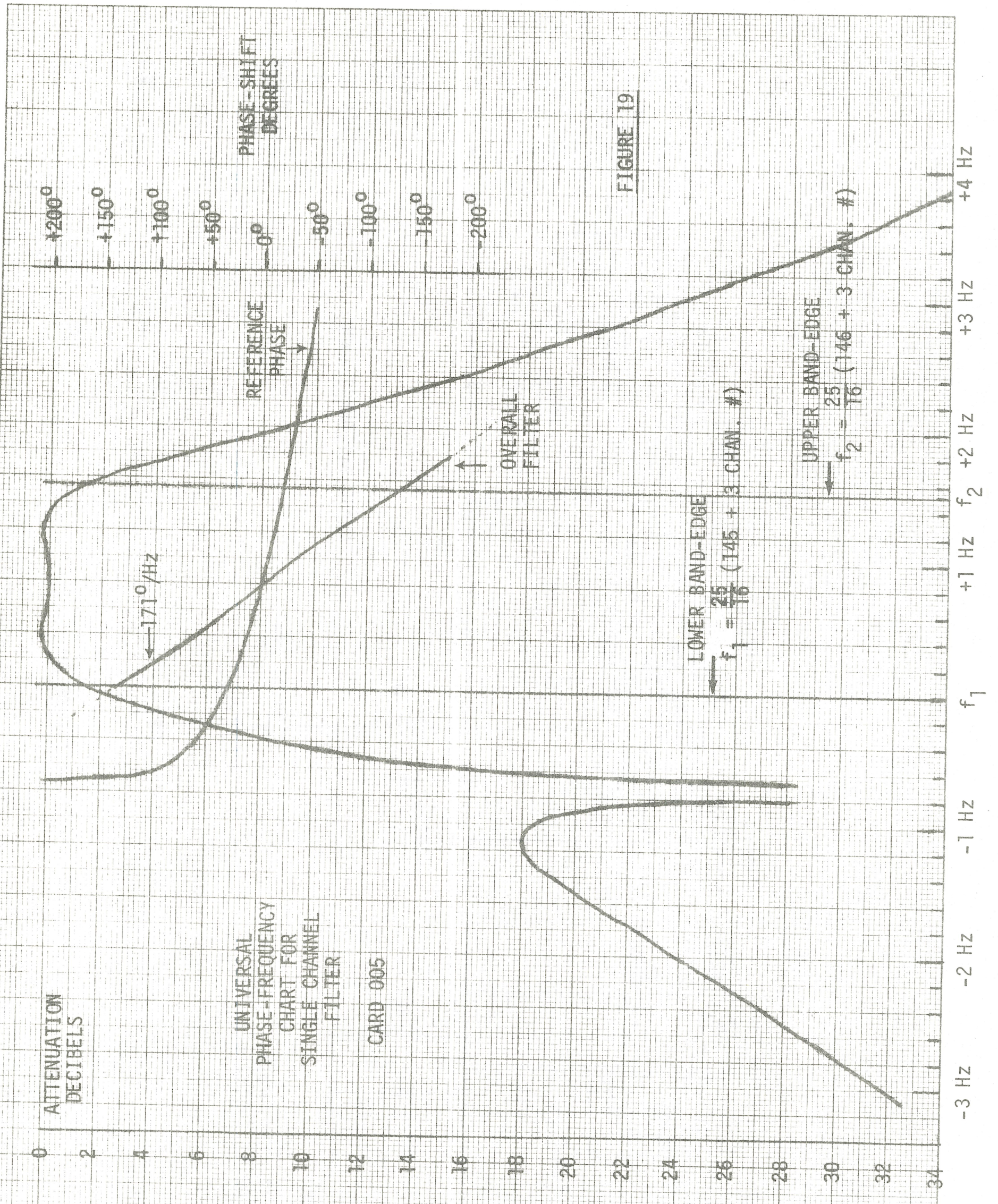


The Net Phase column on the Alignment Record is the difference between the Reference Phase and the Overall Filtex plots on the chart.

A dual-channel memory oscilloscope is used for the measurements because the frequencies are in the 1 to $2.5 \mathrm{~Hz}$ range.

In measuring, set the mid-frequency, taken from the Alignment Record, at some convenient level into pin 30 to give about one volt at pin 10 . This level will be used as the 0 db reference for the $A$ column ( $I^{\mathrm{V}} \mathrm{P}-\mathrm{P}, 0.35$ RMS $)$. Connect pin 29] of the Phase Reference Card to pin 29 of the Single Channel Filter; pin 30 to pin 30 ; pin 9 to pin 9 ; and pin 12 of the Phase Reference Card to pin 5 of the Single Channel Filter.

A Rockland Frequency Synthesizer or equivalent should be used as the signal source. The Rockland will provide a constant amplitude at the inputs of the two cards as frequency is varied. The signal at pin [10] of the Single Channel Filter (Analog Signal Out) is recorded at the frequencies designated on the Alignment Record. It will be noted that the frequencies on the Alignment Record are chosen with arbitrary $\Delta \mathrm{f}^{\prime} \mathrm{s}$ for convenience in setting up the test signal source which makes $f_{2}$ about $0.05 \mathrm{~Hz}$ higher than the formula would give.

When the A column is completed, it is spot checked against the values on the frequency curve, Figure 19. The $Q$ adjustments, R17 and R23 on the first I. F. filters, may be used to trim the response if necessary. Pin 28 of the Single Channel Filter is connected to one memory scope input and pin 28 of the Phase Reference Amplifier is connected to the other scope input.

The column < A is now filled in for the designated frequencies. Net Phase < A added to < Reference will give values that fall on or close to the Overall Filter plot on Figure 19. 
TABIIE 4

ALIGNMENT RECORD, CARD \#005B

L.0. Div $=3914$

Ist Local Osc. $=255.4931 \mathrm{~Hz}$

Preset

Pins

Center Freq $=232.01$

$\mathrm{Hz}$

4059

\begin{tabular}{|c|c|c|c|c|c|c|c|}
\hline $10+9 \mathrm{G}$ & $8 \mathrm{G}$ & $7 \mathrm{G}$ & $18+$ & $17 \mathrm{G}$ & $16 \mathrm{G}$ & $15+$ \\
\hline $22+$ & $21 \mathrm{G}$ & $20+$ & $19 \mathrm{G}$ & $3+$ & $4+$ & $5+$ & 6 G \\
\hline
\end{tabular}

Min. Sat. Level for 1st Mixer $=$

$V_{p t p}$ (output)

Ist I.F.

$\begin{aligned} f_{1}= & \mathrm{Hz}(22.79 \mathrm{~Hz} \text { Nom. }) \\ B W_{1}= & \mathrm{Hz}(.98 \mathrm{~Hz} \mathrm{Nom}) \\ f_{2}= & \mathrm{Hz}(24.17 \mathrm{~Hz} \text { Nom. }) \\ B W_{2}= & \mathrm{Hz}(1.0 \mathrm{~Hz} \mathrm{Nom})\end{aligned}$

$V_{\text {out }}$ (Lo Pass After 2nd Mix.) $=$

$V_{p t p}$ for $V_{i n}=100 \mathrm{~m} V_{p t p}$

Dynamic Range Referred to $100 \mathrm{~m} \mathrm{~V} V_{p t p}=V_{\text {in }}$

No Jitter $=\quad \mathrm{dB} \quad$ No Sig. $=\quad \mathrm{dB}$

RESPONSE RELATIVE TO INPUT

$\Delta f \quad$ Input Freq
\begin{tabular}{|c|c|c|c|c|c|}
\hline-2.0 & 229.25 & & & & \\
\hline-1.0 & 230.25 & & & & \\
\hline-0.4 & 230.85 & & & $+40^{\circ}$ & \\
\hline 0.0 & 231.25 & & & $+32^{\circ}$ & \\
\hline 0.2 & 231.45 & & & $+20^{\circ}$ & \\
\hline 0.4 & 231.65 & & & $+12.5^{\circ}$ & \\
\hline 0.6 & 231.85 & & & $+5^{\circ}$ & \\
\hline 0.8 & 232.05 & Set 0 dB & & $-2^{\circ}$ & \\
\hline 1.0 & 232.25 & & & $-7^{\circ}$ & \\
\hline 1.2 & 232.45 & & & $-10^{\circ}$ & \\
\hline 1.4 & 232.65 & & & $-15^{\circ}$ & \\
\hline 1.6 & 232.85 & & & $-20^{\circ}$ & \\
\hline 2.0 & 233.25 & & & $-37^{\circ}$ & \\
\hline 2.6 & 233.85 & & & & \\
\hline 3.6 & 234.85 & & & & \\
\hline
\end{tabular}


TABLE 5

ALIGNMENT RECORD, CARD \#005B

L.O. Div $=3844$

1st Local Osc. $=260.1457 \mathrm{~Hz}$

Center Freq $=236.70$

$\mathrm{Hz}$

\begin{tabular}{|c|c|c|c|c|c|c|c|c|}
\hline $\begin{array}{l}\text { Preset } \\
\text { Pins }\end{array}$ & $10+9$ & $8 \mathrm{G}$ & 7 & $18+$ & $17 \mathrm{c}$ & & $16 \mathrm{G}$ & $15+$ \\
\hline 4050 & \begin{tabular}{ll|l}
22 & $\mathrm{G}$ & 21
\end{tabular} & $20 \mathrm{G}$ & $19 \mathrm{G}$ & $3 \mathrm{G}$ & $4+$ & & & $6 \mathrm{G}$ \\
\hline
\end{tabular}

Min. Sat. Level for 1st Mixer =

$$
V_{p t p} \text { (output) }
$$

lst I.F.

$$
\begin{aligned}
\mathrm{f}_{1}= & \mathrm{Hz}(22.79 \mathrm{~Hz} \text { Nom. }) \\
\mathrm{BW}_{1}= & \mathrm{Hz}(.98 \mathrm{~Hz} \text { Nom. }) \\
\mathrm{f}_{2}= & \mathrm{Hz}(24.17 \mathrm{~Hz} \text { Nom. }) \\
\mathrm{BW}_{2}= & \mathrm{Hz}\left(1.0 \mathrm{~Hz} \mathrm{Nom}_{\circ}\right)
\end{aligned}
$$

$V_{\text {out }}$ (Lo Pass After 2nd Mix.) =

$$
V_{p t p} \text { for } V_{\text {in }}=100 \mathrm{~m} \mathrm{~V} \text { ptp }
$$

Dynamic Range Referred to $100 \mathrm{~m} V_{p t p}=V_{i n}$

$$
\text { No Jitter }=\quad d B \quad \text { No Sig. }=
$$

$d B$

\section{RESPONSE RELATIVE TO INPUT}

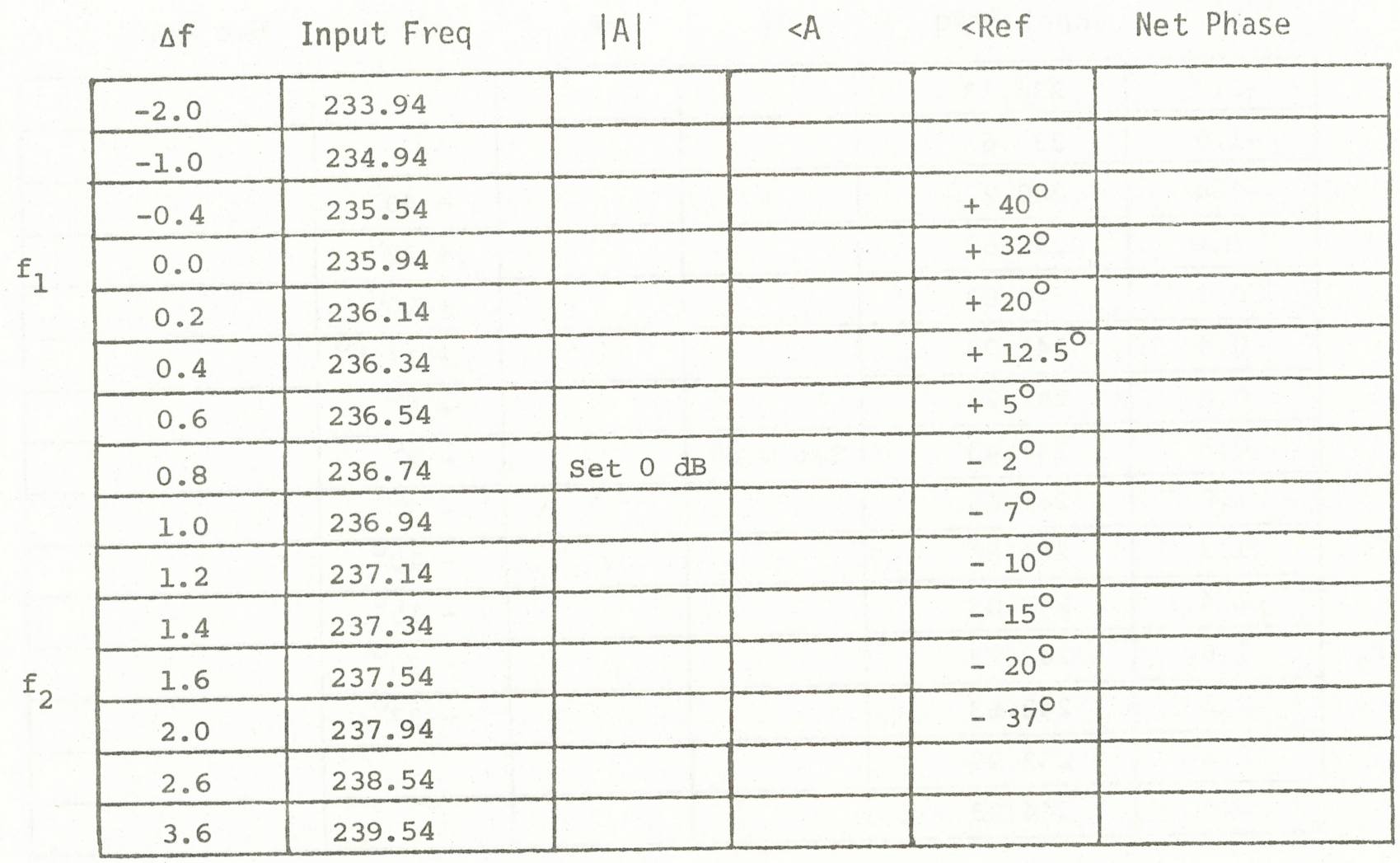


TABLE 6

ALIGNMENT RECORD, CARD \#005B

$\mathrm{CH} \# 3$

L.O. Div $=3776$

1st Local OSC. $=264.8305 \mathrm{~Hz}$

Preset
Pins
on
4059

\begin{tabular}{|c|c|c|c|c|c|c|c|c|}
\hline $10+$ & $9 \mathrm{G}$ & $8 \mathrm{G}$ & 7 & & $18 \mathrm{G}$ & $17 \mathrm{G}$ & $16 \mathrm{G}$ & $15+$ \\
\hline $22 \mathrm{G}$ & $21 \mathrm{G}$ & $20 \mathrm{G}$ & $19+$ & & $3 \mathrm{G}$ & $4 \mathrm{G}$ & $5 \mathrm{G}$ & $6+$ \\
\hline
\end{tabular}

Center Freq $=241.39$

$\mathrm{Hz}$

Min. Sat. Level for Ist Mixer =

$V_{p t p}$ (output)

Ist I.F.

$$
\begin{aligned}
f_{1}= & \mathrm{Hz}(22.79 \mathrm{~Hz} \mathrm{Nom} .) \\
B W_{1}= & \mathrm{Hz}(.98 \mathrm{~Hz} \mathrm{Nom} .) \\
f_{2}= & \mathrm{Hz}(24.77 \mathrm{~Hz} \mathrm{Nom} .) \\
B W_{2}= & \mathrm{Hz}(1.0 \mathrm{~Hz} \mathrm{Nom} .)
\end{aligned}
$$

$V_{\text {out }}$ (Lo Pass After 2nd Mix.) =

$$
V_{p t p} \text { for } V_{i n}=700 \mathrm{~m} V_{p t p}
$$

Dynamic Range Referred to $100 \mathrm{~m} \mathrm{~V}$ ptp $=V_{\text {in }}$

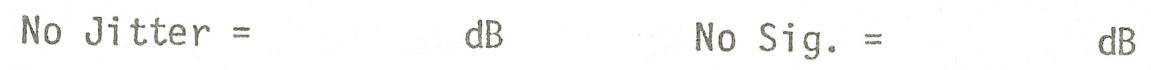

\section{RESPONSE RELATIVE TO INPUT}

If Input Freq
\begin{tabular}{|c|c|c|c|c|c|}
\hline-2.0 & 238.63 & & & & \\
\hline-1.0 & 239.63 & & & & \\
\hline-0.4 & 240.23 & & & $+40^{\circ}$ & \\
\hline 0.0 & 240.63 & & & $+32^{\circ}$ & \\
\hline 0.2 & 240.83 & & & $+20^{\circ}$ & \\
\hline 0.4 & 241.03 & & & $+12.5^{\circ}$ & \\
\hline 0.6 & 241.23 & & & $+5^{\circ}$ & \\
\hline 0.8 & 241.43 & Set 0 dB & & $-2^{\circ}$ & \\
\hline 1.0 & 241.63 & & & $-7^{\circ}$ & \\
\hline 1.2 & 241.83 & & & $-10^{\circ}$ & \\
\hline 1.4 & 242.03 & & & $-15^{\circ}$ & \\
\hline 1.6 & 242.23 & & & $-20^{\circ}$ & \\
\hline 2.0 & 242.63 & & & $-37^{\circ}$ & \\
\hline 2.6 & 243.23 & & & & \\
\hline 3.6 & 244.23 & & & & \\
\hline$f_{2}$ & & & & & \\
\hline
\end{tabular}


TABIEE 7

ALIGNMENT RECORD, CARD \#005B

L.0. Div $=3710$

1st Local Osc. $=269.5418 \mathrm{~Hz}$

Preset
Pins
on
4059

\begin{tabular}{|c|c|c|c|c|c|c|c|c|c|}
\hline $10+9 \mathrm{G}$ & $8 \mathrm{G}$ & $7 \quad \mathrm{G}$ & $18 \mathrm{G}$ & & & $17 \mathrm{G}$ & & & \\
\hline+2 & $20+$ & $19 \mathrm{G}$ & & & & & & & \\
\hline
\end{tabular}

Center Freq $=246.07$

$\mathrm{Hz}$

Min. Sat. Level for 1st Mixer =

$$
v_{p t p} \text { (output) }
$$

1st I.F.

$$
\begin{array}{rlrl}
\mathrm{f}_{1} & = & \mathrm{Hz}(22.79 \mathrm{~Hz} \text { Nom. }) \\
B W_{1}= & \mathrm{Hz}(.98 \mathrm{~Hz} \text { Nom. }) \\
\mathrm{f}_{2}= & \mathrm{Hz}(24.17 \mathrm{~Hz} \text { Nom. }) \\
B W_{2}= & \mathrm{Hz}(1.0 \mathrm{~Hz} \text { Nom. })
\end{array}
$$

$$
V_{\text {out }}\left(\text { Lo Pass After 2nd Mix.) }=\quad V_{p t p} \text { for } V_{\text {in }}=100 \mathrm{~m} V_{p t p}\right.
$$

Dynamic Range Referred to $100 \mathrm{~m} \mathrm{~V}_{\mathrm{ptp}}=\mathrm{V}_{\text {in }}$

$$
\text { No Jitter }=\mathrm{dB} \quad \text { No Sig. }=\mathrm{dB}
$$

\section{RESPONSE RELATIVE TO INPUT}

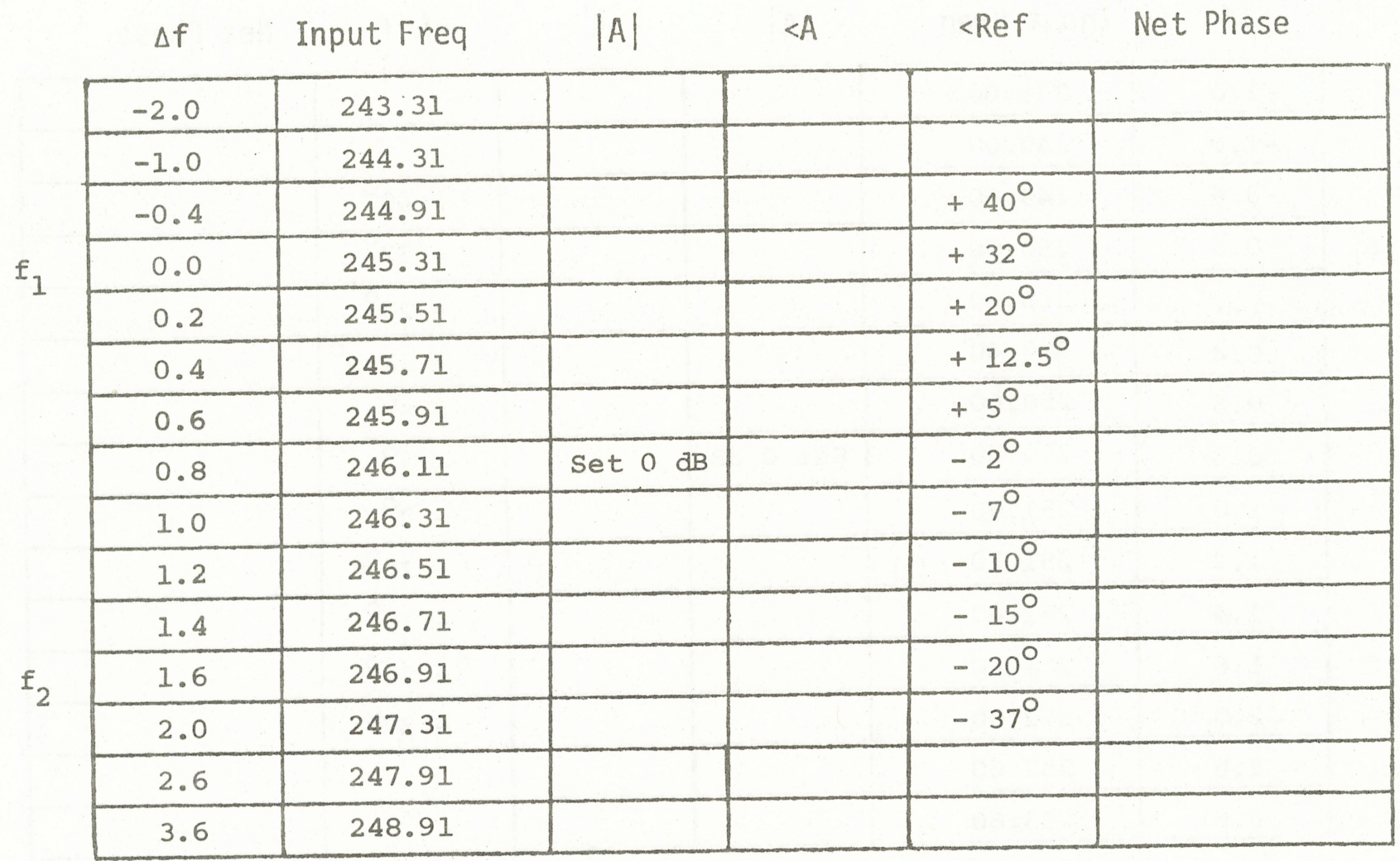


TABLE 8

ALIGNMENT RECORD, CARD \#005B

L.0. Div $=3646$

Preset

Tst Local Osc. $=274.2732 \mathrm{~Hz}$ on

Center Freq $=250.76 \quad \mathrm{~Hz}$

4059

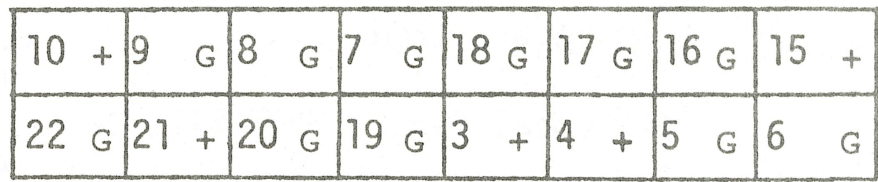

Min. Sat. Level for Ist Mixer =

$V_{p t p}$ (output)

Ist I.F.

$$
\begin{aligned}
f_{1}= & \mathrm{Hz}(22.79 \mathrm{~Hz} \mathrm{Nom} .) \\
B W_{1}= & \mathrm{Hz}(.98 \mathrm{~Hz} \text { Nom. }) \\
f_{2}= & \mathrm{Hz}(24.77 \mathrm{~Hz} \mathrm{Nom} .) \\
B W_{2}= & \mathrm{Hz}(1.0 \mathrm{HzNom})
\end{aligned}
$$

$V_{\text {out }}($ Lo Pass After 2nd Mix.) $=$

$$
V_{p t p} \text { for } V_{\text {in }}=100 \mathrm{~m} V_{p t p}
$$

Dynamic Range Referred to $100 \mathrm{~m} \mathrm{~V} \mathrm{Vtp}_{\text {tp }}=\mathrm{V}_{\text {in }}$

$$
\text { No jitter }=\quad \mathrm{dB} \quad \text { No Sig. }=
$$

$d B$

\section{RESPONSE RELATIVE TO INPUT}

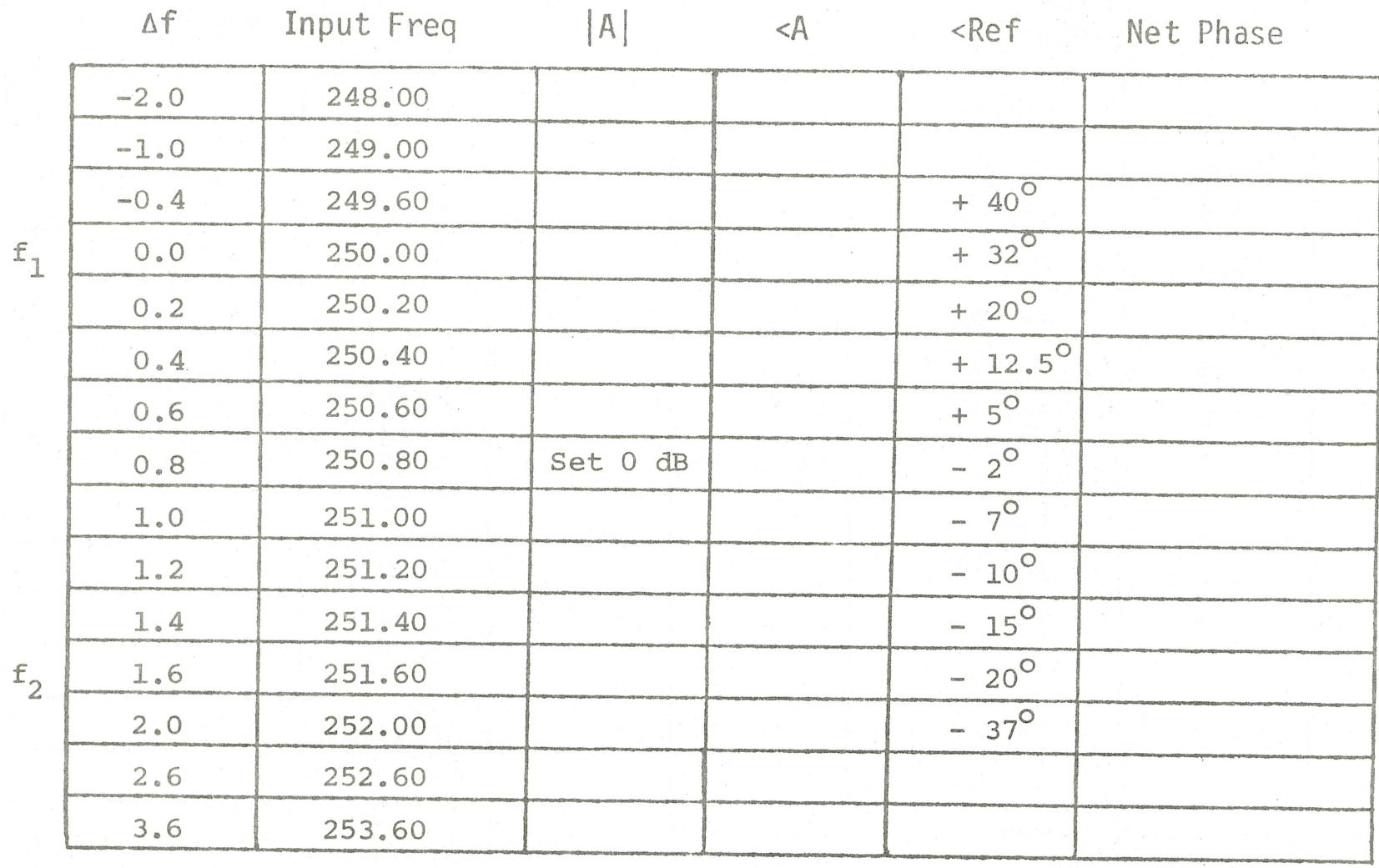


TABLE 9

ALIGNMENT RECORD, CARD \#005B

$\mathrm{CH} \# 6$

L.0. Div $=3586$

Preset

1st Local Osc. $=278.8622 \mathrm{~Hz}$

Pins

Center Freq $=255.45$

$\mathrm{Hz}$

on 4059

\begin{tabular}{|c|c|c|c|c|c|c|c|}
\hline $10+$ & $9 G$ & $8 G$ & $7 G$ & $18+$ & $17+$ & $16+$ & $15 G$ \\
\hline $22+$ & $21 G$ & $20 G$ & $19+$ & $3+$ & $4+$ & 5 G & 6 G \\
\hline
\end{tabular}

Min. Sat. Level for 1st Mixer =

$V_{p t p}$ (output)

Ist I.F.
$f_{1}=$
$\mathrm{Hz}(22.79 \mathrm{~Hz}$ Nom.)
$\mathrm{BW}_{1}=$
$\mathrm{Hz}$ (.98 Hz Nom.)
$f_{2}=$
$\mathrm{Hz}$ (24.17 Hz Nom.)
$\mathrm{BW}_{2}=$
$\mathrm{Hz}(1.0 \mathrm{~Hz} \mathrm{Nom}$.

$V_{\text {out }}$ (Lo Pass After 2nd Mix.) =

$$
V_{p t p} \text { for } V_{i n}=100 \mathrm{~m} \mathrm{~V} V_{p t p}
$$

Dynamic Range Referred to $100 \mathrm{~m} \mathrm{~V}_{\mathrm{ptp}}=\mathrm{V}_{\text {in }}$

$$
\text { No Jitter }=\mathrm{dB} \quad \text { No Sig. } \quad \mathrm{dB}
$$

RESPONSE RELATIVE TO INPUT

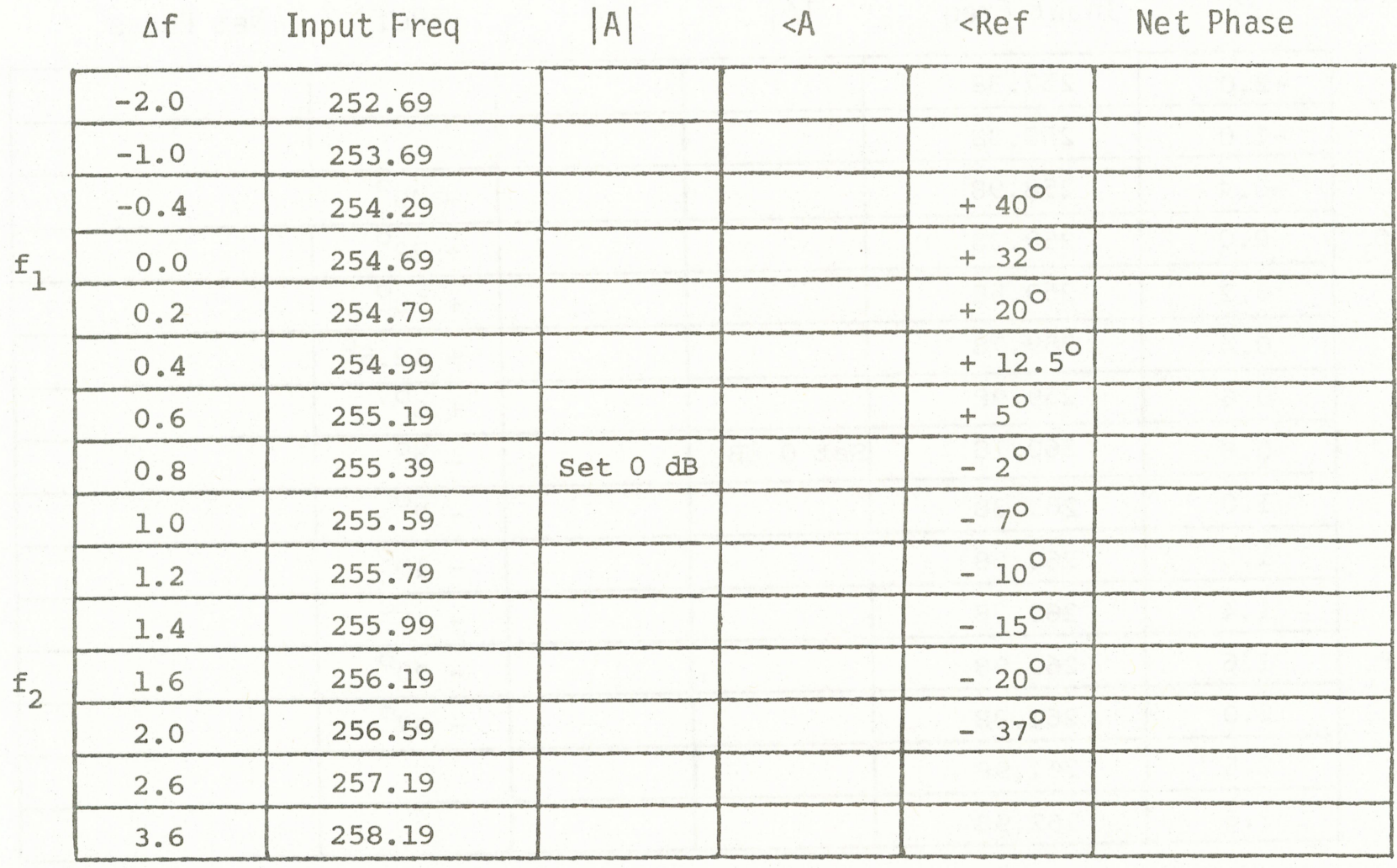


TABLE 10

ALIGNMENT RECORD, CARD \#005B

L.0. Div $=3526$

1st Local Osc. $=283.6075 \mathrm{~Hz}$

Preset
Pins
on
4059

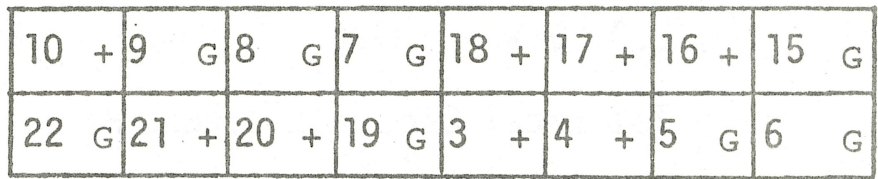

Center Freq $=260.14$

$\mathrm{Hz}$

Min. Sat. Level for Tst Mixer =

$$
V_{p t p} \text { (output) }
$$

Ist I.F.

$$
\begin{array}{rlrl}
f_{1} & = & H z(22.79 \mathrm{~Hz} \text { Nom. }) \\
B W_{1} & = & H z(.98 \mathrm{~Hz} \mathrm{Nom}) \\
f_{2}= & H z(24.17 \mathrm{~Hz} \text { Nom. }) \\
B W_{2}= & \mathrm{Hz}(1.0 \mathrm{~Hz} \text { Nom. })
\end{array}
$$

$V_{\text {out }}$ (Lo Pass After 2nd Mix.) =

$$
V_{p t p} \text { for } V_{i n}=100 \mathrm{~m} V_{p t p}
$$

Dynamic Range Referred to $100 \mathrm{~m} V_{p t p}=V_{\text {in }}$

$$
\text { No Jitter }=\mathrm{dB} \quad \text { No Sig. }=
$$

\section{RESPONSE RELATIVE TO INPUT}

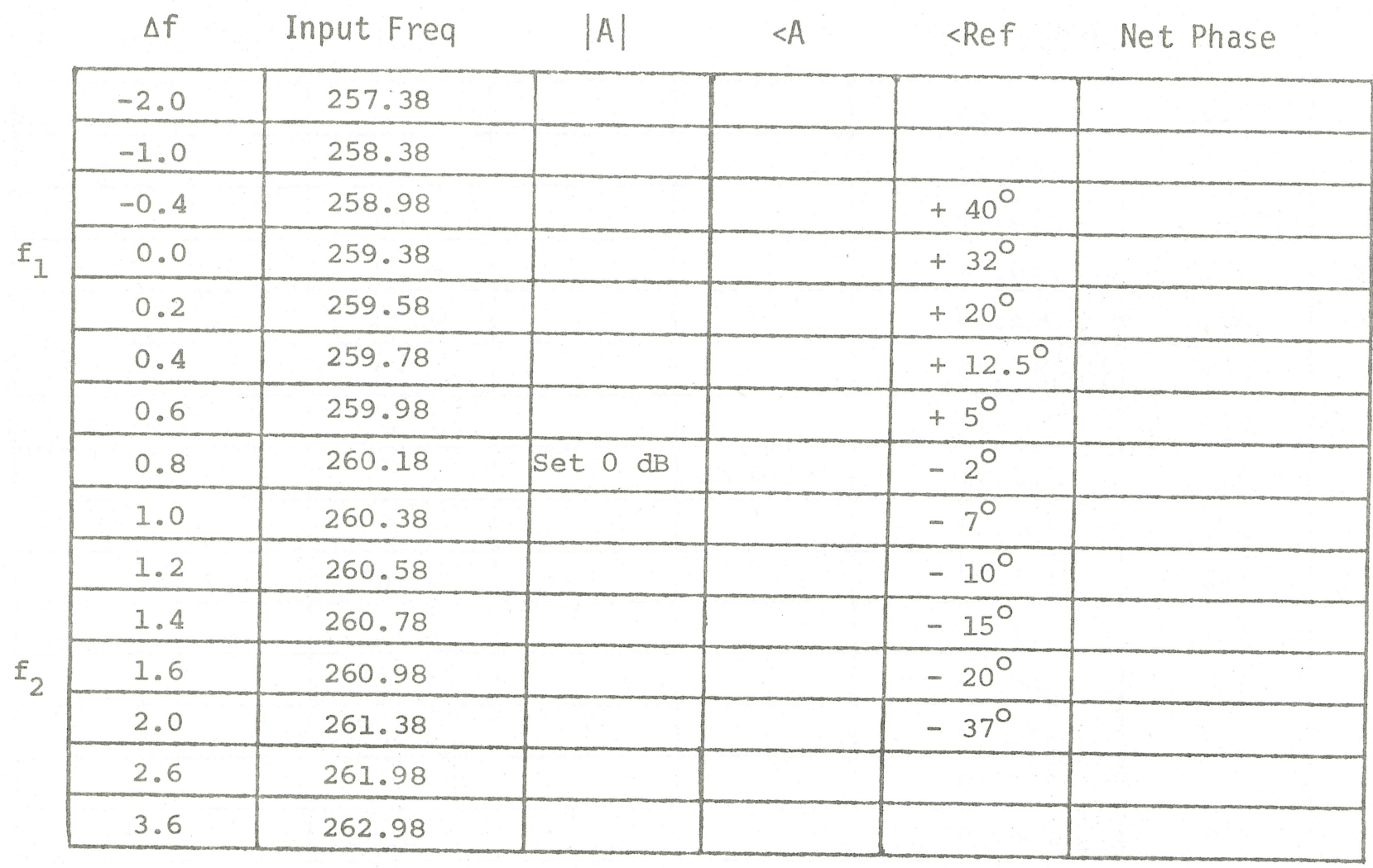


TABLE 11

ALIGNMENT RECORD, CARD \#005B

$\mathrm{CH} \# 8$

L.O. Div $=3468$

1st Local Osc. $=288.3506 \mathrm{~Hz}$

\begin{tabular}{|c|c|c|c|c|c|c|c|c|}
\hline $\begin{array}{c}\text { Preset } \\
\text { Pins }\end{array}$ & $10+$ & G & G & 7 & $18+$ & $17+$ & $16+$ & $15 \mathrm{G}$ \\
\hline $\begin{array}{c}\text { on } \\
4059\end{array}$ & $22+$ & $21+$ & $20 \mathrm{G}$ & $19 \mathrm{G}$ & $3 \mathrm{G}$ & $4 \mathrm{G}$ & $5+$ & 6 \\
\hline
\end{tabular}

Center Freq $=264.82$

$\mathrm{Hz}$

Min. Sat. Level for Tst Mixer =

$V_{p t p}$ (output)

lst I.F.

$\begin{aligned} \mathrm{f}_{1}= & \mathrm{Hz}(22.79 \mathrm{~Hz} \text { Nom. }) \\ \mathrm{BW}_{1}= & \mathrm{Hz}(.98 \mathrm{~Hz} \mathrm{Nom} .) \\ \mathrm{f}_{2}= & \mathrm{Hz}(24.77 \mathrm{~Hz} \text { Nom. }) \\ \mathrm{BW}_{2}= & \mathrm{Hz}(1.0 \mathrm{~Hz} \mathrm{Nom})\end{aligned}$

$V_{\text {out }}$ (Lo Pass After 2nd Mix.) $=$

$V_{p t p}$ for $V_{\text {in }}=100 \mathrm{~m} \mathrm{~V} V_{p t p}$

Dynamic Range Referred to $100 \mathrm{~m} \mathrm{~V}$ ptp $=V_{\text {in }}$

$\begin{array}{lll}\text { No Jitter }= & d B & \text { No Sig. }=\end{array}$

RESPONSE RELATIVE TO INPUT

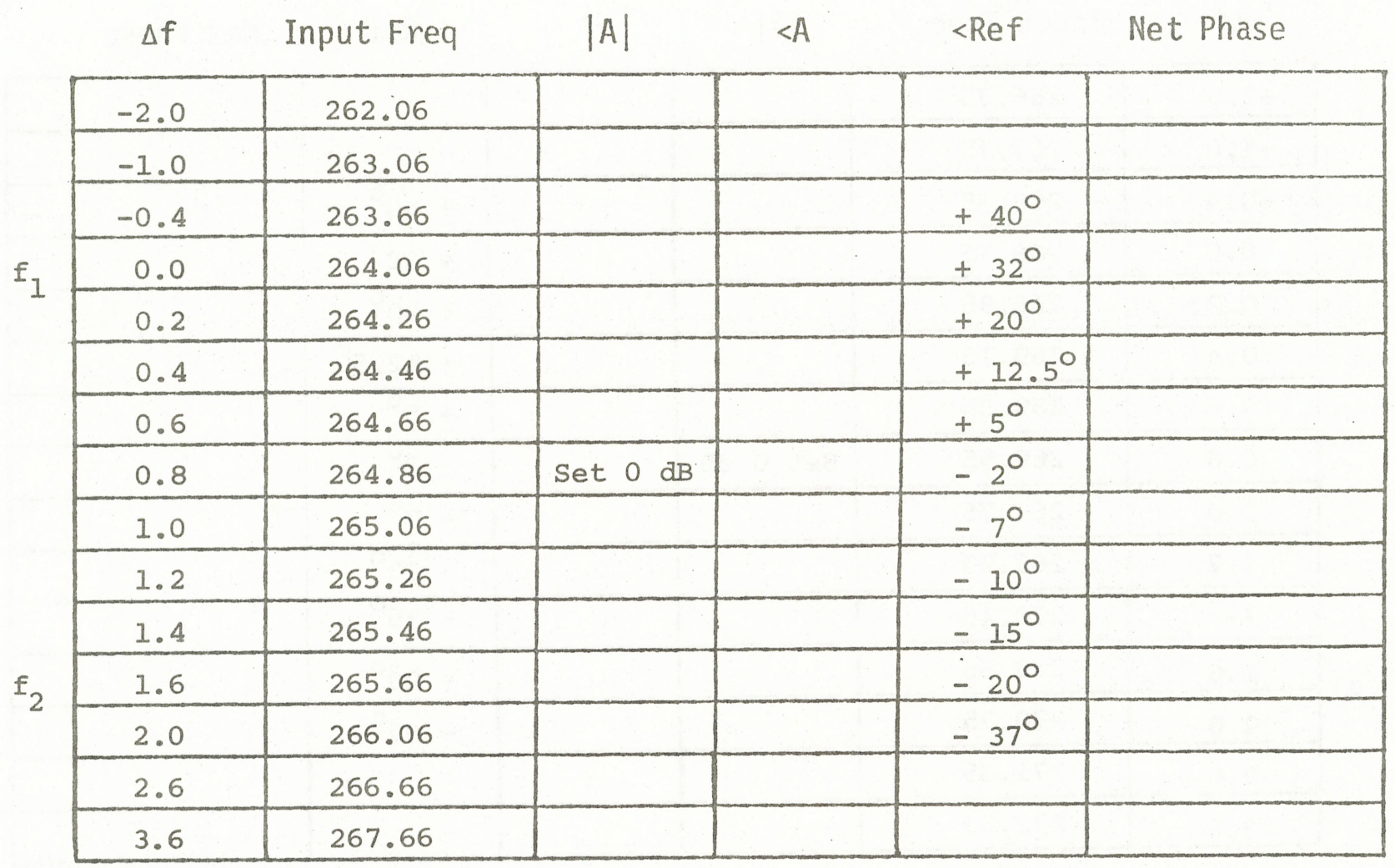


TABLE 12

ALIGNMENT RECORD, CARD \#005B

L.0. Div $=3412$

1st Local Osc. $=293.0832 \mathrm{~Hz}$

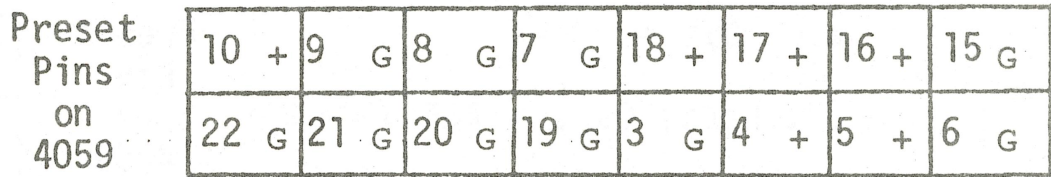

Center Freq $=269.51$

$\mathrm{Hz}$

Min. Sat. Level for Ist Mixer =

$V_{p t p}$ (output)

Ist I.F.

$\begin{aligned} f_{1}= & H z(22.79 \mathrm{~Hz} \mathrm{Nom} .) \\ B W_{1}= & H z(.98 \mathrm{~Hz} \mathrm{Nom} .) \\ f_{2}= & \mathrm{Hz}(24.17 \mathrm{~Hz} \mathrm{Nom} .) \\ B W_{2}= & \mathrm{Hz}(1.0 \mathrm{~Hz} \mathrm{Nom} .)\end{aligned}$

$V_{\text {out }}$ (Lo Pass After 2nd Mix.) =

$V_{p t p}$ for $V_{i n}=100 \mathrm{~m} V_{p t p}$

Dynamic Range Referred to $100 \mathrm{~m} \mathrm{~V}$ ptp $=V_{\text {in }}$

No jitter $=\quad \mathrm{dB} \quad$ No Sig. $=\quad \mathrm{dB}$

RESPONSE RELATIVE TO INPUT

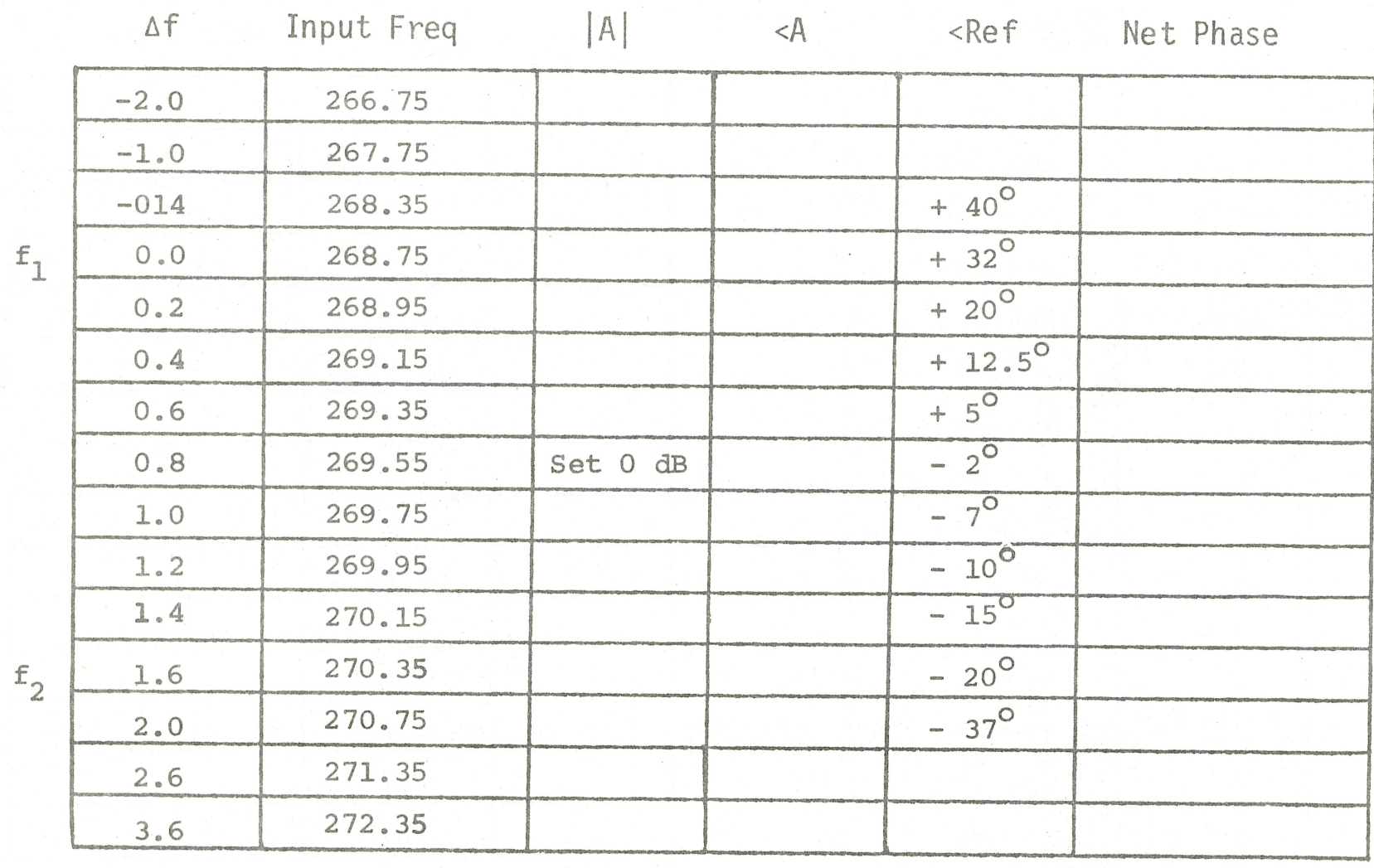


TABLE 13

ALIGNMENT RECORD, CARD \#005B

L.0. Div $=3360$

1st Local Osc. $=297.6190 \mathrm{~Hz}$

Preset
Pins
on
4059

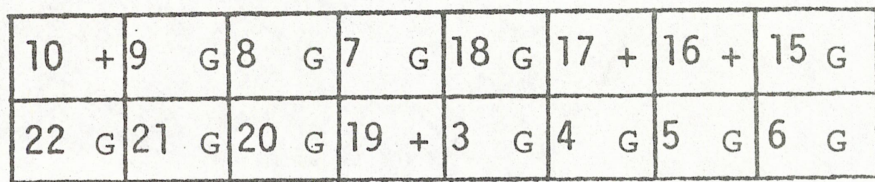

Center Freq $=274.20$

$\mathrm{Hz}$

Min. Sat. Level for 1st Mixer $=$

$v_{p t p}$ (output)

Ist I.F.

$$
\begin{array}{rlrl}
f_{1} & = & H z(22.79 \mathrm{~Hz} \mathrm{Nom} .) \\
B W_{1} & = & H z(.98 \mathrm{~Hz} \text { Nom. }) \\
f_{2}= & \mathrm{Hz}(24.17 \mathrm{~Hz} \text { Nom. }) \\
B W_{2}= & \mathrm{Hz}(1.0 \mathrm{~Hz} \text { Nom. })
\end{array}
$$

$$
V_{\text {out }} \text { (Lo Pass After 2nd Mix.) }=\quad V_{p t p} \text { for } V_{\text {in }}=100 \mathrm{~m} V_{p t p}
$$

Dynamic Range Referred to $100 \mathrm{~m} V_{p t p}=V_{\text {in }}$

$$
\text { No Jitter }=\quad \mathrm{dB} \quad \text { No Sig. }=
$$

RESPONSE RELATIVE TO INPUT

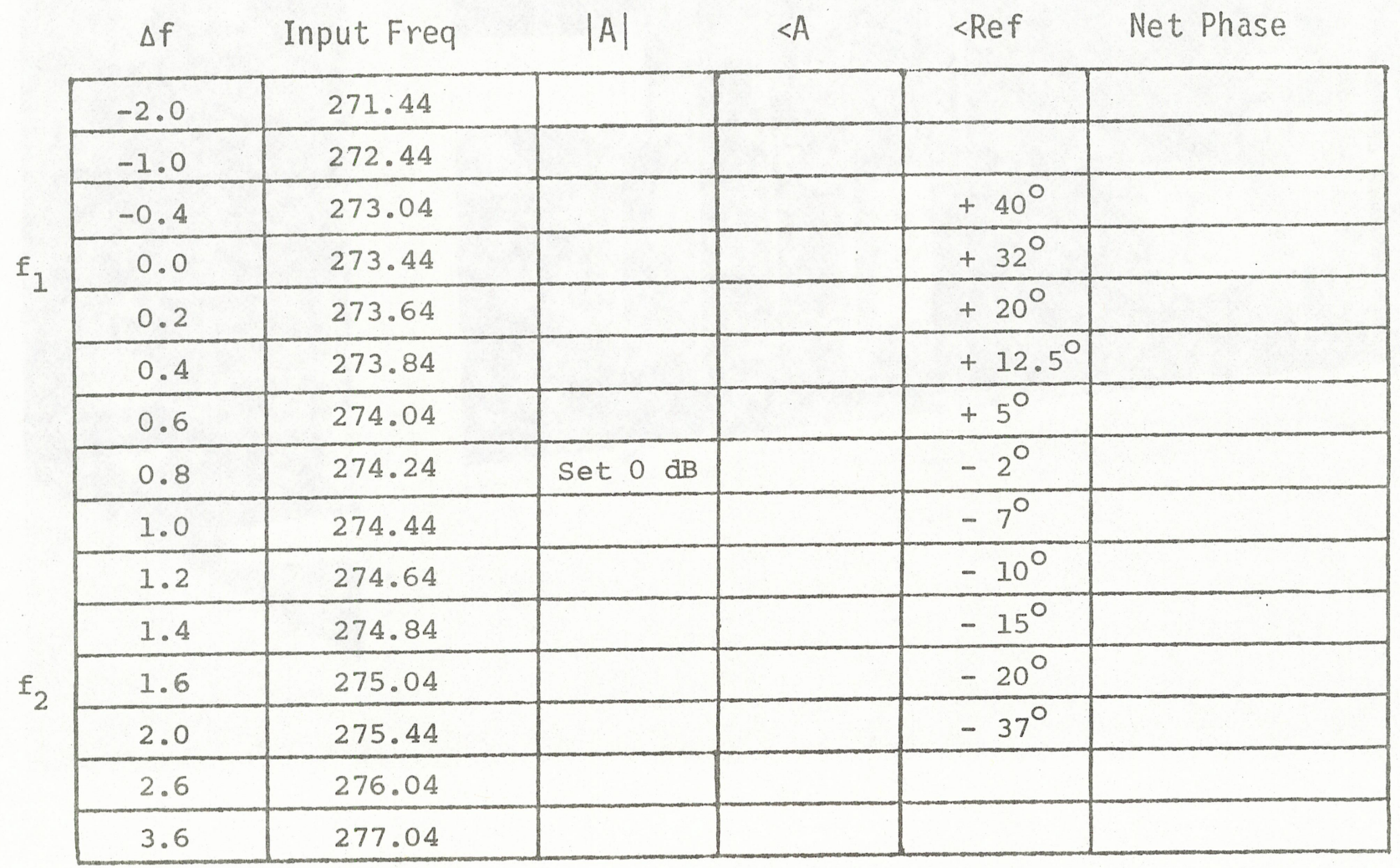




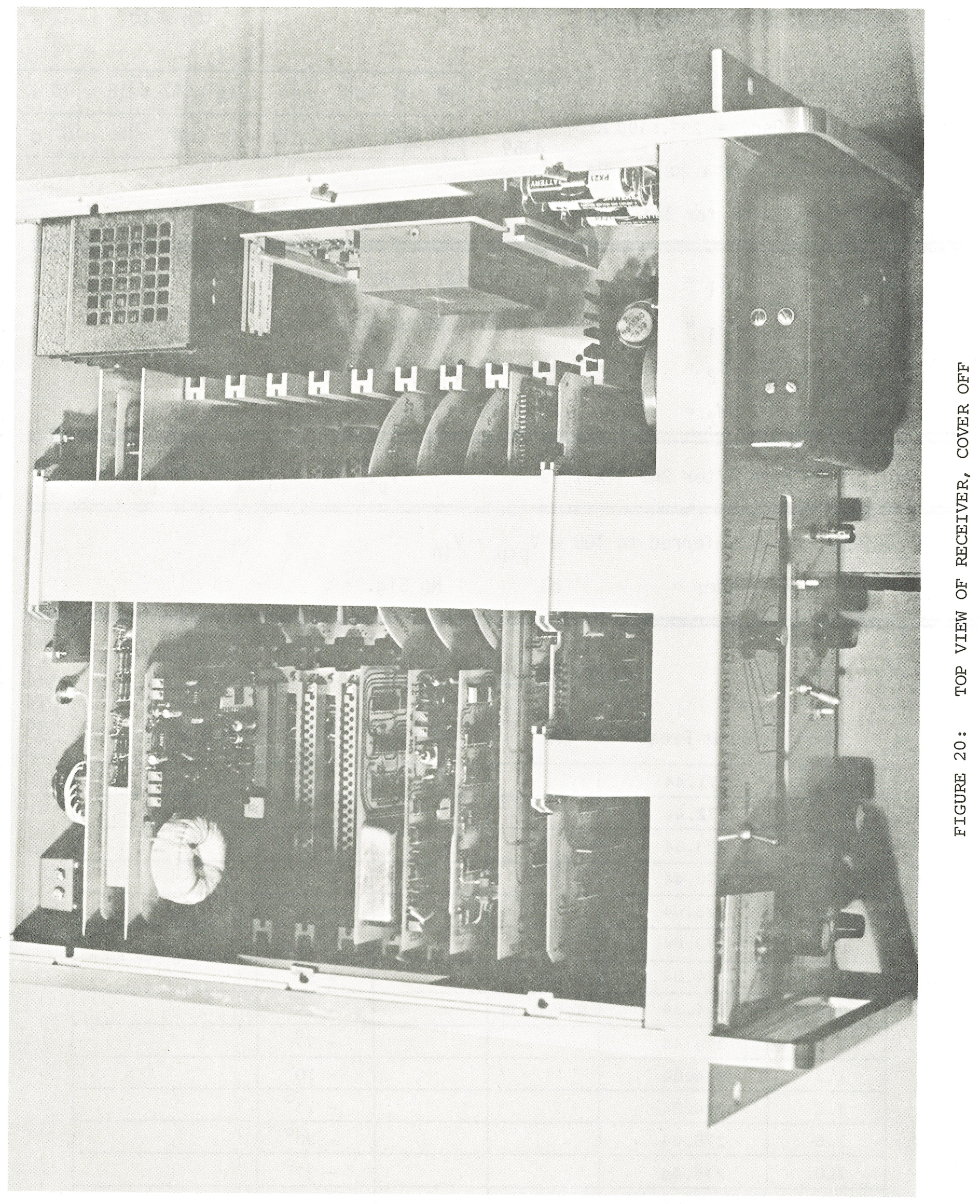



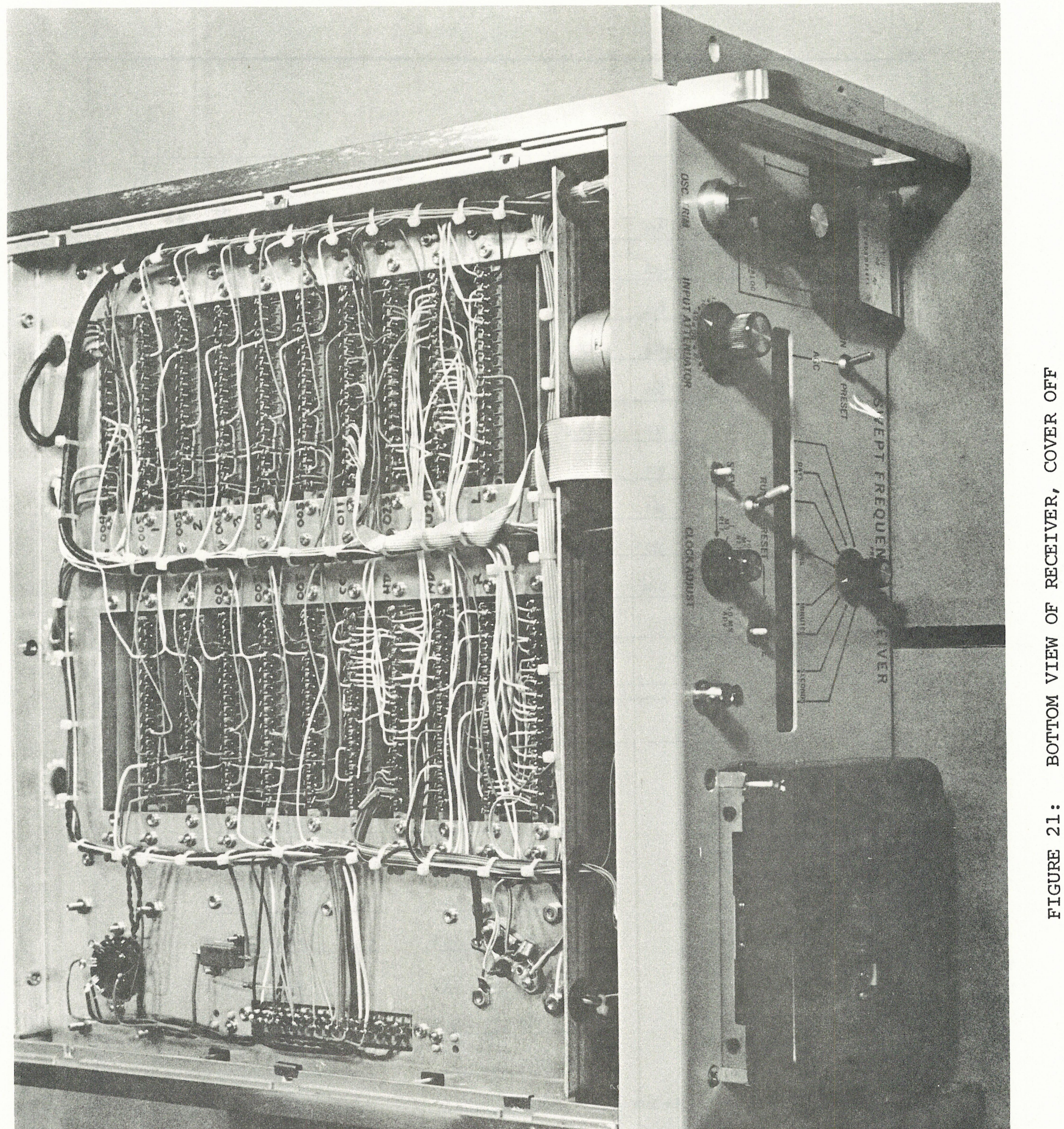


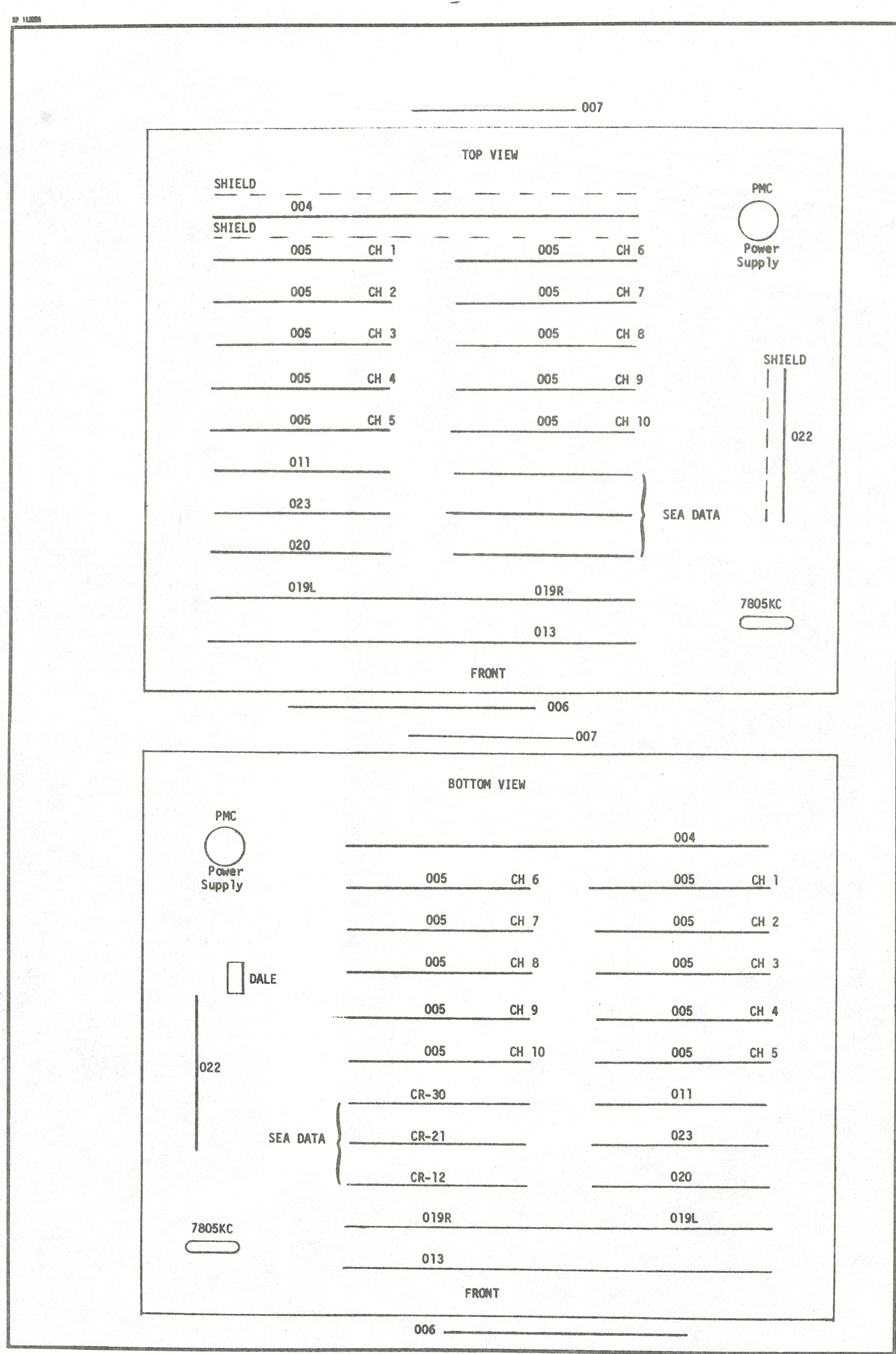

FIGURE 22: CARD PLACEMENT LAYOUT 


\subsubsection{Overall Record}

The following records are to be kept nominally as indicated.

It is expected, however, that anomalies which may show up in the data from the tape cassette during data reduction and analysis will be immediately reported to the Field Engineering staff. 
3.2 .3 .0

1976

\begin{tabular}{|c|c|c|c|c|c|c|c|c|c|c|c|}
\hline WEEK & DATE & CORR. & SETTING & WEEK & DATE & CORR. & SETTING & WEEK & DATE & CORR. & SETTING \\
\hline 1 & & & & 1 & & & & 1 & & & \\
\hline 2 & & & & 2 & & & & 2 & & & \\
\hline 3 & & & & 3 & & & & 3 & & & \\
\hline 4 & & & & 4 & & & & 4 & & & \\
\hline 5 & & & & 5 & & & & 5 & & & \\
\hline 6 & & & & 6 & & & & 6 & & & \\
\hline 7 & & & & 7 & & & & 7 & & & \\
\hline 8 & & & & 8 & & & & 8 & & & \\
\hline 9 & & & & 9 & & & & 9 & & & \\
\hline 10 & & & & 10 & & & & 10 & & & \\
\hline 11 & & & & 11 & & & & 11 & & & \\
\hline 12 & & & & 12 & & & & 12 & & & \\
\hline 13 & & & & 13 & & & & 13 & & & \\
\hline 14 & & & & 14 & & & & 14 & & & \\
\hline 15 & & & & 15 & & & & 15 & & & \\
\hline 16 & & & & 16 & & & & 16 & & & \\
\hline 17 & & & & 17 & & & & 17 & & & \\
\hline 18 & & & & 18 & & & & 18 & & & \\
\hline 19 & & & & 19 & & & & 19 & & & \\
\hline 20 & & & & 20 & & & & 20 & & & \\
\hline 21 & & & & 21 & & & & 21 & & & \\
\hline 22 & & & & 22 & & & & 22 & & & \\
\hline 23 & & & & 23 & & & & 23 & & & \\
\hline 24 & & & & 24 & & & & 24 & & & \\
\hline 25 & & & & 25 & & & & 25 & & & \\
\hline 26 & & & & 26 & & & & 26 & & & \\
\hline 27 & & & & 27 & & & & 27 & & & \\
\hline 28 & & & & 28 & & & & 28 & & & \\
\hline 29 & & & & 29 & & & & 29 & & & \\
\hline 30 & & & & 30 & & & & 30 & & & \\
\hline 31 & & & & 31 & & & & 31 & & & \\
\hline 32 & & & & 32 & & & & 32 & & & \\
\hline 33 & & & & 33 & & & & 33 & & & \\
\hline 34 & & & & 34 & & & & 34 & & & \\
\hline 35 & & & & 35 & & & & 35 & & & \\
\hline 36 & & & & 36 & & & & 36 & & & \\
\hline 37 & & & & 37 & & & & 37 & & & \\
\hline 38 & & & & 38 & & & & 38 & & & \\
\hline 39 & & & & 39 & & & & 39 & & & \\
\hline 40 & & & & 40 & & & & 40 & & & \\
\hline 41 & & & & 41 & & & & 41 & & & \\
\hline 42 & & & & 42 & & & & 42 & & & \\
\hline 43 & & & & 43 & & & & 43 & & & \\
\hline 44 & & & & 44 & & & & 44 & & & \\
\hline 45 & & & & 45 & & & & 45 & & & \\
\hline 46 & & & & 46 & & & & 46 & & & \\
\hline 47 & & & & 47 & & & & 42 & & & \\
\hline 48 & & & & 48 & & & & 48 & & & \\
\hline 49 & & & & 49 & & & & 49 & & & \\
\hline 50 & & & & 50 & & & & 50 & & & \\
\hline 57 & & & 1 & 51 & & & & 51 & & & \\
\hline 32 & & & & 52 & & & & 52 & & & \\
\hline
\end{tabular}

* Refer to Paragraph 3.2.1.0.2, Display Board 
WEEKLY CLOCK SET*

1979

1980

1981

\begin{tabular}{|c|c|c|c|c|c|c|c|c|c|c|c|}
\hline WEEK & DATE & CORR. & SETTING & WEEK & DATE & CORR. & SETTING & WEEK & DATE & CORR. & SETTING \\
\hline 1 & & & & 1 & & & & 1 & & & \\
\hline 2 & & & & 2 & & & & 2 & & & \\
\hline 3 & & & & 3 & & & & 3 & & & \\
\hline 4 & & & & 4 & & & & 4 & & & \\
\hline 5 & & & & 5 & & & & 5 & & & \\
\hline 6 & & & & 6 & & & & 6 & & & \\
\hline 7 & & & & 7 & & & & 7 & & & \\
\hline 8 & & & & 8 & & & & 8 & & & \\
\hline 9 & & & & 9 & & & & 9 & & & \\
\hline 10 & & & & 10 & & & & 10 & & & \\
\hline 11 & & & & 11 & & & & 11 & & & \\
\hline 12 & & & & 12 & & & & 12 & & & \\
\hline 13 & & & & 13 & & & & 13 & & & \\
\hline 14 & & & & 14 & & & & 14 & & & \\
\hline 15 & & & & 15 & & & & 15 & & & \\
\hline 16 & & & & 16 & & & & 16 & & & \\
\hline 17 & & & & 17 & & & & 17 & & & \\
\hline 18 & & & & 18 & & & & 18 & & & \\
\hline 19 & & & & 19 & & & & 19 & & & \\
\hline 20 & & & & 20 & & & & 20 & & & \\
\hline 21 & & & & 21 & & & & 21 & & & \\
\hline 22 & & & & 22 & & & & 22 & & & \\
\hline 23 & & & & 23 & & & & 23 & & & \\
\hline 24 & & & & 24 & & & & 24 & & & \\
\hline 25 & & & & 25 & & & & 25 & & & \\
\hline 26 & & & & 26 & & & & 26 & & & \\
\hline 27 & & & & 27 & & & & 27 & & & \\
\hline 28 & & & & 28 & & & & 28 & & & \\
\hline 29 & & & & 29 & & & & 29 & & & \\
\hline 30 & & & & 30 & & & & 30 & & & \\
\hline 31 & & & & 31 & & & & 31 & & & \\
\hline 32 & & & & 32 & & & & 32 & & & \\
\hline 33 & & & & 33 & & & & 33 & & & \\
\hline 34 & & & & 34 & & & & 34 & & & \\
\hline 35 & & & & 35 & & & & 35 & & & \\
\hline 36 & & & & 36 & & & & 36 & & & \\
\hline 37 & & & & 37 & & & & 37 & & & \\
\hline 38 & & & & 38 & & & & 38 & & & \\
\hline 39 & & & & 39 & & & & 39 & & & \\
\hline 40 & & & & 40 & & & & 40 & & & \\
\hline 41 & & & & 41 & & & & 41 & & & \\
\hline 42 & & & & 42 & & & & 42 & & & \\
\hline 43 & & & & 43 & & & & 43 & & & \\
\hline 44 & & & & 44 & & & & 44 & & & \\
\hline 45 & & & & 45 & & & & 45 & & & \\
\hline 46 & & & & 46 & & & & 46 & & & \\
\hline 47 & & & & 47 & & & & 47 & & & \\
\hline 48 & & & & 48 & & & & 48 & & & \\
\hline 49 & & & & 49 & & & & 49 & & & \\
\hline 50 & & & & 50 & & & & 50 & & & \\
\hline 51 & & & & 51 & & & & 51 & & & \\
\hline 52 & & & & 52 & & & & 52 & & & \\
\hline
\end{tabular}

* Refer to Paragraph 3.2.1.0.2, Display Board 
WEERIY CLOCK SET\%

\begin{tabular}{|c|c|c|c|c|c|c|c|c|c|c|c|}
\hline WEEK & DATE & CORR. & SETTING & WEEK & DAIE & CORR. & SETTING & WEEK & DATE & CORR. & SETTING \\
\hline 1 & & & & 1 & & & & 1 & & & \\
\hline 2 & & & & 2 & & & & 2 & & & \\
\hline 3 & & & & 3 & & & & 3 & & & \\
\hline 4 & & & & 4 & & & & 4 & & & \\
\hline 5 & & & & 5 & & & & 5 & & & \\
\hline 6 & & & & 6 & & & & 6 & & & \\
\hline 7 & & & & 7 & & & & 7 & & & \\
\hline 8 & & & & 8 & & & & 8 & & & \\
\hline 9 & & & & 9 & & & & 9 & & & \\
\hline 10 & & & & 10 & & & & 10 & & & \\
\hline 11 & & & & 11 & & & & 11 & & & \\
\hline 12 & & & & 12 & & & & 12 & & & \\
\hline 13 & & & & 13 & & & & 13 & & & \\
\hline 14 & & & & 14 & & & & 14 & & & \\
\hline 15 & & & & 15 & & & & 15 & & & \\
\hline 16 & & & & 16 & & & & 16 & & & \\
\hline 17 & & & & 17 & & & & 17 & & & \\
\hline 18 & & & & 18 & & & & 18 & & & \\
\hline 19 & & & & 19 & & & & 19 & & & \\
\hline 20 & & & & 20 & & & & 20 & & & \\
\hline 21 & & & & 21 & & & & 21 & & & \\
\hline 22 & & & & 22 & & & & 22 & & & \\
\hline 23 & & & & 23 & & & & 23 & & & \\
\hline 24 & & & & 24 & & & $\therefore$ & 24 & & & \\
\hline 25 & & & & 25 & & & & 25 & & & \\
\hline 26 & & & & 26 & & & & 26 & & & \\
\hline 27 & & & & 27 & & & & 27 & & & \\
\hline 28 & & & & 28 & & & & 28 & & & \\
\hline 29 & & & & 29 & & & & 29 & & & \\
\hline 30 & & & & 30 & & & & 30 & & & \\
\hline 31 & & & & 31 & & & & 31 & & & \\
\hline 32 & & & & 32 & & & & 32 & & & \\
\hline 33 & & & & 33 & & & & 33 & & & \\
\hline 34 & & & & 34 & & & & 34 & & & \\
\hline 35 & & & & 35 & & & & 35 & & & \\
\hline 36 & & & & 36 & & & & 36 & & & \\
\hline 37 & & & & 37 & & & & 37 & & & \\
\hline 38 & & & & 38 & & & & 38 & & & \\
\hline 39 & & & & 39 & & & & 39 & & & \\
\hline 40 & & & & 40 & & & & 40 & & & \\
\hline 41 & & & & 41 & & & & 41 & & & \\
\hline 42 & & & & 42 & & & & 42 & & & \\
\hline 43 & & & & 43 & & & & 43 & & & \\
\hline 44 & & & & 44 & & & & 44 & & & \\
\hline 45 & & & & 45 & & & & 45 & & & \\
\hline 46 & & & & 46 & & & & 46 & & & \\
\hline 47 & & & & 47 & & & & 47 & & & \\
\hline 48 & & & & 48 & & & & 48 & & & \\
\hline 49 & & & & 49 & & & & 49 & & & \\
\hline 50 & & & & 50 & & & & 50 & & & \\
\hline 51 & & & & 51 & & & & 51 & & & \\
\hline 52 & & & & 52 & & & & 52 & & & \\
\hline
\end{tabular}

* Refer to Paragraph 3.2.1.0.2, Display Board 
WEEKIY CLOCK SET*

1985

1986

\begin{tabular}{|c|c|c|c|c|c|c|c|c|c|c|c|}
\hline WEEK & DATE & CORR. & SETTING & WEEK & DATE & CORR. & SETTING & WEEK & DATE & CORR. & SETTING \\
\hline 1 & & & & 1 & & & & 1 & & & \\
\hline 2 & & & & 2 & & & & 2 & & & \\
\hline 3 & & & & 3 & & & & 3 & & & \\
\hline 4 & & & & 4 & & & & 4 & & & \\
\hline 5 & & & & 5 & & & & 5 & & & \\
\hline 6 & & & & 6 & & & & 6 & & & \\
\hline 7 & & & & 7 & & & & 7 & & & \\
\hline 8 & & & & 8 & & & & 8 & & & \\
\hline 9 & & & & 9 & & & & 9 & & & \\
\hline 10 & & & & 10 & & & & 10 & & & \\
\hline 11 & & & & 11 & & & & 11 & & & \\
\hline 12 & & & & 12 & & & & 12 & & & \\
\hline 13 & & & & 13 & & & & 13 & & & \\
\hline 14 & & & & 14 & & & & 14 & & & \\
\hline 15 & & & & 15 & & & & 15 & & & \\
\hline 16 & & & & 16 & & & & 16 & & & \\
\hline 17 & & & & 17 & & & & 17 & & & \\
\hline 18 & & & & 18 & & & & 18 & & & \\
\hline 19 & & & & 19 & & & & 19 & & & \\
\hline 20 & & & & 20 & & & & 20 & & & \\
\hline 21 & & & & 21 & & & & 21 & & & \\
\hline 22 & & & & 22 & & & & 22 & & & \\
\hline 23 & & & & 23 & & & & 23 & & & \\
\hline 24 & & & & 24 & & & & 24 & & & \\
\hline 25 & & & & 25 & & & & 25 & & & \\
\hline 26 & & & & 26 & & & & 26 & & & \\
\hline 27 & & & & 27 & & & & 27 & & & \\
\hline 28 & & & & 28 & & & & 28 & & & \\
\hline 29 & & & & 29 & & & & 29 & & & \\
\hline 30 & & & & 30 & & & & 30 & & & \\
\hline 31 & & & & 31 & & & & 31 & & & \\
\hline 32 & & & & 32 & & & & 32 & & & \\
\hline 33 & & & & 33 & & & & 33 & & & \\
\hline 34 & & & & 34 & & & & 34 & & & \\
\hline 35 & & & & 35 & & & & 35 & & & \\
\hline 36 & & & & 36 & & & & 36 & & & \\
\hline 37 & & & & 37 & & & & 37 & & & \\
\hline 38 & & & & 38 & & & & 38 & & & \\
\hline 39 & & & & 39 & & & & 39 & & & \\
\hline 40 & & & & 40 & & & & 40 & & & \\
\hline 41 & & & & 41 & & & & 41 & & & \\
\hline 42 & & & & 42 & & & & 42 & & & \\
\hline 43 & & & & 43 & & & & 43 & & & \\
\hline 44 & & & & 44 & & & & 44 & & & \\
\hline 45 & & & & 45 & & & & 45 & & & \\
\hline 46 & & & & 46 & & & & 46 & & & \\
\hline 47 & & & & 47 & & & & 47 & & & \\
\hline 48 & & & & 48 & & & & 48 & & & \\
\hline 49 & & & & 49 & & & & 49 & & & \\
\hline 50 & & & & 50 & & & & 50 & & & \\
\hline 51 & & & & 51 & & & & 52 & & & \\
\hline 52 & & & & 52 & & & & 52 & & & \\
\hline
\end{tabular}

*Refer to Paragraph 3.2.1.0.2, Display Board 
3.2.3.1 Monthly Meter Readings

The following check list is to be filled in with a number where a nominal reading is given or with a check meaning an acceptable response. The meter selector switch is to monitor the following:
1) Signal level, slow
2) Signal level, fast
3) Battery voltage
4) +12 volt line
5) -12 volt line
analog supply
6) +12 volt line, recorder power
7) Output of each channel before limiting 
CHECK LIST FOR MONTHLY METER READINGS

\begin{tabular}{|c|c|c|c|c|c|c|c|}
\hline Month & $\begin{array}{c}+12^{\mathrm{V}} \\
\text { Analog } \\
\end{array}$ & $\begin{array}{c}-12^{\mathrm{V}} \\
\text { Analog } \\
\end{array}$ & $\begin{array}{r}+12^{\mathrm{V}} \\
\text { Recorder } \\
\end{array}$ & Battery & $\begin{array}{l}\text { Fast } \\
\text { Level } \\
\end{array}$ & $\begin{array}{l}\text { Slow } \\
\text { Level }\end{array}$ & Date \\
\hline $\begin{array}{l}\text { Nominal } \\
\text { Meter } \\
\text { Reading }\end{array}$ & 100 & 100 & 100 & $\begin{array}{c}100 \\
\left(24^{v}\right)\end{array}$ & 20 & 50 & \\
\hline \multicolumn{8}{|l|}{ JANUARY } \\
\hline \multicolumn{8}{|l|}{ FEBRUARY } \\
\hline \multicolumn{8}{|l|}{ MARCH } \\
\hline \multicolumn{8}{|l|}{ APRIL } \\
\hline \multicolumn{8}{|l|}{ MAY } \\
\hline \multicolumn{8}{|l|}{ JUNE } \\
\hline \multicolumn{8}{|l|}{ JULY } \\
\hline \multicolumn{8}{|l|}{ AUGUST } \\
\hline \multicolumn{8}{|l|}{ SEPTENBER } \\
\hline \multicolumn{8}{|l|}{ OCTOBER } \\
\hline NOVEMBER & & & & & & & \\
\hline DECEMBER & & & & & & & \\
\hline
\end{tabular}

\begin{tabular}{|c|c|c|c|c|c|c|c|c|c|c|c|c|}
\hline \multirow[b]{3}{*}{$\begin{array}{l}\text { Nominal } \\
\text { Meter } \\
\text { Reading }\end{array}$} & \multirow[b]{3}{*}{$50 \pm$} & \multirow{3}{*}{1} & \multirow{3}{*}{$\underline{2}$} & \multirow{3}{*}{3} & \multicolumn{3}{|c|}{ Channels } & \multirow{3}{*}{7} & \multirow{3}{*}{8} & \multirow{3}{*}{9} & \multirow{3}{*}{10} & \multirow{3}{*}{ Date } \\
\hline & & & & & 4 & $\underline{5}$ & 6 & & & & & \\
\hline & & & & & & & & & & & & \\
\hline JANUARY & & & & & & & & & & & & \\
\hline FEBRUARY & & & & & & & & & & & & \\
\hline MARCH & & & & & & & & & & & & \\
\hline APRIL & & & & & & & & & & & & \\
\hline MAY & & & & & & & & & & & & \\
\hline JUNE & & & & & & & & & & & & \\
\hline JULY & & & & & & & & & & & & \\
\hline AUGUST & & & & & & & & & & & & \\
\hline SEPTEMBER & & & & & & & & & & & & \\
\hline OCTOBER & & & & & & & & & & & & \\
\hline NOVEMBER & & & & & & & & & & & & \\
\hline DECEMBER & & & & & & & & & & & & \\
\hline
\end{tabular}


CHECK IIST FOR MONTHIY METER READINGS

1977

\begin{tabular}{|c|c|c|c|c|c|c|c|}
\hline $\begin{array}{l}\text { Month } \\
\text { Nominal } \\
\text { Meter } \\
\text { Reading }\end{array}$ & $\begin{array}{c}+12^{\mathrm{V}} \\
\text { Analog }\end{array}$ & $\begin{array}{c}\begin{array}{c}-12^{\mathrm{V}} \\
\text { Analog } \\
100\end{array} \\
\end{array}$ & $\begin{array}{c}\begin{array}{c}+12^{\mathrm{V}} \\
\text { Recorder }\end{array} \\
100\end{array}$ & $\begin{array}{l}\text { Battery } \\
100 \\
\left(24^{\mathrm{V}}\right)\end{array}$ & $\begin{array}{c}\text { Fast } \\
\text { Level } \\
20\end{array}$ & $\begin{array}{l}\text { Slow } \\
\text { Level }\end{array}$ & Date \\
\hline JANUARY & & & & & & & \\
\hline FEBRUARY & & & & & & & \\
\hline MARCH & & & & & & & \\
\hline APRIL & & & & & & & \\
\hline MAY & & & & & & & \\
\hline JUNE & & & & & & & \\
\hline JULY & & & & & & & \\
\hline AUGUST & & & & & & & \\
\hline SEPTEN $3 E R$ & & & & & & & \\
\hline OCTOBER & & & & & & & \\
\hline NOVEMBER & & & & & & & \\
\hline DECEMBER & & & & & & & \\
\hline
\end{tabular}

\begin{tabular}{|c|c|c|c|c|c|c|c|c|c|c|c|c|}
\hline \multirow[b]{2}{*}{$\begin{array}{l}\text { Nominal } \\
\text { Meter } \\
\text { Reading }\end{array}$} & \multirow[b]{2}{*}{$50 \pm$} & \multirow[b]{2}{*}{1} & \multirow[b]{2}{*}{$\underline{2}$} & \multirow[b]{2}{*}{3} & \multicolumn{3}{|c|}{ Channels } & \multirow[b]{2}{*}{7} & \multirow[b]{2}{*}{8} & \multirow[b]{2}{*}{9} & \multirow[b]{2}{*}{10} & \multirow[b]{2}{*}{ Date } \\
\hline & & & & & 4 & 5 & 6 & & & & & \\
\hline JANUARY & & & & & & & & & & & & \\
\hline FEBRUARY & & & & & & & & & & & & \\
\hline MARCH & & & & & & & & & & & & \\
\hline APRIL & & & & & & & & & & & & \\
\hline MAY & & & & & & & & & & & & \\
\hline JUNE & & & & & & & & & & & & \\
\hline JULY & & & & & & & & & & & & \\
\hline AUGUST & & & & & & & & & & & & \\
\hline SEPTEMBER & & & & & & & & & & & & \\
\hline OCTOBER & & & & & & & & & & & & \\
\hline NOVEMBER & & & & & & & & & & & & \\
\hline DECEMBER & & & & & & & & & & & & \\
\hline
\end{tabular}


CHECK LIST FOR MONTHLY METER READINGS

1978

\begin{tabular}{|c|c|c|c|c|c|c|c|}
\hline Month & $\begin{array}{r}+12^{v} \\
\text { Analog } \\
\end{array}$ & $\begin{array}{c}-12^{\mathrm{V}} \\
\text { Analog } \\
\end{array}$ & $\begin{array}{r}+12^{\mathrm{V}} \\
\text { Recordex } \\
\end{array}$ & Battery & $\begin{array}{l}\text { Fast } \\
\text { Level } \\
\end{array}$ & $\begin{array}{l}\text { Slow } \\
\text { Level } \\
\end{array}$ & Date \\
\hline $\begin{array}{l}\text { Nominal } \\
\text { Meter } \\
\text { Reading }\end{array}$ & 100 & 100 & 100 & $\begin{array}{c}100 \\
\left(24^{V}\right)\end{array}$ & 20 & 50 & \\
\hline JANUARY & & & & & & & \\
\hline FEBRUARY & & & & & & & \\
\hline MARCH & & & & & & & \\
\hline APRIL & & & & & & & \\
\hline MAY & & & & & & & \\
\hline JUNE & & & & & & & \\
\hline JULY & & & & & & & \\
\hline AUGUST & & & & & & & \\
\hline SEPTEN & & & & & & & \\
\hline OCTOBER & & & & & & & \\
\hline NOVEMBER & & & & & & & \\
\hline DECEMBER & & & & & & & \\
\hline
\end{tabular}

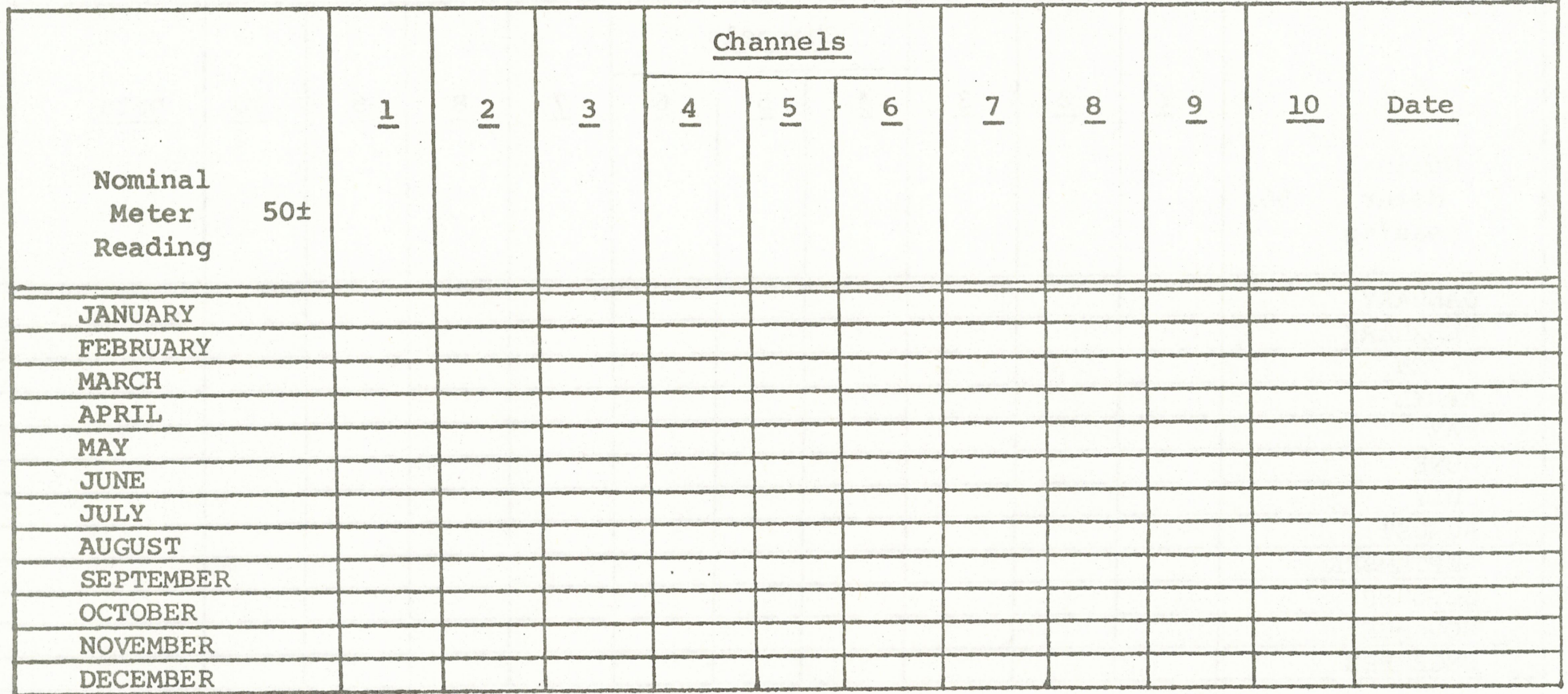


CHECK LIST FOR MONTHLY METER READINGS

1979

\begin{tabular}{|c|c|c|c|c|c|c|c|}
\hline Month & $\begin{array}{c}+12^{\mathrm{V}} \\
\text { Analog }\end{array}$ & $\begin{array}{c}-12^{\mathrm{V}} \\
\text { Analog }\end{array}$ & $\begin{array}{r}+12^{\mathrm{v}} \\
\text { Recorder } \\
\end{array}$ & Battery & $\begin{array}{l}\text { Fast } \\
\text { Level }\end{array}$ & $\begin{array}{l}\text { Slow } \\
\text { Leve } 1\end{array}$ & Date \\
\hline $\begin{array}{l}\text { Nominal } \\
\text { Meter } \\
\text { Reading }\end{array}$ & 100 & 100 & 100 & $\begin{array}{c}100 \\
\left(24^{V}\right)\end{array}$ & 20 & 50 & \\
\hline JANUARY & & & & & & & \\
\hline FEBRUARY & & & & & & & \\
\hline MARCH & & & & & & & \\
\hline APRIL & & & & & & & \\
\hline MAY & & & & & & & \\
\hline JUNE & & & & & & & \\
\hline JULY & & & & & & & \\
\hline AUGUST & & & & & & & \\
\hline SEPTEN13ER & & & & & & & \\
\hline OCTOBER & & & & & & & \\
\hline NOVEMBER & & & & & & & \\
\hline DECEMBER & & & & & & & \\
\hline
\end{tabular}

\begin{tabular}{|c|c|c|c|c|c|c|c|c|c|c|c|c|}
\hline \multirow[b]{2}{*}{$\begin{array}{l}\text { Nominal } \\
\text { Metex } \\
\text { Reading }\end{array}$} & \multirow[b]{2}{*}{$50 \pm$} & \multirow[b]{2}{*}{1} & \multirow[b]{2}{*}{2} & \multirow[b]{2}{*}{$\underline{3}$} & \multicolumn{3}{|c|}{ ChanneIs } & \multirow[b]{2}{*}{7} & \multirow[b]{2}{*}{8} & \multirow[b]{2}{*}{9} & \multirow[b]{2}{*}{10} & \multirow[b]{2}{*}{ Date } \\
\hline & & & & & 4 & 5 & 6 & & & & & \\
\hline JANUARY & & & & & & & & & & & & \\
\hline FEBRUARY & & & & & & & & & & & & \\
\hline MARCH & & & & & & & & & & & & \\
\hline APRIL & & & & & & & & & & & & \\
\hline MAY & & & & & & & & & & & & \\
\hline JUNE & & & & & & & & & & & & \\
\hline JULY & & & & & & & & & & & & \\
\hline AUGUST & & & & & & & & & & & & \\
\hline SEPTEMBER & & & & & & & & & & & & \\
\hline OCTOBER & & & & & & & & & & & & \\
\hline NOVEMBER & & & & & & & & & & & & \\
\hline DECEMBER & & & & & & & & & & & & \\
\hline
\end{tabular}


CHECK IIST FOR MONTHLY METER READINGS

\begin{tabular}{|c|c|c|c|c|c|c|c|}
\hline Month & $\begin{array}{r}+12^{\mathrm{V}} \\
\text { Analog } \\
\end{array}$ & $\begin{array}{r}-12^{\mathrm{V}} \\
\text { Analog } \\
\end{array}$ & $\begin{array}{c}+12^{\mathrm{V}} \\
\text { Recorder } \\
\end{array}$ & Battery & $\begin{array}{l}\text { Fast } \\
\text { Leve } 1 \\
\end{array}$ & $\begin{array}{l}\text { Slow } \\
\text { Leve } 1 \\
\end{array}$ & Date \\
\hline $\begin{array}{c}\text { Nominal } \\
\text { Meter } \\
\text { Reading }\end{array}$ & 100 & 100 & 100 & $\begin{array}{c}100 \\
\left(24^{V}\right)\end{array}$ & 20 & 50 & \\
\hline JANUARY & & & & & & & \\
\hline FEBRUARY & & & & & & & \\
\hline MARCH & & & & & & . & \\
\hline APRIL & & & & & & & \\
\hline MAY & & & & & & & \\
\hline JUNE & & & & & & & \\
\hline JULY & & & & & & & \\
\hline AUGUST & & & & & & & \\
\hline SEPTEN $13 E R$ & & & & & & & \\
\hline OCTOBER & & & & & & & \\
\hline NOVEMBER & & & & & & & \\
\hline DECEMBER & & & & & & & \\
\hline
\end{tabular}

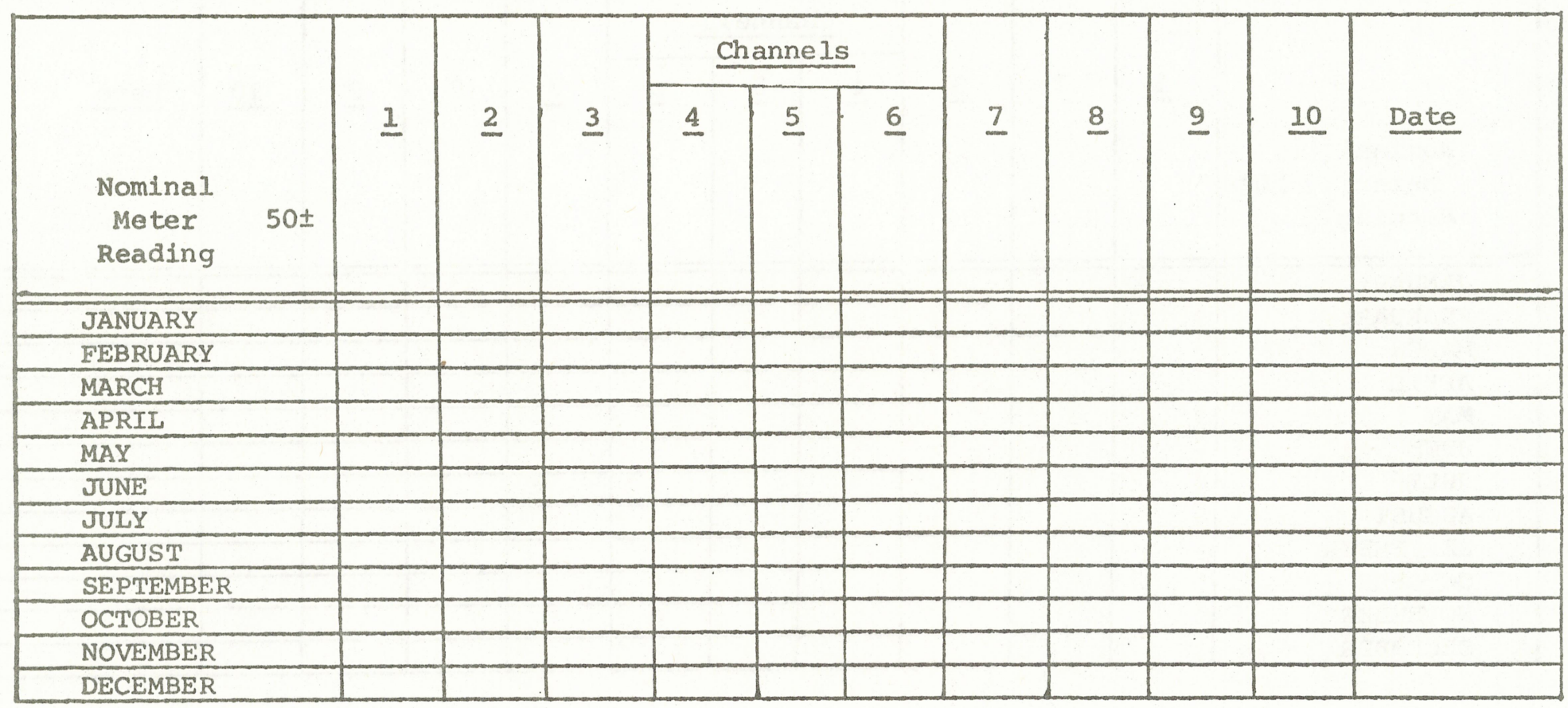


CHECK LIST FOR MONTHLY METER READINGS

1981

\begin{tabular}{|c|c|c|c|c|c|c|c|}
\hline $\begin{array}{l}\text { Month } \\
\text { Nominal } \\
\text { Metex } \\
\text { Reading }\end{array}$ & $\begin{array}{c}+12^{\mathrm{V}} \\
\text { Analog } \\
100\end{array}$ & 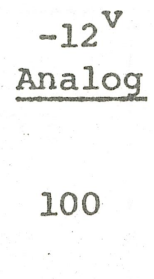 & $\begin{array}{c}\begin{array}{c}+12^{\mathrm{V}} \\
\text { Recorder }\end{array} \\
100\end{array}$ & $\begin{array}{c}\text { Battery } \\
100 \\
(24 v)\end{array}$ & $\begin{array}{l}\begin{array}{l}\text { Fast } \\
\text { Leve } 1\end{array} \\
20\end{array}$ & $\begin{array}{l}\begin{array}{l}\text { Slow } \\
\text { Level }\end{array} \\
\begin{array}{l}50\end{array}\end{array}$ & Date \\
\hline JANUARY & & & & & & & \\
\hline FEBRUARY & & & & & & & \\
\hline MARCH & & & & & & & \\
\hline APRIL & & & & & & & \\
\hline MAY & & & & & & & \\
\hline JUNE & & & & & & & \\
\hline JULY & & & & & & & \\
\hline AUGUST & & & & & & & \\
\hline SEPTENBBER & & & & & & & \\
\hline OCTOBER & & & & & & & \\
\hline NOVEMBER & & & & & & & \\
\hline DECEMBER & & & & & & & \\
\hline
\end{tabular}

\begin{tabular}{|c|c|c|c|c|c|c|c|c|c|c|c|c|}
\hline \multirow[b]{3}{*}{$\begin{array}{l}\text { Nominal } \\
\text { Meter } \\
\text { Reading }\end{array}$} & \multirow[b]{3}{*}{$50 \pm$} & \multirow{3}{*}{1} & \multirow{3}{*}{2} & \multirow{3}{*}{3} & \multicolumn{3}{|c|}{ Channe Is } & \multirow{3}{*}{7} & \multirow{3}{*}{8} & \multirow{3}{*}{9} & \multirow{3}{*}{10} & \multirow{3}{*}{ Date } \\
\hline & & & & & 4 & $\underline{5}$ & 6 & & & & & \\
\hline & & & & & & & & & & & & \\
\hline \multicolumn{13}{|l|}{ JANUARY } \\
\hline \multicolumn{13}{|l|}{ FEBRUARY } \\
\hline \multirow{2}{*}{\multicolumn{13}{|c|}{$\frac{\text { MARCH }}{\text { APRIL }}$}} \\
\hline & & & & & & & & & & & & \\
\hline \multicolumn{13}{|l|}{ MAY } \\
\hline \multicolumn{13}{|l|}{ JUNE } \\
\hline \multicolumn{13}{|l|}{ JULY } \\
\hline \multirow{2}{*}{\multicolumn{13}{|c|}{ AUGUST }} \\
\hline \multirow{2}{*}{\multicolumn{13}{|c|}{$\frac{\text { SEPTEMBER }}{\text { OCTOBER }}$}} \\
\hline & & & & & & & & & & & & \\
\hline \multicolumn{13}{|l|}{ NOVEMBER } \\
\hline DECEMBER & & & & & & & & & & & & \\
\hline
\end{tabular}


CHECK IIST FOR MONTHLY METER READINGS

\begin{tabular}{|c|c|c|c|c|c|c|c|}
\hline Month & $\begin{array}{c}+12^{\mathrm{v}} \\
\text { Analog } \\
\end{array}$ & $\begin{array}{c}-12^{\mathrm{V}} \\
\text { Analog } \\
\end{array}$ & $\begin{array}{r}+12^{\mathrm{V}} \\
\text { Recorder } \\
\end{array}$ & Battery & $\begin{array}{l}\text { Fast } \\
\text { Leve I }\end{array}$ & $\begin{array}{l}\text { Slow } \\
\text { Leve } 1\end{array}$ & Date \\
\hline $\begin{array}{l}\text { Nominal } \\
\text { Meter } \\
\text { Reading }\end{array}$ & 100 & 100 & 100 & $\begin{array}{c}100 \\
\left(24^{v}\right)\end{array}$ & 20 & 50 & \\
\hline \multicolumn{8}{|l|}{ JANUARY } \\
\hline \multicolumn{8}{|l|}{ FEBRUARY } \\
\hline \multicolumn{8}{|l|}{ MARCH } \\
\hline \multicolumn{8}{|l|}{ APRIL } \\
\hline \multicolumn{8}{|l|}{ MAY } \\
\hline \multicolumn{8}{|l|}{ JUNE } \\
\hline \multicolumn{8}{|l|}{ JULY } \\
\hline \multicolumn{8}{|l|}{ AUGUST } \\
\hline \multicolumn{8}{|l|}{ SEPTEMBER } \\
\hline \multicolumn{8}{|l|}{ OCTOBER } \\
\hline NOVEMBER & & & & & & & \\
\hline DECEMBER & & & & & & & \\
\hline
\end{tabular}

\begin{tabular}{|c|c|c|c|c|c|c|c|c|c|c|c|c|}
\hline \multirow[b]{3}{*}{$\begin{array}{l}\text { Nominal } \\
\text { Meter } \\
\text { Reading }\end{array}$} & \multirow[b]{3}{*}{$50 \pm$} & \multirow{3}{*}{1} & \multirow{3}{*}{$\underline{2}$} & \multirow{3}{*}{3} & \multicolumn{3}{|c|}{ Channels } & \multirow{3}{*}{7} & \multirow{3}{*}{8} & \multirow{3}{*}{9} & \multirow{3}{*}{10} & \multirow{3}{*}{ Date } \\
\hline & & & & & $\underline{4}$ & $\underline{5}$ & 6 & & & & & \\
\hline & & & & & & & & & & & & \\
\hline JANUARY & & & & & & & & & & & & \\
\hline FEBRUARY & & & & & & & & & & & & \\
\hline MARCH & & & & & & & & & & & & \\
\hline APRIL & & & & & & & & & & & & \\
\hline MAY & & & & & & & & & & & & \\
\hline JUNE & & & & & & & & & & & & \\
\hline JULY & & & & & & & & & & & & \\
\hline AUGUST & & & & & & & & & & & & \\
\hline SEPTEMBER & & & & & & & & & & & & \\
\hline OCTOBER & & & & & & & & & & & & \\
\hline NOVEMBER & & & & & & & & & & & & \\
\hline DECEMBER & & & & & & & & & & & & \\
\hline
\end{tabular}


CHECK LIST FOR MONTHLY METER READINGS

1983

\begin{tabular}{|c|c|c|c|c|c|c|c|}
\hline Month & $\begin{array}{c}+12^{\mathrm{V}} \\
\text { Ana log }\end{array}$ & $\begin{array}{c}-12^{\mathrm{V}} \\
\text { Analog } \\
\end{array}$ & $\begin{array}{c}+12^{\mathrm{V}} \\
\text { Recorder } \\
\end{array}$ & Battery & $\begin{array}{l}\text { East } \\
\text { Leve } 1 \\
\end{array}$ & $\begin{array}{l}\text { Slow } \\
\text { Leve } 1 \\
\end{array}$ & Date \\
\hline $\begin{array}{l}\text { Nominal } \\
\text { Meter } \\
\text { Reading }\end{array}$ & 100 & 100 & 100 & $\begin{array}{c}100 \\
\left(24^{V}\right)\end{array}$ & 20 & 50 & \\
\hline JANUARY & & & & & & & \\
\hline FEBRUARY & & & & & & & \\
\hline MARCH & & & & & & & \\
\hline APRIL & & & & & & & \\
\hline MAY & & & & & & & \\
\hline JUNE & & & & & & & \\
\hline JULY & & & & & & & \\
\hline AUGUST & & & & & & & \\
\hline SEPTEMBER & & & & & & & \\
\hline OCTOBER & & & & & & & \\
\hline NOVEMBER & & & & & & & \\
\hline DECEMBER & & & & & & & \\
\hline
\end{tabular}

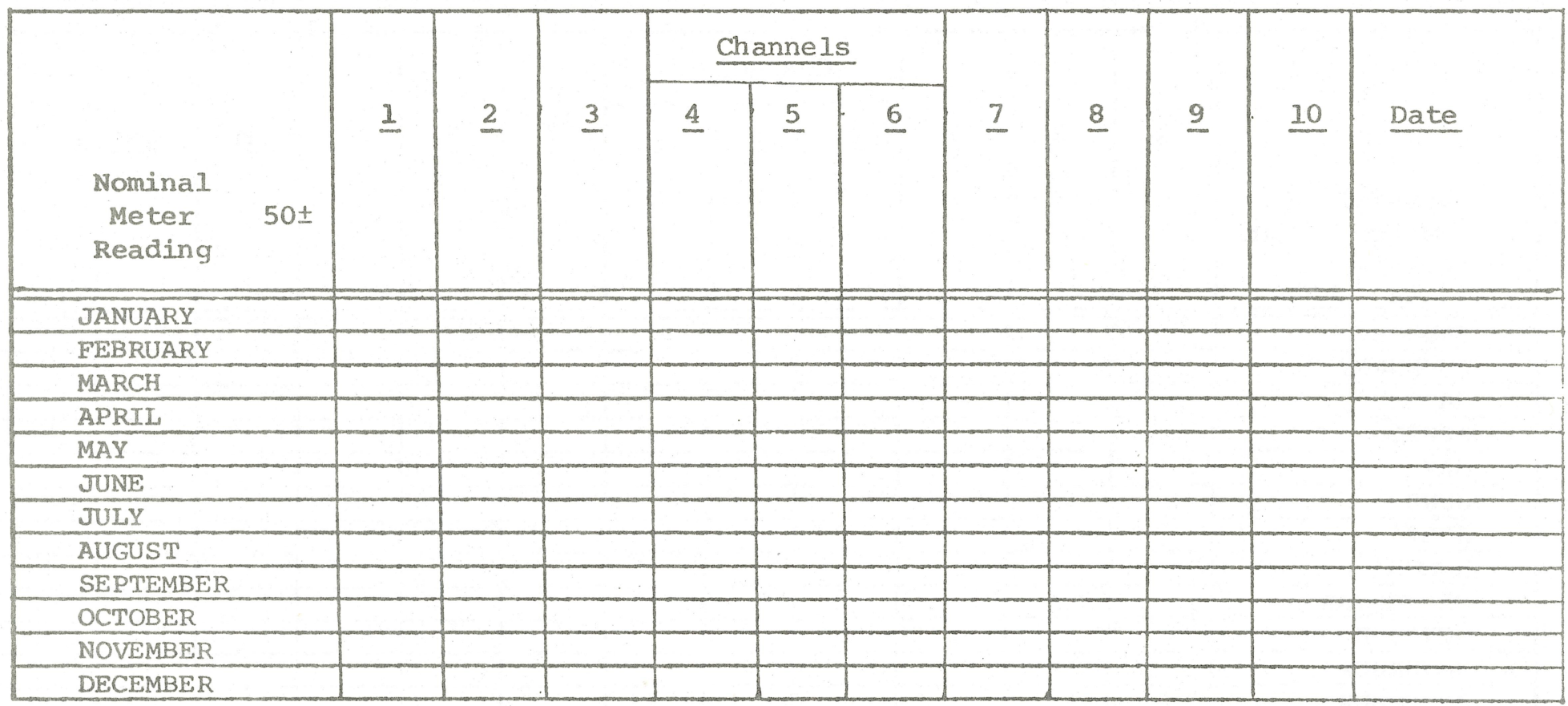


CHECK LIST FOR MONTHLY METER READINGS

\begin{tabular}{|c|c|c|c|c|c|c|c|}
\hline Month & $\begin{array}{c}+12^{\mathrm{v}} \\
\text { Analog } \\
\end{array}$ & $\begin{array}{c}-12^{\mathrm{V}} \\
\text { Analog } \\
\end{array}$ & $\begin{array}{r}+12^{\mathrm{V}} \\
\text { Recorder } \\
\end{array}$ & Battery & $\begin{array}{l}\text { Fast } \\
\text { Leve I }\end{array}$ & $\begin{array}{l}\text { Slow } \\
\text { Leve I }\end{array}$ & Date \\
\hline $\begin{array}{l}\text { Nominal } \\
\text { Meter } \\
\text { Reading }\end{array}$ & 100 & 100 & 100 & $\begin{array}{c}100 \\
\left(24^{v}\right)\end{array}$ & 20 & 50 & \\
\hline \multicolumn{8}{|l|}{ JANUARY } \\
\hline \multicolumn{8}{|l|}{ FEBRUARY } \\
\hline \multicolumn{8}{|l|}{ MARCH } \\
\hline \multicolumn{8}{|l|}{ APRIL } \\
\hline \multicolumn{8}{|l|}{ MAY } \\
\hline \multicolumn{8}{|l|}{ JUNE } \\
\hline \multicolumn{8}{|l|}{ JULY } \\
\hline \multicolumn{8}{|l|}{ AUGUST } \\
\hline \multicolumn{8}{|l|}{ SEPTEMBER } \\
\hline \multicolumn{8}{|l|}{ OCTOBER } \\
\hline \multicolumn{8}{|l|}{ NOVEMBER } \\
\hline DECEMBER & & & & & & & \\
\hline
\end{tabular}

\begin{tabular}{|c|c|c|c|c|c|c|c|c|c|c|c|c|}
\hline \multirow[b]{3}{*}{$\begin{array}{l}\text { Nominal } \\
\text { Meter } \\
\text { Reading }\end{array}$} & \multirow[b]{3}{*}{$50 \pm$} & \multirow{3}{*}{1} & \multirow{3}{*}{2} & \multirow{3}{*}{3} & \multicolumn{3}{|c|}{ Channels } & \multirow{3}{*}{2} & \multirow{3}{*}{8} & \multirow{3}{*}{9} & \multirow{3}{*}{10} & \multirow{3}{*}{ Date } \\
\hline & & & & & 4 & $\underline{5}$ & 6 & & & & & \\
\hline & & & & & & & & & & & & \\
\hline JANUARY & & & & & & & & & & & & \\
\hline FEBRUARY & & & & & & & & & & & & \\
\hline MARCH & & & & & & & & & & & & \\
\hline APRII & & & & & & & & & & & & \\
\hline MAY & & & & & & & & & & & & \\
\hline JUNE & & & & & & & & & & & & \\
\hline JULY & & & & & & & & & & & & \\
\hline AUGUST & & & & & & & & & & & & \\
\hline SEPTEMBER & & & & & & & & & & & & \\
\hline OCTOBER & & & & & & & & & & & & \\
\hline NOVEMBER & & & & & & & & & & & & \\
\hline DECEMBER & & & & & & & & & & & & \\
\hline
\end{tabular}


CHECK IIST FOR MONTHLY METER READINGS

\begin{tabular}{|c|c|c|c|c|c|c|c|}
\hline Month & $\begin{array}{r}+12^{\mathrm{V}} \\
\text { Analog } \\
\end{array}$ & $\begin{array}{c}-12^{\mathrm{V}} \\
\text { Analog } \\
\end{array}$ & $\begin{array}{c}+12^{\mathrm{V}} \\
\text { Recorder } \\
\end{array}$ & Battery & $\begin{array}{l}\text { East } \\
\text { Leve } 1 \\
\end{array}$ & $\begin{array}{l}\text { Slow } \\
\text { Leve1 }\end{array}$ & Date \\
\hline $\begin{array}{l}\text { Nominal } \\
\text { Meter } \\
\text { Reading }\end{array}$ & 100 & 100 & 100 & $\begin{array}{c}100 \\
\left(24^{V}\right)\end{array}$ & 20 & 50 & \\
\hline \multicolumn{8}{|l|}{ JANUARY } \\
\hline \multicolumn{8}{|l|}{ FEBRUARY } \\
\hline \multicolumn{8}{|l|}{ MARCH } \\
\hline \multicolumn{8}{|l|}{ APRIL } \\
\hline \multicolumn{8}{|l|}{ MAY } \\
\hline \multicolumn{8}{|l|}{ JUNE } \\
\hline \multicolumn{8}{|l|}{ JULY } \\
\hline \multicolumn{8}{|l|}{ AUGUST } \\
\hline \multicolumn{8}{|l|}{ SEPTEN]BER } \\
\hline \multicolumn{8}{|l|}{ OCTOBER } \\
\hline \multicolumn{8}{|l|}{ NOVEMBER } \\
\hline DECEMBER & & & & & & & \\
\hline
\end{tabular}

\begin{tabular}{|c|c|c|c|c|c|c|c|c|c|c|c|c|}
\hline \multirow[b]{2}{*}{$\begin{array}{c}\text { Nominal } \\
\text { Meter } \\
\text { Reading }\end{array}$} & \multirow[b]{2}{*}{$50 \pm$} & \multirow[b]{2}{*}{1} & \multirow[b]{2}{*}{2} & \multirow[b]{2}{*}{3} & \multicolumn{3}{|c|}{ Channels } & \multirow[b]{2}{*}{7} & \multirow[b]{2}{*}{8} & \multirow[b]{2}{*}{9} & \multirow[b]{2}{*}{10} & \multirow[b]{2}{*}{ Date } \\
\hline & & & & & 4 & 5 & 6 & & & & & \\
\hline \multicolumn{13}{|l|}{ JANUARY } \\
\hline \multicolumn{13}{|l|}{ FEBRUARY } \\
\hline \multicolumn{13}{|l|}{ MARCH } \\
\hline \multicolumn{13}{|l|}{ APRIL } \\
\hline \multicolumn{13}{|l|}{ MAY } \\
\hline \multicolumn{13}{|l|}{ JUNE } \\
\hline \multicolumn{13}{|l|}{ JULY } \\
\hline \multicolumn{13}{|l|}{ AUGUST } \\
\hline \multicolumn{13}{|l|}{ SEPTEMBER } \\
\hline \multicolumn{13}{|l|}{ OCTOBER } \\
\hline \multicolumn{13}{|l|}{ NOVEMBER } \\
\hline DECEMBER & & & & & & & & & & & & \\
\hline
\end{tabular}


CHECK LIST FOR MONTHLY METER READINGS

\begin{tabular}{|c|c|c|c|c|c|c|c|}
\hline Month & $\begin{array}{r}+12^{\mathrm{V}} \\
\text { Analog } \\
\end{array}$ & $\begin{array}{c}-12^{\mathrm{V}} \\
\text { Analog } \\
\end{array}$ & $\begin{array}{r}+12^{\mathrm{V}} \\
\text { Recorder } \\
\end{array}$ & Battery & $\begin{array}{l}\text { Fast } \\
\text { Level }\end{array}$ & $\begin{array}{l}\text { Slow } \\
\text { Leve I }\end{array}$ & Date \\
\hline $\begin{array}{l}\text { Nominal } \\
\text { Meter } \\
\text { Reading }\end{array}$ & 100 & 100 & 100 & $\begin{array}{c}100 \\
\left(24^{v}\right)\end{array}$ & 20 & 50 & \\
\hline \multicolumn{8}{|l|}{ JANUARY } \\
\hline \multicolumn{8}{|l|}{ FEBRUARY } \\
\hline \multicolumn{8}{|l|}{ MARCH } \\
\hline \multicolumn{8}{|l|}{ APRIL } \\
\hline \multirow{2}{*}{\multicolumn{8}{|c|}{$\frac{\text { MAY }}{\text { JUNE }}$}} \\
\hline \multirow{2}{*}{\multicolumn{8}{|c|}{$\frac{\pi U N E}{J U L Y}$}} \\
\hline JULY & & & & & & & \\
\hline \multicolumn{8}{|l|}{ AUGUST } \\
\hline \multicolumn{8}{|l|}{ SEPTEMFSER } \\
\hline \multicolumn{8}{|l|}{ OCTOBER } \\
\hline \multicolumn{8}{|l|}{ NOVEMBER } \\
\hline DECEMBER & & & & & & & \\
\hline
\end{tabular}

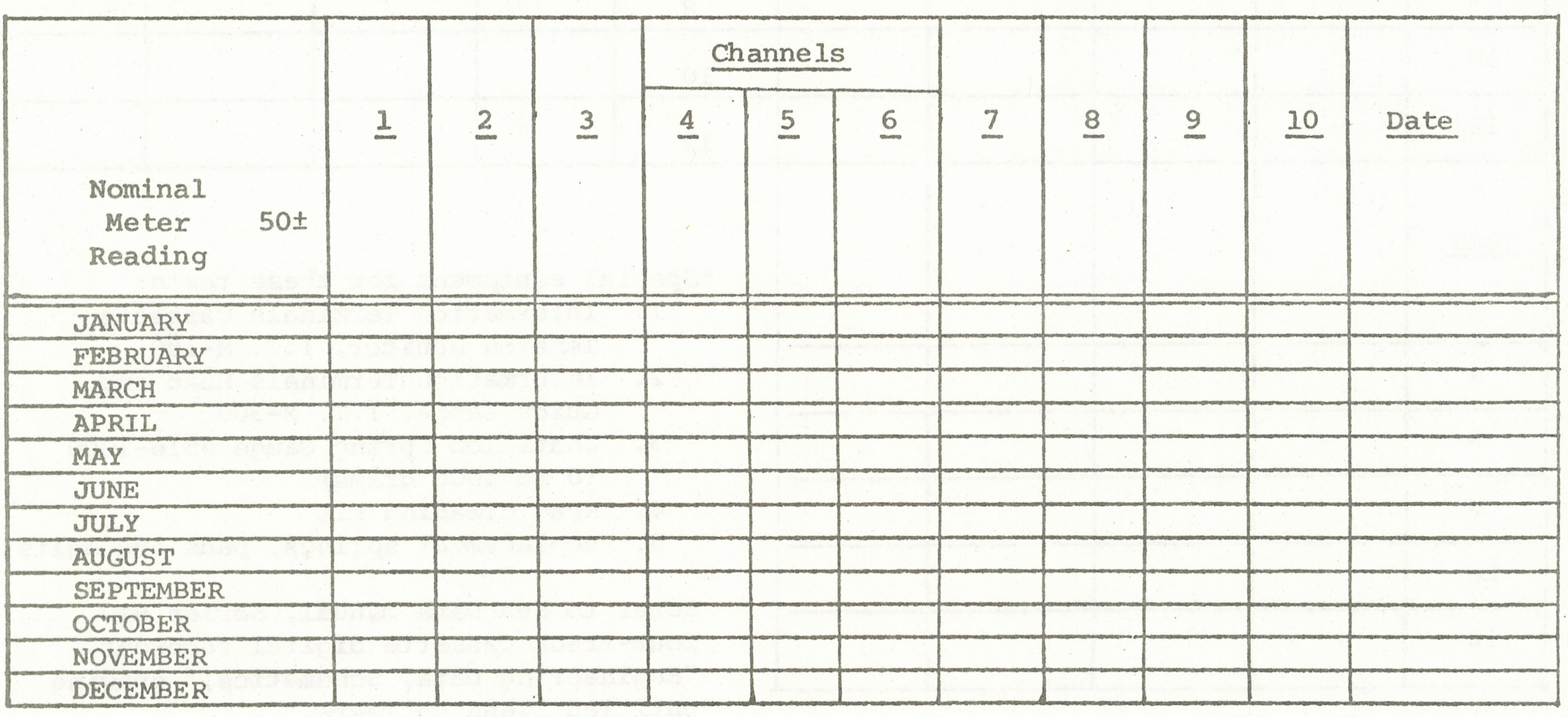


3.2.3.2 BIMONTHLY SEA DATA TRANSPORT CHECK*

\begin{tabular}{|c|c|c|c|c|c|c|c|c|c|}
\hline $\begin{array}{l}\text { YEAR- } \\
\text { MON TH } \\
\frac{1976}{2}\end{array}$ & $\begin{array}{l}\text { FEED } \\
\text { TORQUE }\end{array}$ & $\begin{array}{l}\text { TAKE-UP } \\
\text { TORQUE }\end{array}$ & $\begin{array}{l}\text { PINCH } \\
\text { ROLIER } \\
\text { TENSION }\end{array}$ & $\begin{array}{l}\text { CLEAN } \\
\text { HEAD }\end{array}$ & $\begin{array}{l}\text { YEAR- } \\
\text { MONTH } \\
\frac{1977}{2}\end{array}$ & $\begin{array}{c}\text { FEED } \\
\text { TORQUE }\end{array}$ & $\begin{array}{l}\text { TAKE-UP } \\
\text { TORQUE }\end{array}$ & $\begin{array}{l}\text { PINCH } \\
\text { ROLLER } \\
\text { TENSION }\end{array}$ & $\begin{array}{l}\text { CLEAN } \\
\text { HEAD }\end{array}$ \\
\hline 4 & & & & & 4 & & & & \\
\hline 6 & & & & & 6 & & & & \\
\hline 8 & & & & & 8 & & & & \\
\hline 10 & & & & & 10 & & & & \\
\hline 12 & & & & & 12 & & & & \\
\hline$\frac{1978}{2}$ & & & & & $\begin{array}{c}1979 \\
2\end{array}$ & & & & \\
\hline 4 & & & & & 4 & & & & \\
\hline 6 & & & & & 6 & & & & \\
\hline 8 & & & & & 8 & & & & \\
\hline 10 & & & & & 10 & & & & \\
\hline 12 & & & & & 12 & & & & \\
\hline
\end{tabular}

*Special equipment for these tests:

1. Information Terminals Cassette Tension Monitor "I.T.M-100

2. Information Terminals Head and Guide Gauge, I.T. M-300

3. Chatillon Spring Gauge \#516-1000 (0 to 1000 grams)

4. Head Cleaning Kit

5. Replacement springs, pads and belts

Refer to Sea Data manual, Series 610 four-track cassette digital recorder, "Engineering Data, Schematics," drawing entitled "Tension Tests." 
BIMONTHLY SEA DATA TRANSPORT CHECK (cont.)

\begin{tabular}{|c|c|c|c|c|c|c|c|c|c|}
\hline $\begin{array}{l}\text { YEAR- } \\
\text { MONTH } \\
\frac{1981}{2}\end{array}$ & $\begin{array}{c}\text { FEED } \\
\text { TORQUE }\end{array}$ & $\begin{array}{l}\text { TAKE-UP } \\
\text { TORQUE }\end{array}$ & $\begin{array}{l}\text { PINCH } \\
\text { ROLIER } \\
\text { TENSION }\end{array}$ & $\begin{array}{l}\text { CLEAN } \\
\text { HEAD }\end{array}$ & $\begin{array}{c}\text { YEAR- } \\
\text { MONTH } \\
\frac{1982}{2}\end{array}$ & $\begin{array}{c}\text { FEED } \\
\text { TORQUE }\end{array}$ & $\begin{array}{l}\text { TAKE-UP } \\
\text { TORQUE }\end{array}$ & $\begin{array}{l}\text { PINCH } \\
\text { ROLLER } \\
\text { TENSION }\end{array}$ & $\begin{array}{l}\text { CLEAN } \\
\text { HEAD }\end{array}$ \\
\hline 4 & & & & & 4 & & & & \\
\hline 6 & & & & & 6 & & & & \\
\hline 8 & & & & & 8 & & & & \\
\hline 10 & & & & & 10 & & & & \\
\hline 12 & & & & & 12 & & & & \\
\hline$\frac{1983}{2}$ & & & & & $\frac{1984}{2}$ & & & & \\
\hline 4 & & & & & 4 & & & & \\
\hline 6 & & & & & 6 & & & & \\
\hline 8 & & & & & 8 & & & & \\
\hline 10. & & & & & 10 & & & & \\
\hline 12 & & & & & 12 & & & & \\
\hline 1985 & & & & & 1986 & & & & \\
\hline 2 & & & & & 2 & & & & \\
\hline 4 & & & & & 4 & & & & \\
\hline 6 & & & & & 6 & & & & \\
\hline 8 & & & & & 8 & & & & \\
\hline 10 & & & & & 10 & & & & \\
\hline 12 & & & & & 12 & & & & \\
\hline
\end{tabular}




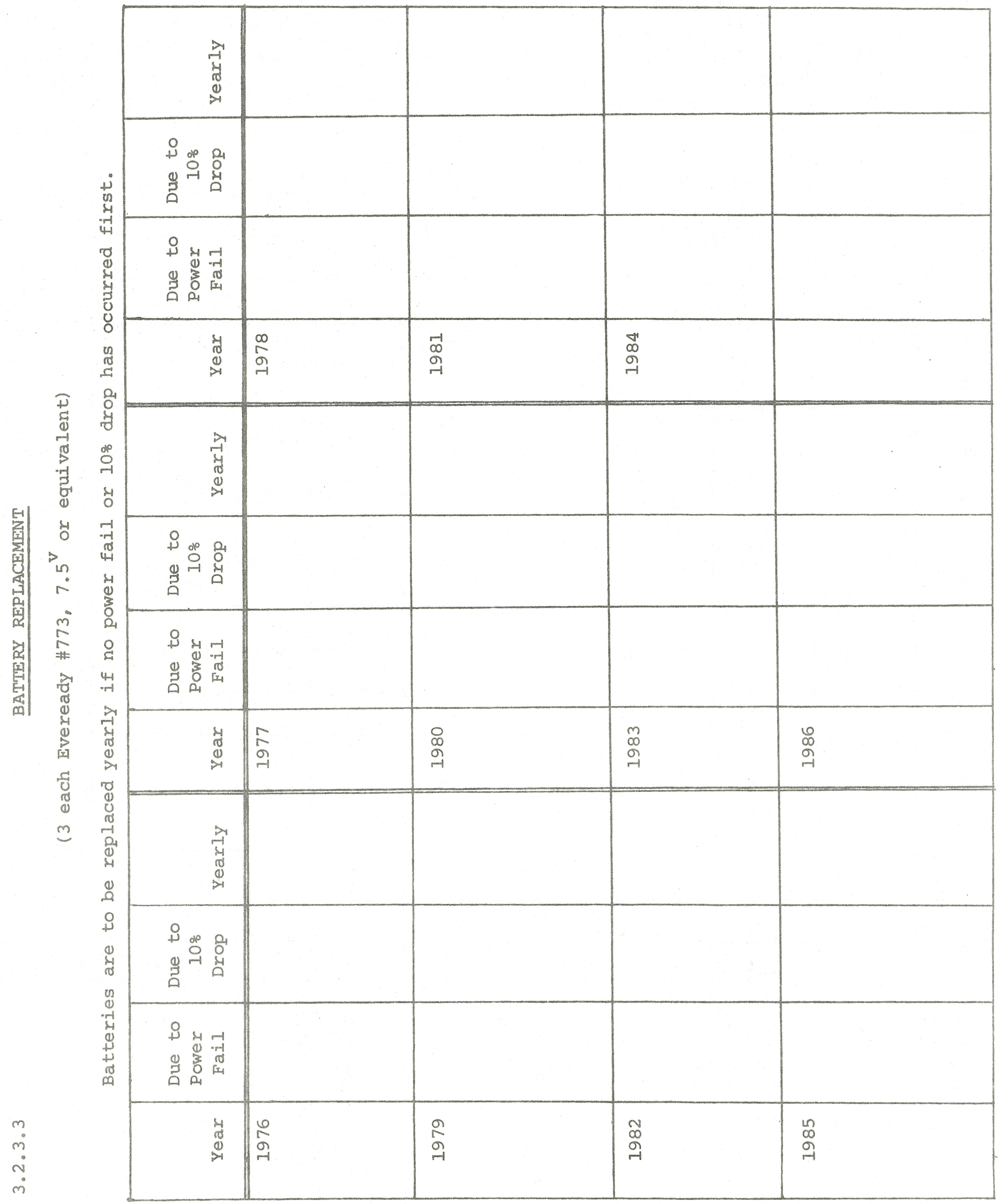




\subsubsection{Yearly Function Checks}

Functions to be performed and observed: (When verifying the time code, reset to real time before checking the next step).

1. Timebase slew pushbutton

2. Slew rate selector switch. 100,10 or $1 \mathrm{~m}-\mathrm{sec} / \mathrm{sec}$ retard

3. $50 \mathrm{~m}-\mathrm{sec} / \mathrm{sec}$ advance

4. Run/preset selector switch

5. Digit preset pushbutton

6. Digit preset selector

7. Eight position: $\mathrm{D}_{100}, \mathrm{D}_{10}, \mathrm{D}_{1}, \mathrm{Hr}, \mathrm{M}_{10}, \mathrm{M}_{1}, \mathrm{~S}_{10}, \mathrm{~S}_{1}$ (Days information to be manually set to 001 on January 1 of each year)

8. IED indicator which lights for $100 \mathrm{~m}$-sec every 1 second (Flashes when system is on standby power also)

9. Input attenuator calibrated in $2 \mathrm{db}$ increments from 0 to $40 \mathrm{db}$

10. LED display of AGC level

(Hexadecimal reading of 0 to $F$ to represent 16 steps of $3 \mathrm{db}$ attenuation per step)

11. Two position toggle switch to select AGC or preset to one of 16 levels determined by internal board mounted switches (AGC to preset to position 8 upon power on)

12. Front panel meter to display average signal level within a frequency band between 230 and $275 \mathrm{~Hz}$ (Time constant of at least $10 \mathrm{sec}$ ) 
FUNCTION CHECK IIST

\begin{tabular}{|c|c|c|c|c|c|c|c|c|c|c|c|}
\hline Date & 1976 & 1977 & 1978 & 1979 & 1980 & 1981 & 1982 & 1983 & 1984 & 1985 & 1986 \\
\hline \multicolumn{12}{|l|}{ slew } \\
\hline \multicolumn{12}{|c|}{ slew select } \\
\hline \multicolumn{12}{|l|}{ Retard } \\
\hline \multicolumn{12}{|l|}{$100 \mathrm{~ms}$} \\
\hline \multicolumn{12}{|l|}{$10 \mathrm{~ms}$} \\
\hline \multicolumn{12}{|l|}{$1 \mathrm{~ms}$} \\
\hline \multicolumn{12}{|l|}{ Advance } \\
\hline \multicolumn{12}{|l|}{$50 \mathrm{~ms}$} \\
\hline \multicolumn{12}{|l|}{ Run/Preset } \\
\hline \multicolumn{12}{|c|}{ Digit Pre P.B. } \\
\hline \multicolumn{12}{|c|}{ Digit Preselect } \\
\hline \multicolumn{12}{|l|}{$D_{100}$} \\
\hline \multicolumn{12}{|l|}{$D_{10}$} \\
\hline \multicolumn{12}{|l|}{$\mathrm{D}_{1}$} \\
\hline \multicolumn{12}{|l|}{$\mathrm{H}_{10}$} \\
\hline \multicolumn{12}{|l|}{$\mathrm{H}_{1}$} \\
\hline \multicolumn{12}{|l|}{$\mathrm{M}_{10}$} \\
\hline \multicolumn{12}{|l|}{$\mathrm{M}_{1}$} \\
\hline \multicolumn{12}{|l|}{$\mathrm{S}_{10}$} \\
\hline \multicolumn{12}{|l|}{$\mathrm{s}_{1}$} \\
\hline \multicolumn{12}{|c|}{ IED one sec. } \\
\hline \multicolumn{12}{|l|}{ Manual Gain } \\
\hline \multicolumn{12}{|l|}{ LED AGC } \\
\hline AGC Manual & & & & & & & & & & & \\
\hline
\end{tabular}




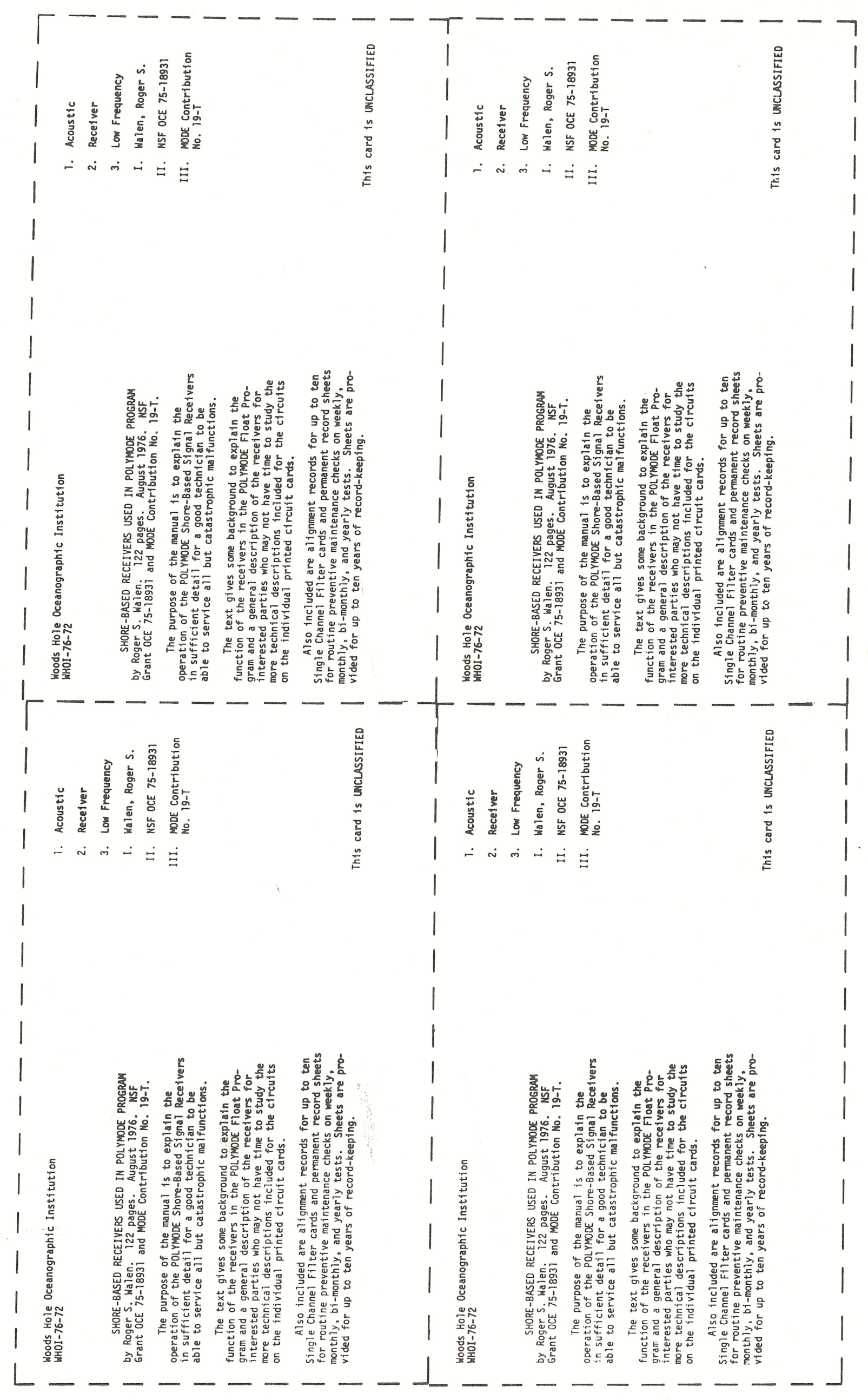




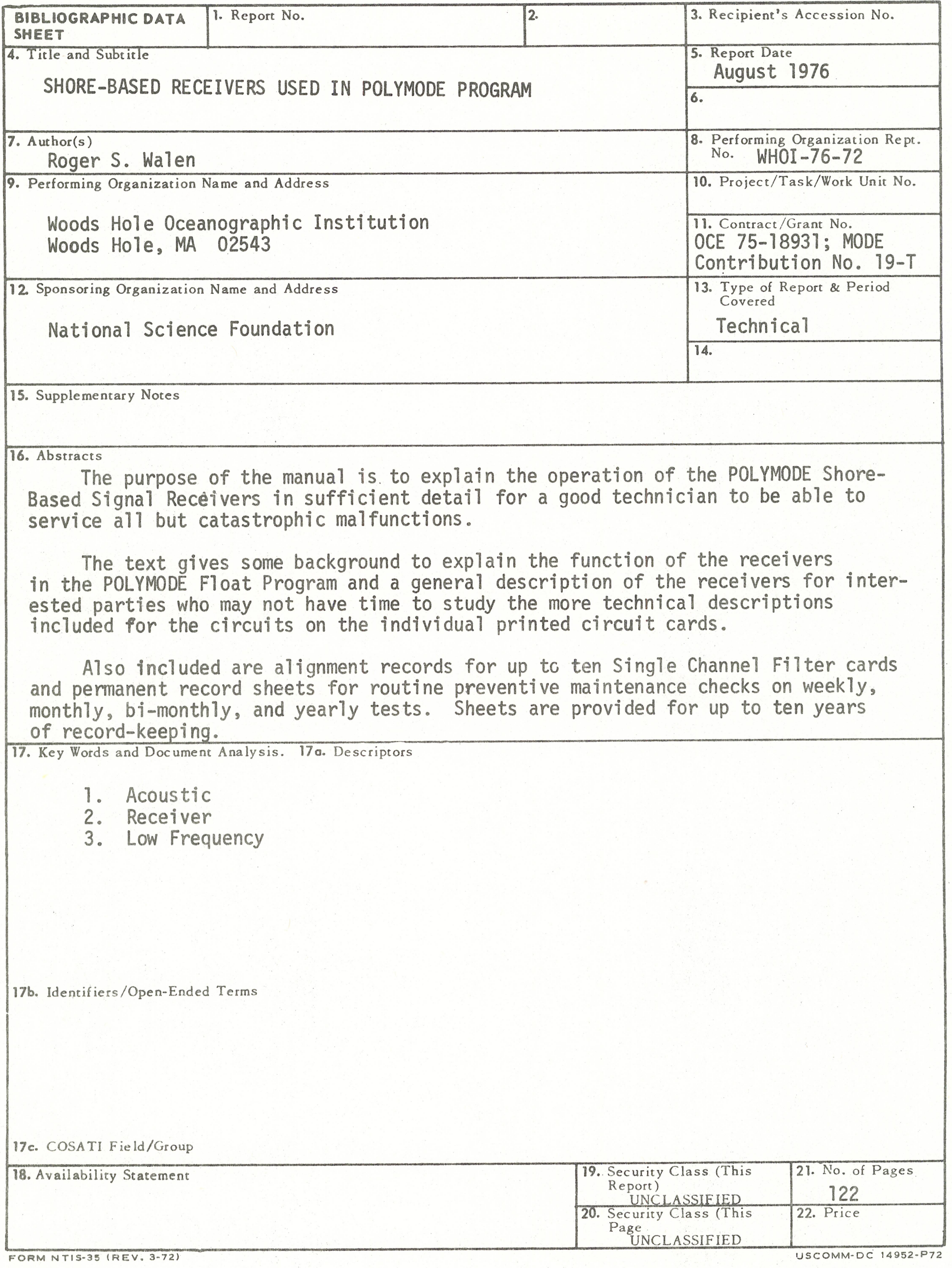

